\title{
A New Geomagnetic Polarity Time Scale for the Late Cretaceous and Cenozoic
}

\author{
STEVEN C. CANDE 1 AND DENNIS V. KENT
}

\author{
Lamont-Doherty Geological Observatory of Columbia University, Palisades, New York
}

\begin{abstract}
We have constructed a magnetic polarity time scale for the Late Cretaceous and Cenozoic based on an analysis of marine magnetic profiles from the world's ocean basins. This is the first time, since Heirtzler et al. (1968) published their time scale, that the relative widths of the magnetic polarity intervals for the entire Late Cretaceous and Cenozoic have been systematically determined from magnetic profiles. A composite geomagnetic polarity sequence was derived based primarily on data from the South Allantic. Anomaly spacings in the South Atlantic were constrained by a combination of finite rotation poles and averages of stacked profiles. Fine-scale information was derived from magnetic profiles on faster spreading ridges in the Pacific and Indian Oceans and inserted into the South Atlantic sequence. Based on the assumption that spreading rates in the South Allantic were smoothly varying but not necessarily constant, a time scale was generated by using a spline function to fit a set of nine age calibration points plus the zero-age ridge axis to the composite polarity sequence. The derived spreading history of the South Atlantic shows a regular variation in spreading rate, decreasing in the Late Cretaceous from a high of almost $70 \mathrm{~mm} / \mathrm{yr}$ (full rate) at around anomaly $33-34$ time to a low of about $30 \mathrm{~mm} / \mathrm{yr}$ by anomaly 27 time in the early Paleocene, increasing to about $55 \mathrm{~mm} / \mathrm{yr}$ by about anomaly 15 time in the late Eocene, and then gradually decreasing over the Oligocene and the Neogene to the recent rate of about $32 \mathrm{~mm} / \mathrm{yr}$. The new time scale has scveral significant differences from previous time scales. For example, chron $\mathrm{C} 5 \mathrm{n}$ is $\sim 0.5$ m.y. older and chrons C9 through C24 are 2-3 m.y. younger than in the chronologies of Berggren et al. (1985b) and Harland et al. (1990). Additional small-scale anomalies (tiny wiggles) that represent either very short polarity intervals or intensity fluctuations of the dipole field have been identified from several intervals in the Cenozoic including a large number of tiny wiggles between anomalies 24 and 27 . Spreading rates on several other ridges, including the Southeast Indian Ridge, the East Pacific Rise, the Pacific-Antarctic Ridge, the Chile Ridge, the North Pacific, and the Central Atlantic, were analyzed in order to evaluate the accuracy of the new time scale. Globally synchronous variations in spreading rate that were previously observed around anomalies $20,6 \mathrm{C}$, and in the late Neogene have been eliminated. The new time scale helps to resolve events at the times of major plate reorganizations. For example, anomaly $3 \mathrm{~A}$ (5.6 $\mathrm{Ma}$ ) is now seen to be a time of sudden spreading rate changes in the Southeast Indian, Pacific-Antarctic, and Chile ridges and may correspond to the time of the change in Pacific absolute plate motion proposed by others. Spreading rates in the North Pacific became increasingly irregular in the Oligocene, culminating in a precipitous drop at anomaly $6 \mathrm{C}$ time.
\end{abstract}

\section{INTRODUCTION}

The geomagnetic polarity time scale of Heirtzler et al. [1968] (HDHPL68; see Table 1 for acronyms of time scales used in this paper) was one of the foundations of the plate tectonic revolution. Building on the seafloor spreading hypothesis of Vine and Matthews [1963] and the remarkable symmetry found by Pitman and Heirtzler [1966] in the Eltanin 19 magnetic anomaly profile across the Pacific-Antarctic Ridge, Heirtzler et al. [1968] proposed a geomagnetic polarity time scale for the Late Cretaceous to Recent, about the last $75 \mathrm{Ma}$ (from anomaly 32), based on a few long magnetic anomaly profiles. The success of HDHPL68 can be gauged by the fact that although parts of the reversal sequence have been subsequently revised, nearly half of the original relative spacings of reversals (nominally anomalies 6C to 29) have been used in virtually all revisions to the present [e.g., Harland et al., 1990].

It has also become increasingly clear that there are errors in the relative widths of the polarity intervals as given in HDHPL68 and in the subsequent time scales that are based on it. For example, Barker [1979] used HDHPL68 to analyze a magnetic profile collected along a flow line in the South Atlantic and found that there were several rapid changes in spreading rates over the Cenozoic. The discovery of sudden changes in spreading rate in the South Atlantic is suspicious

\footnotetext{
'Now at Scripps Institution of Oceanography, La Jolla, California.
}

Copyright 1992 by the American Geophysical Union.

Paper number 92JB01202.

0148-0227/92/92JB-01202\$05.00 because the HDHPL68 time scale was constructed based on the assumption that the spreading rate in the South Atlantic has been constant. Because of the fundamental importance of the geomagnetic polarity time scale to numerous disciplines, we sought to improve the resolution of the relative polarity widths by analyzing magnetic anomaly profiles now available from throughout the world's ocean basins.

\section{BACKGROUND}

Heirtzler et al. [1968] constructed their time scale by assuming a constant spreading rate for a profile collected on $\mathrm{R} / \mathrm{V}$ Vema, cruise 20 , in the South Atlantic. They then incorporated a polarity sequence derived from the higher spreading rate North Pacific according to the curve for the relative spreading rate between the two oceans. A time scale extrapolated from the South Atlantic profile was selected as a standard because (1) the anomaly pattern for the South Indian Ocean was not sufficiently long, (2) the North Pacific profile was too distorted near the ridge axis for extrapolation, and (3) the spreading history in the South Pacific was variable and gave an extrapolated time scale that became unacceptably too young.

The evolution of the geomagnetic polarity time scale since 1968 involved two types of revision: adjustment of the relative spacing of some anomalies given by HDHPL68 and calibration of the polarity sequence in time. Most of the revisions to the relative spacings were done over relatively short segments of HDHPL68. Talwani et al. [1971] proposed revisions to the relative ages of anomalies 2 to $4 \mathrm{~A}$ based on a detailed study of the Reykjanes Ridge. Larson and Pitman [1972] added anomalies 33 and 34 to the sequence. Blakely [1974] stacked 
TABLE 1. Geomagnetic Polarity Time Scales Referred to in This Paper

Time Scale Reference

\section{HDHPL68}

LKC77

LA81

BKFV85

GTS89

CK92
Heirtzler et al. [1968]

LaBrecque et al. [1977]

Lowrie and Alvarez [1981]

Berggren et al. [1985b]

Geologic Time Scale 1989

(Harland et al., 1990)

Cande and Kent (this paper) several profiles from the northeast Pacific and revised the relative width of anomalies 4 A to 6. Klitgord et al. [1975] examined deep-tow magnetic profiles across several ridge segments of the Pacific and revised anomalies 1 to $3 \mathrm{~A}$. Cande and Kristoffersen [1977] revised the width of anomalies 30 to 34 from a global analysis.

LaBrecque et al. [1977] incorporated these changes in a revised time scale (LKC77); the only modification made to the entire Paleogene section of the sequence was to delete anomaly 14 which was generally recognized to be an artifact in HDHPL68. However, LaBrecque et al. [1977] encountered difficulties in splicing the revised portions of the sequence into HDHPL68. For example, Blakely [1974] tied his revisions of the relative width of anomalies $4 A$ to 6 to the younger end of anomaly 5 of HDHPL68. Since the relative width of anomaly 4A to 5 in Blakely [1974] is considerably larger than in HDHPL68 [and Talwani et al., 1971], and no change was made to the age of anomaly $3 \mathrm{~A}$ as given by Klitgord et al. [1975], the anomaly $3 \mathrm{~A}$ to $4 \mathrm{~A}$ interval is compressed in LKC77. This problem was recognized but left unresolved even in the most recent time scale (GTS89) of Harland et al. [1990].

Age calibration has been the focus of changes to the geomagnetic polarity time scale since the compilation of LaBrecque et al. [1977]. HDHPL68 assumed a constant rate of seafloor spreading in the South Atlantic, and used a single calibration point at the older end of anomaly $2 \mathrm{~A}$ to extrapolate ages out to anomaly 32 . LaBrecque et al. [1977] added a calibration point at the older end of anomaly 29 , based on magnetobiostratigraphic data which placed the Cretaceous/ Paleogene boundary within the uppermost part of chron C29 [Lowrie and Alvarez, 1977]. This left the assumption of constant spreading in the South Atlantic largely intact. However, subsequent calibration efforts added more control points based on developing magnetobiostratigraphic ties, and relaxed the implicit assumption of constant spreading in the South Atlantic to smaller time intervals [e.g., Ness et al., 1980; Lowrie and Alvarez, 1981; Harland et al., 1982, 1990; Berggren et al., 1985b; Haq et al., 1988].

\section{ACCURACY OF THE GEOMETRIC POLARITY Time SCALE}

One way to evaluate the accuracy of a geomagnetic polarity time scale is to calculate the consequences on spreading rates on various ridges. Ideally, a "type" profile would be available for every ridge system that could be used to determine the spreading rate history of that ridge. In reality, no single magnetic profile reflects the complete spreading history of a ridge system due to irregularities such as periods of asymmetrical spreading, small ridge jumps and propagating rifts.
A more accurate representation of spreading history can be obtained by determining closely spaced finite rotation poles based on magnetic anomalies and fracture zone trends along an entire spreading ridge. Finite rotation poles take into account asymmetric spreading, ridge jumps and other local spreading irregularities that can distort the magnetic anomaly sequence along a particular profile. For example, Cande et al. [1988] calculated a set of 43 finite poles that constrain the spreading history of the South Atlantic for the last $84 \mathrm{~m} . y$. , from anomaly 34 to the ridge axis. Representative distances between anomalies can be determined along a synthetic flow line based on the finite rotation poles.

In Figure 1 we compare the spreading rate history of the South Atlantic for three different time scales (HDHPL68, GTS89, and Berggren et al. [1985b] (BKFV85, which is the same as Kent and Gradstein [1986]), referenced to the distances to anomalies along a synthetic flow line derived from the finite rotation poles of Cande et al. [1988]. We note that there are large variations in apparent spreading rate even with HDHPL68 (Figure 1, bottom), which in fact assumed a constant rate of spreading in the South Atlantic. A very similar pattern of variation is seen between anomalies 6 to 29 in more recent time scales (e.g., Figure 1, BKFV85 and GTS89), even though more age calibration data are used. While the spreading rate variations shown in Figure 1 could indicate very erratic relative plate motion, a more plausible interpretation is that the single profile (Vema 20) available to and used by Heirtzler et al. [1968], and incorporated in virtually all subsequent time scales, is simply not representative of the spreading history of the South Atlantic. It follows that observations of globally

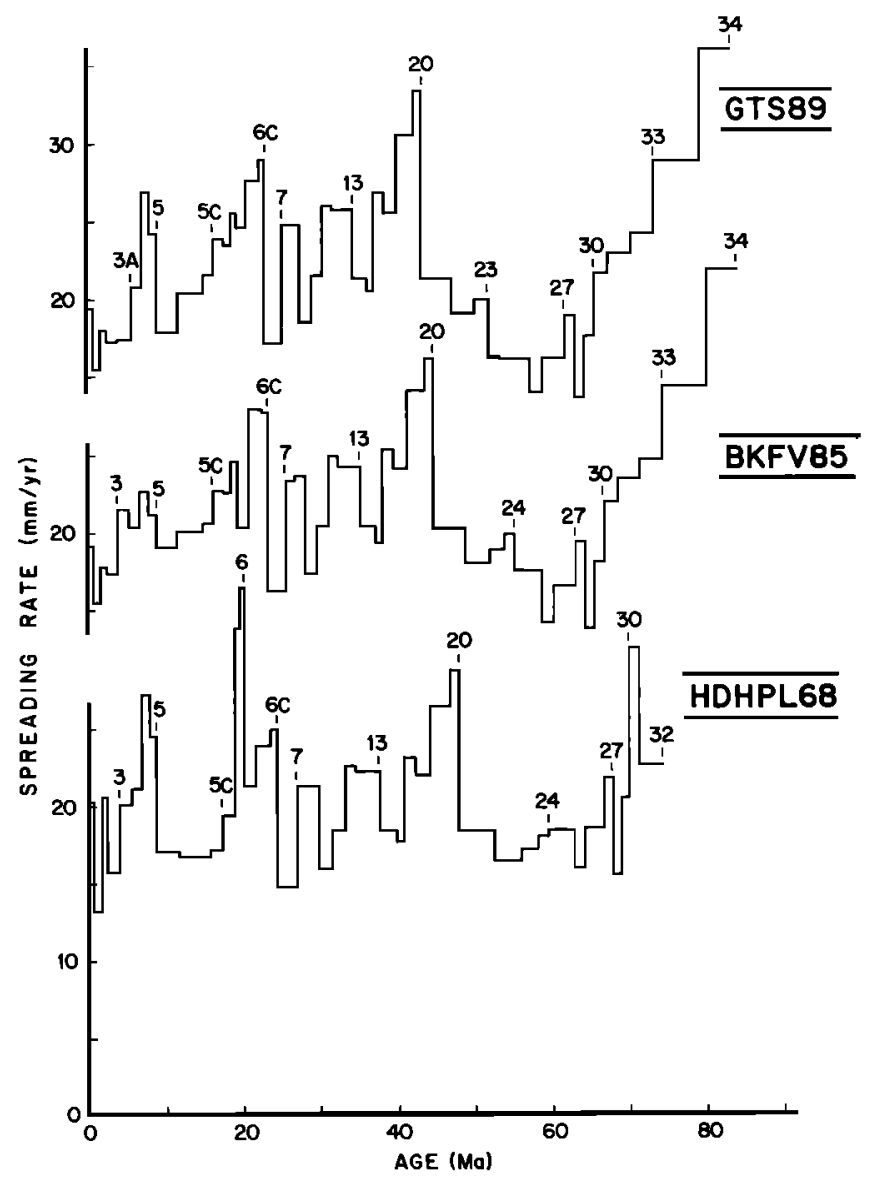

Fig. 1. Comparison of half spreading rates in the South Atlantic using various time scales, as identified in the text. The distance between anomalies is calculated along a synthetic flowline at $30^{\circ} \mathrm{S}$ using a set of 43 rotation poles from Cande et al. [1988]. 
synchronous spreading variation [e.g., Vogt, 1986] based on HDHPL68 or derivative time scales should be regarded as suspect and may well be artifacts of errors in the polarity sequence. This problem motivates our reassessment of the geomagnetic polarity time scale in terms of the relative width of polarity intervals as a framework for age calibration.

\section{CONSTRUCTING a NeW TIME SCALE}

Construction of a magnetic anomaly time scale involves age calibration of a reference sequence of relative anomaly spacings. Our initial approach for a reference section was to search for long magnetic profiles from different oceans that individually were high fidelity records of the polarity reversal pattern over 10 to 20 m.y. time intervals. This procedure was first suggested by Klitgord and Schouten [1986] and later by Aubry et al. [1988], who compared pairs of profiles from different ocean basins and identified sections several hundred kms long that appeared to have formed at a constant spreading rate. We found, however, that it was extremely difficult to assemble a reference section and devise a scheme for calibrating it for the entire Late Cretaceous and Cenozoic, based on individual profiles from different ridges. Individual long profiles, as we noted earlier, almost invariably include discontinuities due to ridge jumps, propagating rifts, intervals of asymmetric spreading or small fracture zones; even when such interruptions in continuity are identified, residual uncertainties, especially within the overlapping portions, make it difficult to splice together a reference section on a normalized distance base.

A procedure that proved more tractable and testable was to determine a reference section based on the seafloor spreading pattern on a single ridge system. The South Atlantic was an obvious choice as the basis of a framework for a reference section from anomaly 34 to present. Seafloor spreading in the South Atlantic is preserved on both limbs of the ridge system, which allows us to compensate for ridge jumps and asymmetric spreading, and is documented by a large data base of ship tracks, aeromagnetic lines, and satellite altimetry observation [Cande et $a l ., 1988$ ]. In comparison, other ridge systems are less useful because of an inadequate length of record (e.g., Reykjanes, and those associated with the smaller plates of the Pacific), major plate reorganization (Indian Ocean), preservation of only one limb (North Pacific), or a more poorly resolved (North and Central Atlantic) or less well documented (Pacific-Antarctic) magnetic anomaly signature. For many of the same reasons discussed above, Heirtzler et al. [1968] had also chosen the South Atlantic as the best ocean to use as a reference.

We used a combination of finite rotation poles and stacked profiles from the South Atlantic to build a framework for the time scale. Distances based on finite rotation poles between selected anomalies are referred to as category I intervals; subdivisions of these intervals based on stacks of selected anomaly profiles are referred to as category $I$ intervals. For a few portions of the time scale we judged that the category II intervals were adequate to define the anomaly spacings, e.g., between anomalies 20 and 23 and between anomalies 33 and 34 . For most time intervals, however it is necessary to fill in the fine detail of the reversal pattern using magnetic anomaly data from faster spreading ridges such as those in the North Pacific and Indian Oceans. We refer to this finer subdivision of the anomaly spacings as category III intervals. A consequence of this procedure is that the very short wavelength anomalies, commonly referred to as tiny wiggles, have not been uniformly resolved over the entire anomaly sequence. To compensate for this nonuniform resolution, and in recognition of the ambiguous origin of the tiny wiggles, we have excluded the shortest events (i.e., with apparent durations of less than 30 kyr) from our final compilation of anomaly spacings and in the resulting geomagnetic polarity time scale.

\section{REFERENCE SECTION FOR THE SOUTH ATLANTIC: CATEGORY I AND II DISTANCES}

Cande et al. [1988] described the spreading history of the South Atlantic since anomaly 34 with a set of 43 finite rotation poles. We used nine of these rotation poles to establish a framework for averaging the widths of anomalies on individual profiles. The choice of nine rotation poles was somewhat arbitrary, and, in fact, we could have used a larger subset. However, the analysis of shorter and larger numbers of profiles becomes progressively more unwieldy as more poles are used.

Distances to key anomalies were constrained along a synthetic flow line in the South Atlantic at (half separation) intervals of 150 to $300 \mathrm{~km}$ (roughly 7 to $13 \mathrm{~m} . \mathrm{y}$.) based on finite rotation poles for the younger ends of anomalies $4 \mathrm{~A}, 5 \mathrm{C}$, $7,13,20,24,30,33$, and 34 [Cande et al., 1988] (Table 2). These category $I$ intervals were chosen, in part, so that anomalies with ambiguous reversal boundaries, such as the young end of anomaly 5 which has fine-scale structure, were not at the end of an interval. The synthetic flow line, which is located at approximately $30^{\circ} \mathrm{S}$, and the location of the distance intervals constrained by the finite rotation poles are shown in Figure 2.

TABLE 2. Intervals of Normal Polarity Crustal Magnetization Along a Synthetic Flow Line in the South Atlantic

\begin{tabular}{|c|c|c|c|}
\hline \multicolumn{3}{|c|}{$\begin{array}{l}\text { Normal Polarity } \\
\text { Interval,* km }\end{array}$} & \multirow{2}{*}{$\begin{array}{r}\text { Magnetic } \\
\text { Anomaly } \\
1\end{array}$} \\
\hline 0.00 & • & 12.14 & \\
\hline 15.37 & - & 16.39 & $1 \mathrm{r} .1$ \\
\hline 27.80 & - & 31.51 & 2 \\
\hline 35.04 & 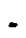 & 35.57 & $2 r .1$ \\
\hline 41.75 & - & 49.44 & 2An.1 \\
\hline 50.70 & - & 52.31 & 2An.2 \\
\hline 54.10 & - & 68.03 & 2An. 3 \\
\hline 66.44 & - & 68.23 & $3 \mathrm{n} .1$ \\
\hline 70.56 & - & 73.56 & 3n.2 \\
\hline 76.76 & - & 78.26 & 3n.3 \\
\hline 80.40 & - & 84.68 & 3n.3 \\
\hline 96.87 & • & 101.42 & 3An. 1 \\
\hline 103.92 & - & 109.60 & 3An. 2 \\
\hline 116.70 & - & 119.74 & 3 \\
\hline 120.62 & - & 121.30 & $3 B r .1$ \\
\hline 124.68 & - & 125.35 & $3 B r .2$ \\
\hline 126.48 & - & 129.08 & $4 n .1$ \\
\hline 130.83 & - & 139.37 & $4 n .2$ \\
\hline 142.49 & - & 143.15 & $4 r .1$ \\
\hline 152,39 & - & 159.16 & $4 A$ \\
\hline 163.49 & - & 165.16 & $4 \mathrm{Ar} .1$ \\
\hline 171.00 & - & 172,34 & 4Ar.2 \\
\hline 174.47 & • & 177.49 & 5n.1 \\
\hline 178.38 & - & 201.13 & $5 \mathrm{n} .2$ \\
\hline 203.44 & - & 204.51 & 5r.1 \\
\hline 213.04 & - & 214.28 & 5r.2 \\
\hline 223.52 & - & 226.81 & 5An. 1 \\
\hline 229.23 & - & 234.25 & $5 \mathrm{An} .2$ \\
\hline 240.65 & - & 241.35 & 5Ar.1 \\
\hline 242.90 & - & 243.94 & 5Ar.2 \\
\hline 247.92 & - & 251.38 & $5 A$ \\
\hline 255.19 & - & 260.03 & $5 A B$ \\
\hline 264.53 & - & 273.28 & $5 A C$ \\
\hline 275.66 & - & 285.80 & $5 A D$ \\
\hline 290.17 & - & 292.24 & 5Bn. 1 \\
\hline 295.63 & 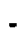 & 298.45 & $5 \mathrm{Bn} .2$ \\
\hline 318.39 & - & 324.87 & $5 \mathrm{Cn} .1$ \\
\hline 325.65 & - & 329.38 & $5 \mathrm{Cn} .2$ \\
\hline 330.95 & - & 334.88 & $5 \mathrm{Cn} .3$ \\
\hline 347.64 & - & 355.45 & $5 \mathrm{D}$ \\
\hline$\underline{370.87}$ & - & 382.45 & $\mathbf{5 E}$ \\
\hline 388.64 & - & 413.88 & 6 \\
\hline
\end{tabular}


TABLE 2. (continued)

\begin{tabular}{|c|c|c|}
\hline \multicolumn{2}{|c|}{$\begin{array}{l}\text { Normal Polarity } \\
\text { Interval, }, \mathbf{k m}\end{array}$} & \multirow{2}{*}{$\begin{array}{r}\text { Magnetic } \\
\text { Anomaly } \\
\text { 6An.1 }\end{array}$} \\
\hline 422.93 & 427.81 & \\
\hline 434.18 & 441.85 & 6An.2 \\
\hline 452.46 & 454.63 & 6AA \\
\hline 461.59 & 463.92 & 6AAr.1 \\
\hline 468.97 & 469.79 & 6AAr.2 \\
\hline 472.08 & 475.99 & 6Bn.1 \\
\hline 477.29 & 483.70 & 6Bn.2 \\
\hline 490.61 & 495.05 & $6 \mathrm{Cn} .1$ \\
\hline 498.54 & 501.55 & $6 \mathrm{Cn} .2$ \\
\hline 506.47 & 509.41 & $6 \mathrm{Cn} .3$ \\
\hline 524.64 & 525.92 & $7 \mathrm{n} .1$ \\
\hline 59729 & 536.04 & $7 \mathrm{n} .2$ \\
\hline 543.97 & 547.82 & $7 A$ \\
\hline 552,30 & 555.55 & $8 n .1$ \\
\hline 556.60 & 571.04 & $8 n .2$ \\
\hline 583.30 & 607.96 & 9 \\
\hline 616.12 & 622.16 & $10 \mathrm{n} .1$ \\
\hline 623.90 & 628.29 & $10 \mathrm{n} .2$ \\
\hline 645.65 & 652.56 & $11 n .1$ \\
\hline 655.31 & 664.15 & $11 n .2$ \\
\hline 674.26 & 686.50 & 12 \\
\hline 74963 & 755.44 & $\overline{13}$ \\
\hline 784.40 & 791.78 & 15 \\
\hline 802.15 & 806.87 & $16 n .1$ \\
\hline 810.93 & 827.67 & $16 n .2$ \\
\hline 834.68 & 856.19 & $17 \mathrm{n} .1$ \\
\hline 859.46 & 865.54 & $17 n .2$ \\
\hline 867.33 & 872.10 & $17 \mathrm{n} .3$ \\
\hline $\mathbf{8 7 9 . 8 3}$ & 907.31 & $18 n .1$ \\
\hline 909.21 & 921.21 & $18 n .2$ \\
\hline 947.96 & 954.12 & 19 \\
\hline 97765 & 1006.06 & $\overline{\boldsymbol{2 0}}$ \\
\hline 1060.24 & 1094.71 & $\overline{21}$ \\
\hline 1117.55 & 1130.78 & 22 \\
\hline 1150.83 & 1163.90 & $23 n .1$ \\
\hline 1155.75 & 1168.20 & $23 n .2$ \\
\hline 1178.96 & 1184.03 & $24 n .1$ \\
\hline 1186.61 & 1186.34 & $24 n .2$ \\
\hline 1188.05 & 1195.35 & $24 n .3$ \\
\hline 1234.51 & 1241.50 & 25 \\
\hline 1257.81 & 1262.74 & $\overline{26}$ \\
\hline 1303.81 & 1308.70 & 27 \\
\hline 1325.71 & 1341.99 & $\mathbf{2 8}$ \\
\hline 1347.03 & 1358.66 & 29 \\
\hline 1371.84 & 1407.22 & $\overline{\mathbf{3 0}}$ \\
\hline 1409.56 & 1429.14 & 31 \\
\hline 1481.12 & 1487.68 & $32 n .1$ \\
\hline 1493.94 & 1531.81 & $32 n .2$ \\
\hline 1539.94 & 1542.32 & $32 \mathrm{r} .1$ \\
\hline 1549,41 & 1723.76 & 33 \\
\hline 1869,92 & - & 34 \\
\hline
\end{tabular}

Category I distances are bold, Category II distances are underlined, and Category III distances are plain text.

* $1.29 \mathrm{~km}$ subtracted for Central Anomaly olfset.

The relative widths of anomalies within each category I interval were constrained by averaging the widths of subintervals on five to nine profiles that appeared to be representative of uniform seafloor spreading. The locations of the profiles that were used are shown in Figure 2. Each selected profile was projected perpendicular to the local strike of the magnetic lineations and deskewed using the phase shifting methods described by Schouten and McCamy [1972] Profiles with obvious ridge jumps or other irregularities in spreading were avoided. To pick more precisely the location of the reversal boundaries corresponding to the anomalies, the profiles were bandpassed and downward continued between 1.5 and $2.5 \mathrm{~km}$ after removal of the long wavelength component, also using the methods of Schouten and McCamy [1972]. The causative reversal boundaries were then determined on the basis of the local zero crossings. Occasionally this procedure did not produce a zero crossing for a desired anomaly pick and we would estimate the reversal boundary by eye. This procedure is illustrated in Figure 3.

The profiles that were averaged to obtain the category II widths are shown in Figures $4 a$ to $4 i$ after being deskewed and stretched to a common distance interval. At the top of each set of profiles in Figure 4 we show the average width of each subinterval as indicated by the vertical bars. It should be noted that the profiles in Figure 4 have not been downward continued. The downward continued versions of the profiles, used to actually determine the vertical bars shown in Figure 4, are not shown. A profile based on a stack of the realigned individual profiles is also shown, although purely as a reference. The distances between the subintervals on the stacked profile represents our best estimate of the relative polarity widths for the interval based on South Atlantic data. These category II distances are given in Table 2.

\section{FINE DetaIl From Fast SPREADING RIDGES}

For most of the category II intervals defined from the stacked South Atlantic profiles, it is necessary to analyze profiles from faster spreading rate ridges in order to resolve finer detail. Accordingly, we have compiled additional profiles, mostly from the Pacific and Indian oceans, in order to define the finer scale structure of the reversal sequence. For two portions of the reversal sequence, between the ridge axis and anomaly $3 \mathrm{~A}$ and between anomalies $4 A$ and 6 , we used the results of previously published studies [Klitgord et al., 1975; Blakely, 1974, respectively].

Our method of construction of a reference section for the relative widths of magnetic anomalies is thus a tiered process in which successively greater detail is added to a basic framework based on the finite poles for the South Atlantic. This process is illustrated in Figure 5, in which the distances to reversal boundaries are shown along the synthetic flow line in the South Atlantic at different stages. The left-hand column shows the category I distances as determined from the finite rotation poles. The next column shows the category II distances as determined from averaging anomaly widths on profiles in the South Atlantic. The following column shows the category III distances based on the fine detail where it has been determined from faster spreading ridges. The right-hand column shows the anomaly spacings after the removal of the nonuniformly mapped tiny wiggles.

\section{Tiny Wiggles}

In many detailed studies of magnetic anomalies from fast spreading ridges, linear, small scale magnetic anomalies (tiny wiggles) that are clearly related to paleomagnetic field behavior are observed. However, there are two problems in interpreting these anomalies and including them in the time scale: (1) ambiguity in the type of dipole geomagnetic field behavior represented by the tiny wiggles, and (2) unevenness in temporal and spatial coverage.

First, it is not clear that all tiny wiggles are due to short polarity intervals. The larger amplitude features are more obviously due to full reversals of the field, and in some cases they correlate with magnetostratigraphically identified short polarity intervals. However, most of the smaller amplitude anomalies have not been confirmed in magnetostratigraphic sections, and can be modeled as either due to very short polarity intervals [e.g., Blakely, 1974] or else as due to longer period $(50-200 \mathrm{kyr})$ intensity variations [Cande and LaBrecque, 1974]. 


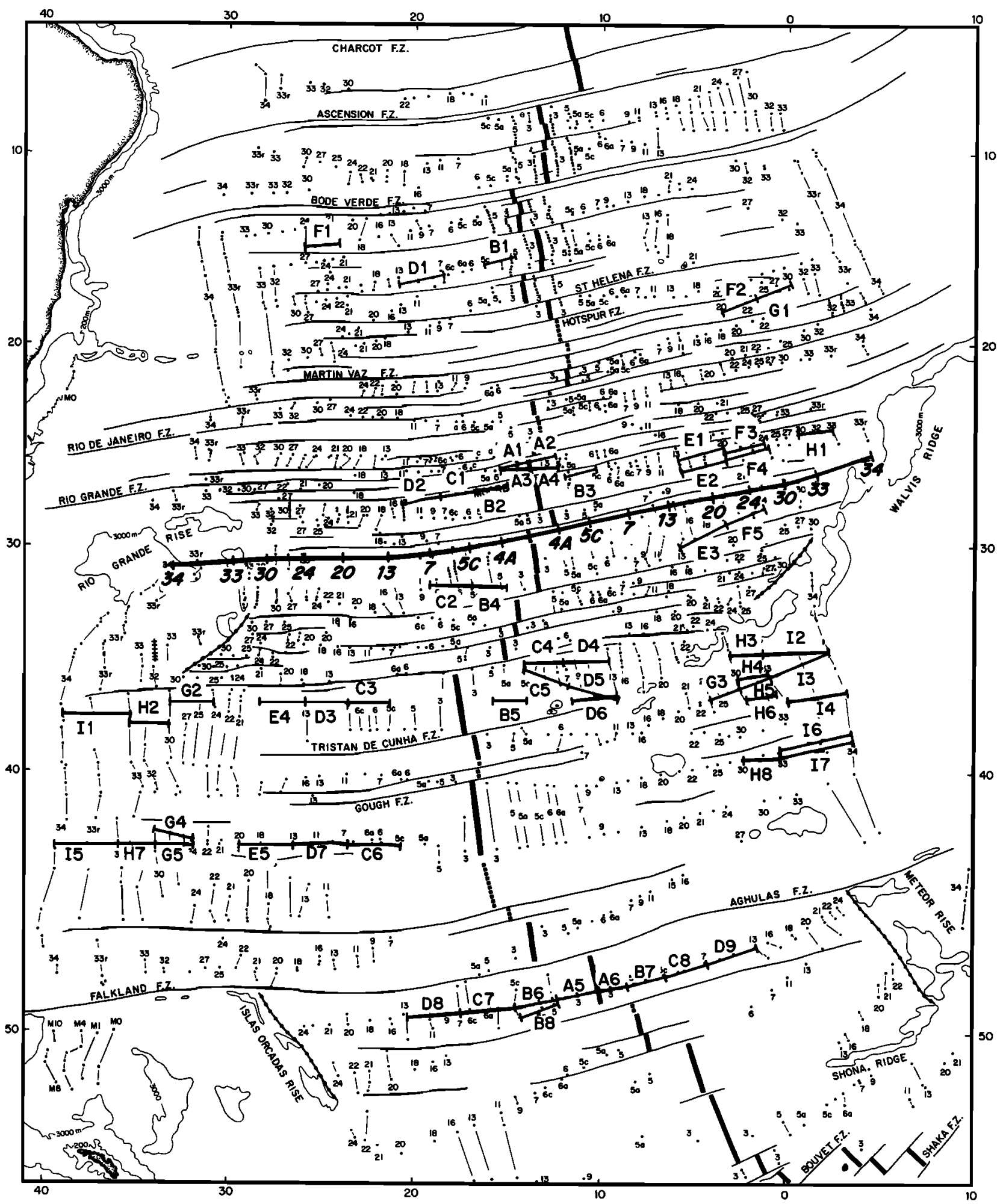

Fig. 2. Location of profiles in the South Atlantic, shown in Figures $4 a$ through $4 i$, that were averaged to obtain the category II distances between anomalies. Heavy line near $30^{\circ}$ is the synthetic flow line constrained by the set of nine rotation poles, representing the category I intervals.

Second, due to both the unevenness of track coverage in different areas of the ocean and the fact that the oceanic crust has recorded some time intervals with higher resolution than others, the record of tiny wiggles is not uniform. Some intervals are well covered, either because of exceptionally detailed surveys (e.g., the Northeast Pacific NOAA surveys of the late 1960s and early 1970s) or because of good coverage in periods of very fast spreading (e.g., the Central Indian Ocean in the early
Cenozoic), while an equivalent high resolution recording of Earth's magnetic field is at least presently not available or specifically studied for other intervals. For these reasons we were not able to model tiny wiggles for anomalies 15 to 23 and 27 to 34.

Tiny wiggles that were well documented in the analyzed profiles were modeled as short polarity intervals as a convenient means of identifying their position within the well 


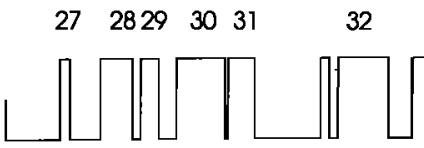

REVERSAL BOUNDARIES

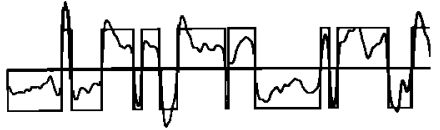

DESKEWED

ingming Downward Continued

$M M N M$

Oasmen Morete
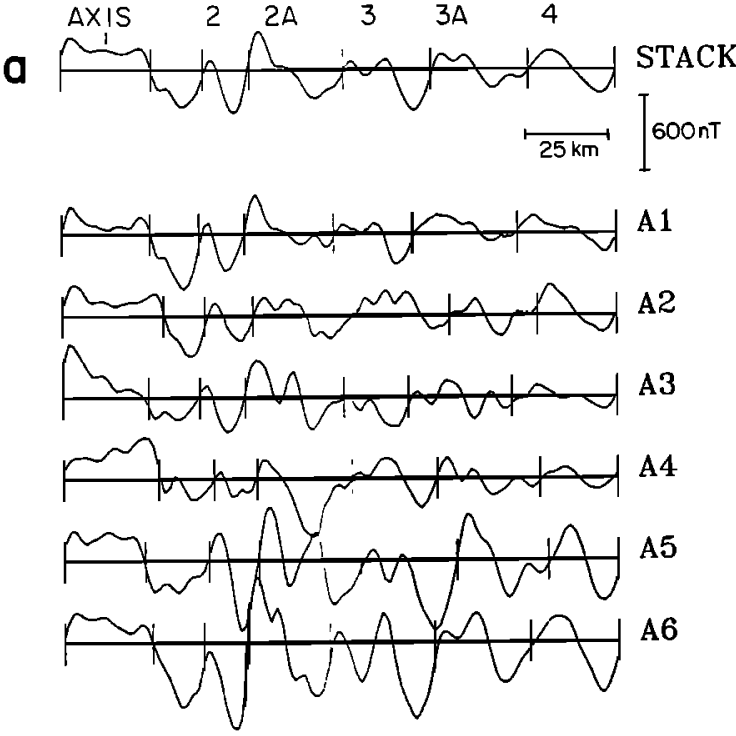

Fig. 3. Example of treatment of profiles. The original profile is projected perpendicular to the strike of the lineations (bottom), bandpassed and downward continued between 1.5 and $2.5 \mathrm{~km}$ (second to the bottom), and then deskewed and detrended (second from the top). The reversal boundaries (top) are detemined from the zero crossings of the deskewed profile.

Fig. 4. Average distances between anomalies in the South Atlantic, corresponding to the category II distances, are indicated by the vertical bars along the horizontal line through the stacked profile. These distances were determined by averaging the widths of the subintervals on the individual profiles. Each profile was treated as in the example in Figure 3 in order to determine the zero crossings shown by the vertical bars. Hand-entered points, when the treatment failed to obtain a zero crossing (very infrequent), are indicated by vertical bars that are half the height of the normal vertical bars. The profiles as shown here have only been deskewed, not downward continued, although downward continued profiles were used to determine the vertical bars. Figures $4 a$ through $4 i$ correspond to the nine category I intervals.

$b \overbrace{}^{4 A}{ }^{5 A}$ STACK

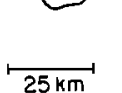
$300 \mathrm{nT}$

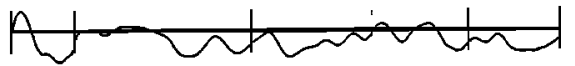

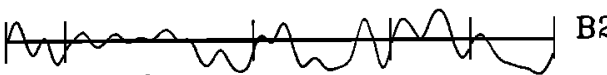

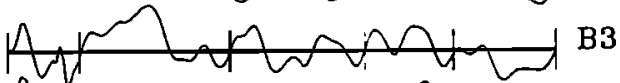
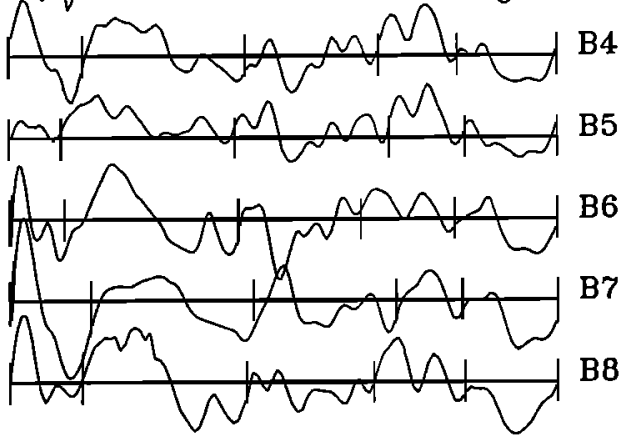

$\begin{array}{lllllll}5 \mathrm{C} & 5 \mathrm{D} & 5 \mathrm{E} & 6 & 6 \mathrm{~A} & 6 \mathrm{~B} & 6 \mathrm{C}\end{array}$

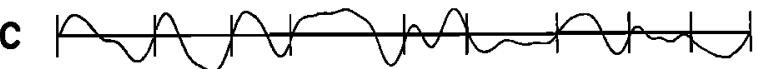

STACK $25 \mathrm{~km} \quad[300 \mathrm{nT}$

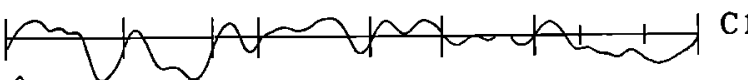

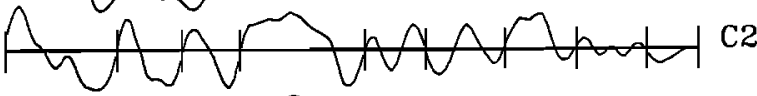

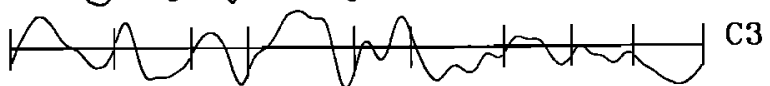

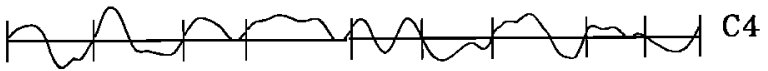

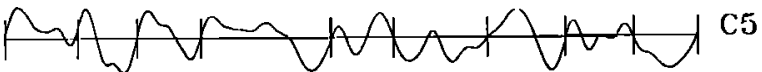

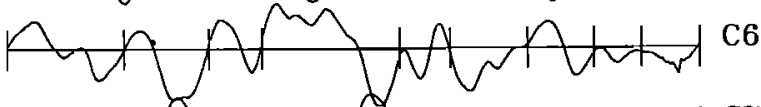

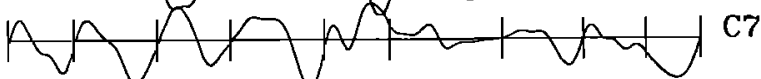

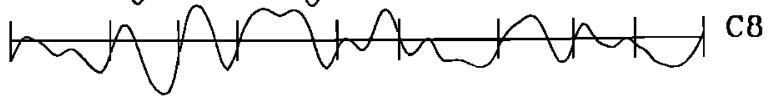

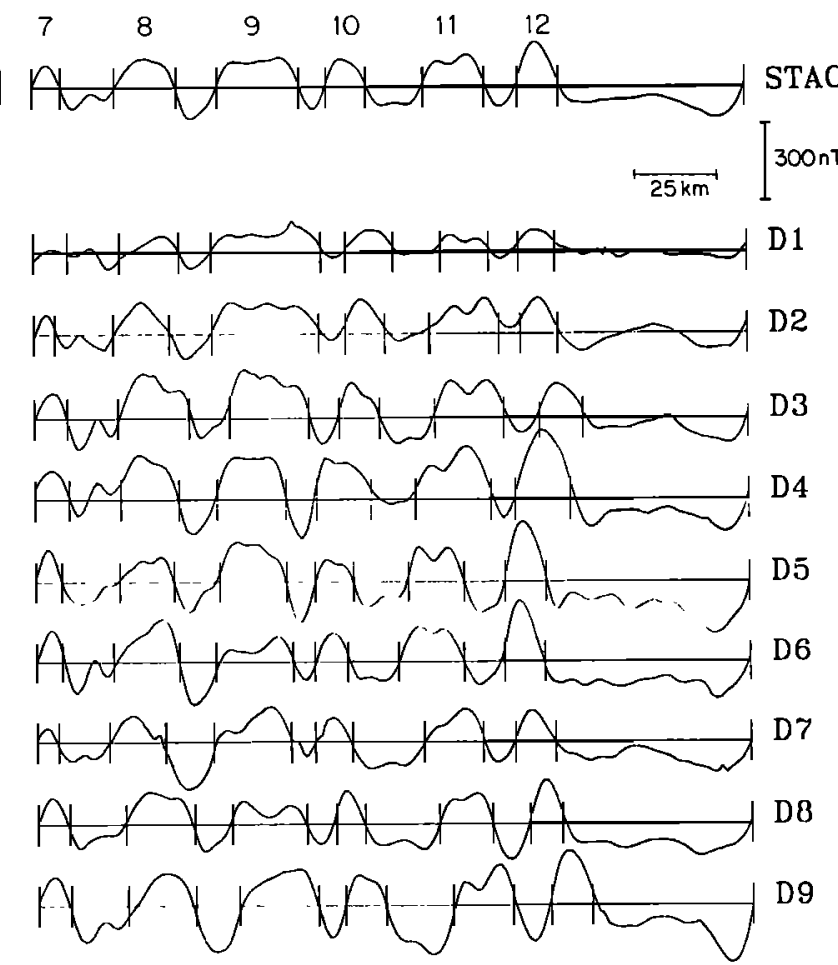




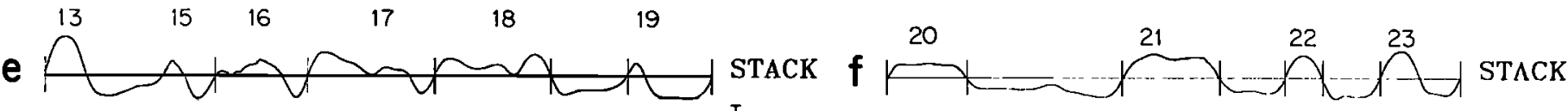

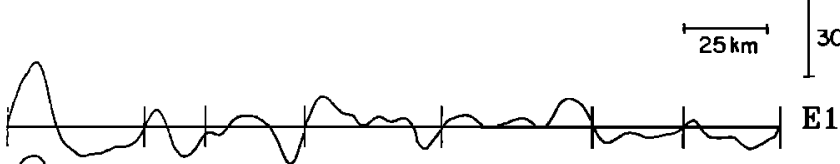
$300 n T$

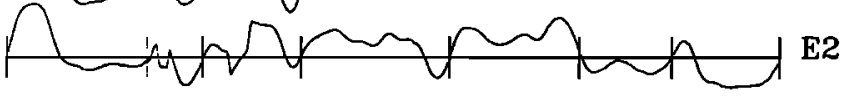

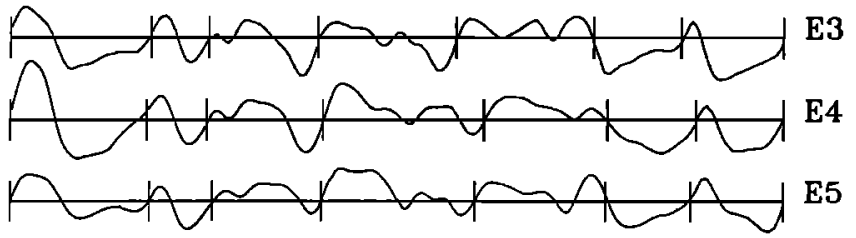

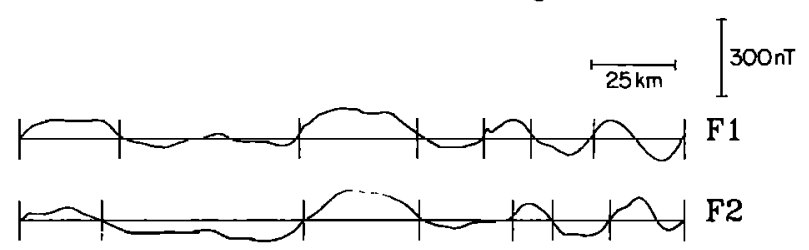

I $\overbrace{}^{24} \overbrace{}^{25} \overbrace{}^{26} \overbrace{\text { STACK }}^{28}$ $\stackrel{25 \mathrm{~km}}{2} I_{300 \mathrm{nT}}$
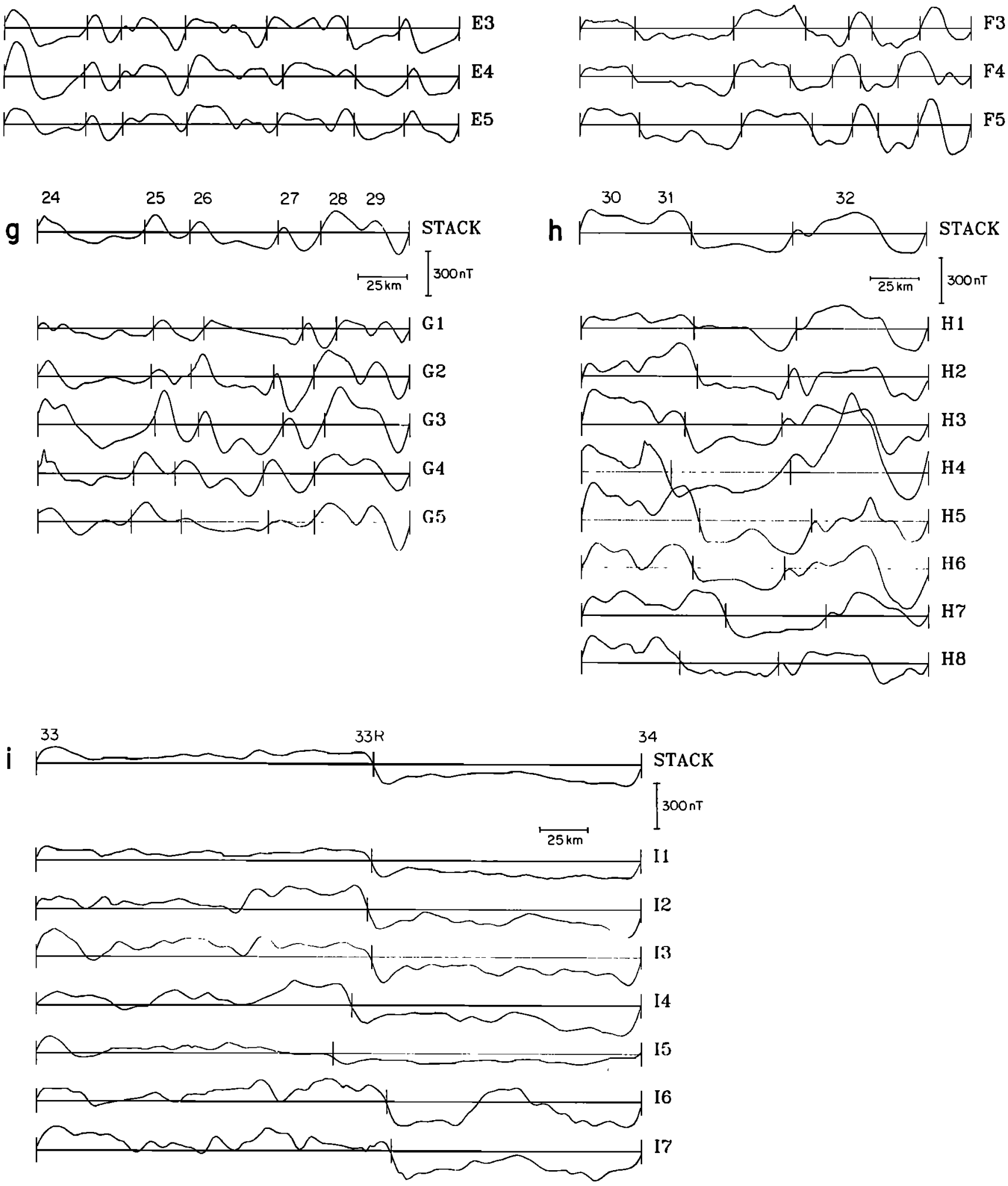

Fig. 4. (continued) 

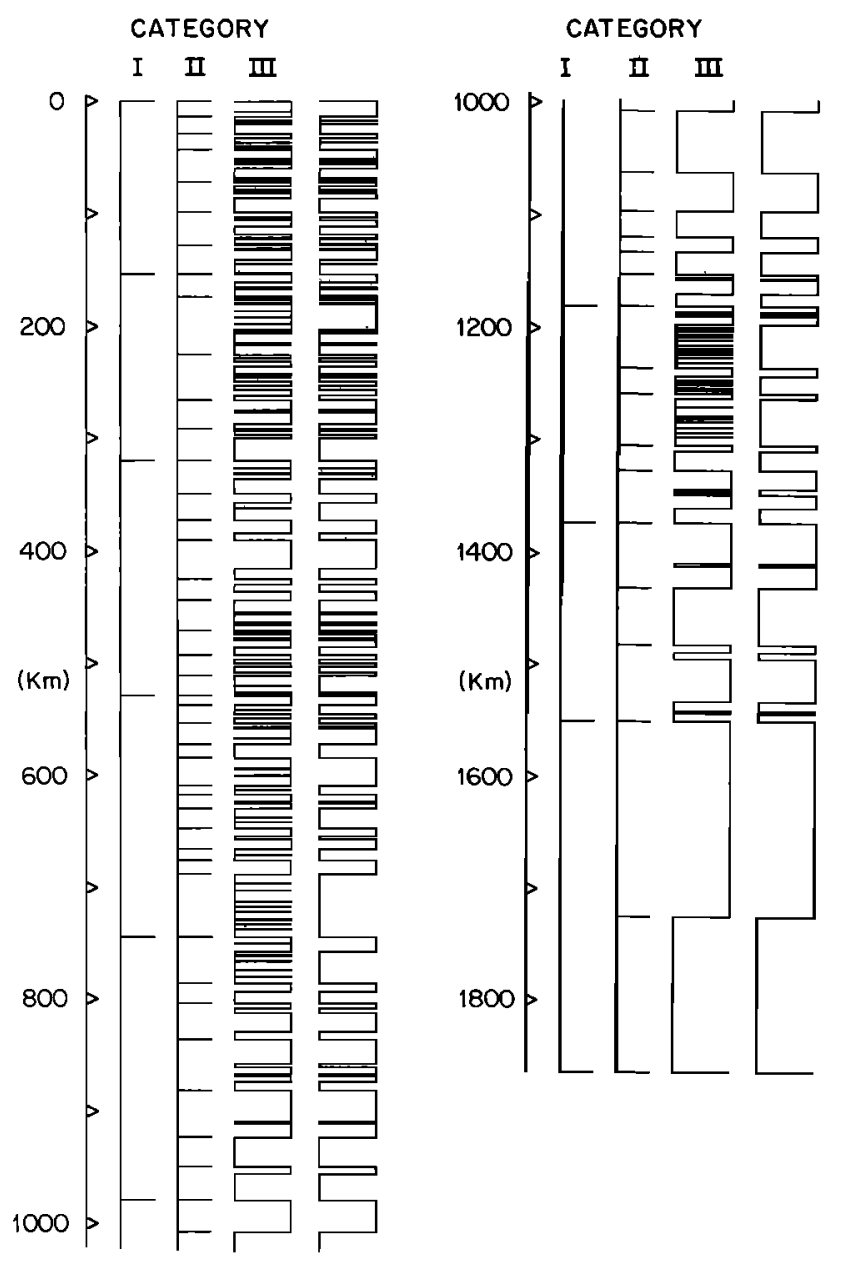

Fig. 5. Distances to anomalies along the synthetic flow line in the South Atlantic. The distances are built up from a combination of finite rotation poles (category I), averaged widths of anomalies in the South Atlantic (category II), and detailed studies of fast spreading rate anomalies (category III). The right-hand column shows the anomaly spacings after the removal of the nonuniformly mapped tiny wiggles.

established reversal sequence and because this produced more realistic appearing models of the observed anomalies. However, in converting the distance reference section into a time scale, we tabulated these presumed short polarity intervals separately to emphasize both the uncertainty in interpretation (dipole field intensity variation vs. polarity reversal) as well as the temporal nonuniformity of the existing record. Tiny wiggles that converted to polarity intervals shorter than $30 \mathrm{kyr}$ are listed separately in Table 3 . We designate the tiny wiggles in Table 3 using a system that parallels the nomenclature adopted for the larger anomalies (Table 2), except that the apparent polarity of the interval must be inferred to be opposite that of the anomaly it occurs in. This nomenclature is discussed in the appendix.

Many tiny wiggles, even on fast spreading ridges, are modeled as bodies only 0.5 to $1 \mathrm{~km}$ wide. When these intervals are interpolated into the South Atlantic flow line, for the purposes of constructing the time scale, they occasionally convert to bodies as narrow as $0.1 \mathrm{~km}$. Consequently, we present the distances in Tables 2 and 3 to a resolution of 0.01 $\mathbf{k m}$, so that these intervals are not inaccurately portrayed due to roundoff errors.

\section{Fine Details of the Reversal Sequence}

Below are descriptions of the magnetic anomaly data used to insert detail of the reversal sequence from faster spreading ridge
TABLE 3. Intervals of Uniform Crustal Magnetization Corresponding to Tiny Wiggles From Anomalies 1 to 13 and From Anomalies 24 to 28

\begin{tabular}{|c|c|c|}
\hline \multicolumn{2}{|c|}{ Interval,* km } & \multirow{2}{*}{$\begin{array}{c}\begin{array}{c}\text { Tiny } \\
\text { Wiggle }\end{array} \\
\ln -1\end{array}$} \\
\hline 7.63 & 7.81 & \\
\hline 18.82 & 18.99 & $1 \mathrm{r} .2 \mathrm{r}-1 \mathrm{n}$ \\
\hline 38.75 & 39.10 & $2 r .2 r-1$ \\
\hline 150.97 & 151.30 & $4 \mathrm{r} .2 \mathrm{r}-1$ \\
\hline 184.42 & 184.60 & $5 \mathrm{n} .2 \mathrm{n}-1$ \\
\hline 189.93 & 190.46 & 5n.2n-2 \\
\hline 195.80 & 196.15 & $5 n .2 n-3$ \\
\hline 360.31 & 360.94 & $5 \mathrm{Dr}-1$ \\
\hline 518.28 & 518.56 & $6 C r-1$ \\
\hline 539.96 & 540.37 & $7 \mathrm{r}-1$ \\
\hline 565.72 & 566.02 & $8 n \cdot 2 n-1$ \\
\hline 592.71 & 593.18 & $9 n-1$ \\
\hline 598.64 & 599.11 & $9 n-2$ \\
\hline 611.80 & 612.11 & $9 r-1$ \\
\hline 635.65 & 636.00 & $10 \mathrm{r}-1$ \\
\hline 639.95 & 640.13 & $10 \mathrm{r}-2$ \\
\hline 668.93 & 669.30 & $11 \mathrm{r}-1$ \\
\hline 694.06 & 694.56 & $12 \mathrm{r}-1$ \\
\hline 700.67 & 700.92 & $12 \mathrm{r}-2$ \\
\hline 710.53 & 711.03 & $12 \mathrm{r}-3$ \\
\hline 715.15 & 715.39 & $12 r-4$ \\
\hline 719.64 & 719.89 & $12 \mathrm{r}-5$ \\
\hline 726.50 & 726.99 & $12 \mathrm{r}-6$ \\
\hline 730.61 & 730.86 & $12 \mathrm{r}-7$ \\
\hline 735.10 & 735.35 & $12 r-8$ \\
\hline 748.12 & 748.56 & $13 \mathrm{n}-1$ \\
\hline 758.91 & 759.34 & $13 \mathrm{r}-1$ \\
\hline 764.15 & 764.36 & $13 r-2$ \\
\hline 771.73 & 772.16 & $13 r-3$ \\
\hline 778.14 & 778.57 & $13 r-4$ \\
\hline 1198.63 & 1198.77 & $24 r-1$ \\
\hline 1200.82 & 1200.96 & $24 r-2$ \\
\hline 1204.11 & 1204.25 & $24 r-3$ \\
\hline 1206.30 & 1206.44 & $24 r-4$ \\
\hline 1209.31 & 1209.45 & $24 r-5$ \\
\hline 1213.97 & 1214.11 & $24 \mathrm{r}-6$ \\
\hline 1217.53 & 1217.67 & $24 r-7$ \\
\hline 1220.54 & 1220.68 & $24 \mathrm{r}-8$ \\
\hline 1222.19 & 1222.32 & $24 r-9$ \\
\hline 1225.47 & 1225.61 & $24 \mathrm{~T}-10$ \\
\hline 1229.58 & 1229.72 & $24 \mathrm{r}-11$ \\
\hline 1245.52 & 1245.75 & $25 r-1$ \\
\hline 1247.76 & 1247.98 & $25 \mathrm{r}-2$ \\
\hline 1249.77 & 1249.88 & $25 r=3$ \\
\hline 1253.12 & 1253.23 & $25 r-4$ \\
\hline 1255.13 & 1255.35 & $25 r-5$ \\
\hline 1269.63 & 1269.88 & $26 \mathrm{r}-1$ \\
\hline 1277.28 & 1277.53 & $26 r-2$ \\
\hline 1280.08 & 1280.21 & $26 r-3$ \\
\hline 1282.64 & 1282.76 & $26 r-4$ \\
\hline 1287.99 & 1288.25 & $26 r-5$ \\
\hline 1292.58 & 1292.71 & $26 r-6$ \\
\hline 1296.16 & 1296.28 & $26 \mathrm{r}-7$ \\
\hline 1344.19 & 1344.58 & $28 r-1$ \\
\hline
\end{tabular}

*1.29 km subtracted for Central Anomaly offset.

systems into the South Atlantic category II distance framework. Figure 6 shows the location of these data in the context of the global ridge system.

The central anomaly to anomaly $3 A$. The detailed spacings from Klitgord et al.'s [1975] study of deep tow and surface data from various ridges in the Pacific were used to define the spacings from the axis to anomaly $3 \mathrm{~A}$. The spacings of reversals within this interval were interpolated into the South Atlantic spacings (Figure 7, bottom) as is shown in Figure 7 (middle). Four tiny wiggles have been identified from marine 


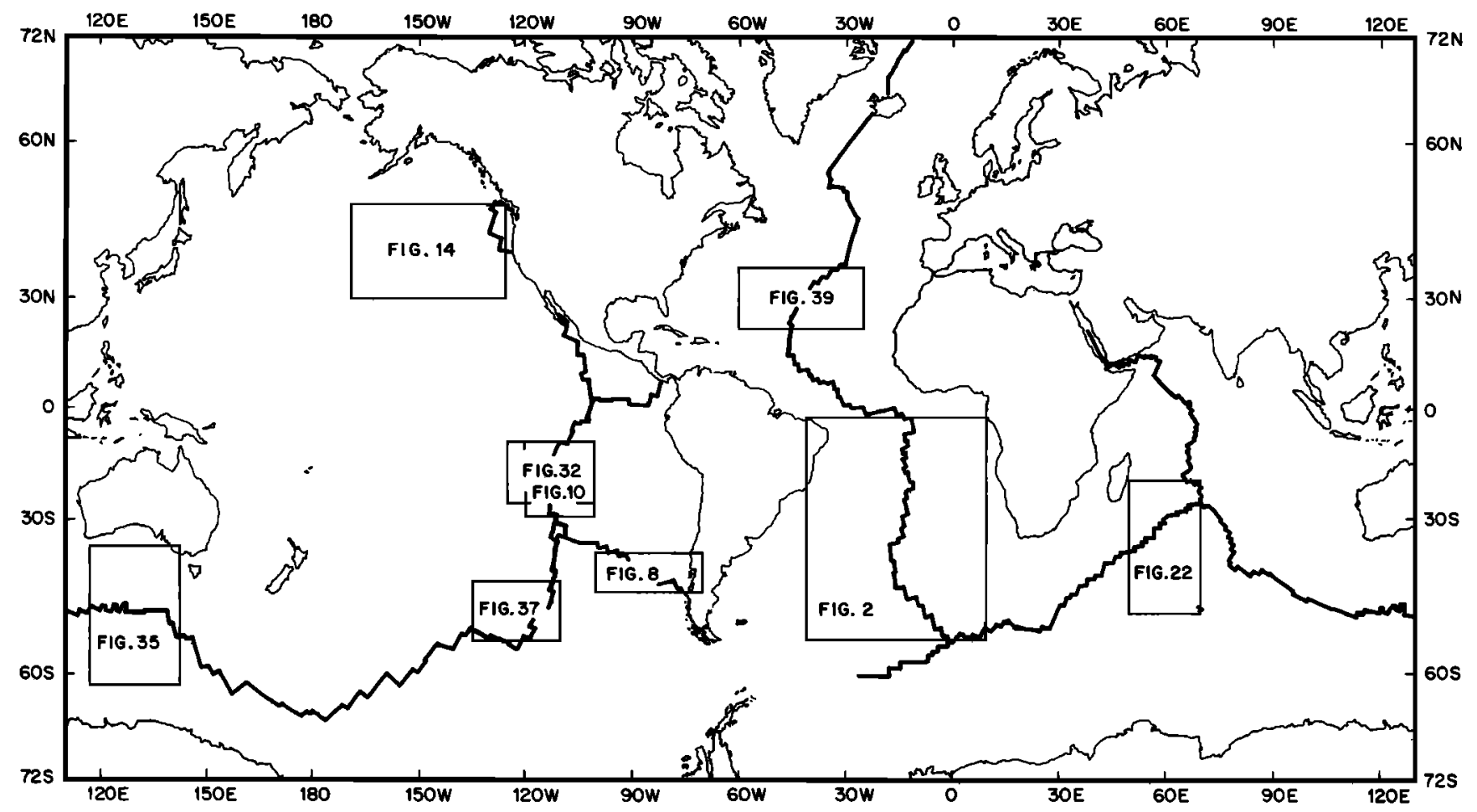

Fig. 6. Reference map showing location of data maps used in this study.
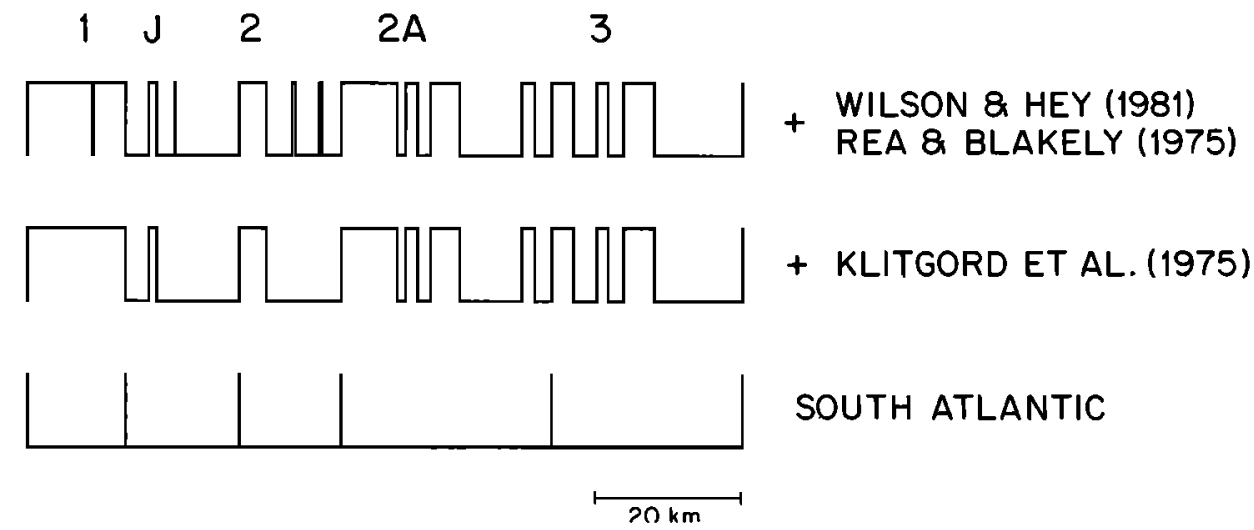

SOUTH ATLANTIC

Fig. 7. Distances between the axis and anomaly $3 \mathrm{~A}$, built up from the category $\Pi$ distances in the South Atlantic (bottom), the study of Klitgord et al. [1975] (middle), and other short events (top).

magnetic studies in this interval. Wilson and Hey [1982] recognized a distinctive tiny wiggle within the Central anomaly which correlates with the Emperor subchron [Ryan, 1972; Champion et al., 1981] (but see Champion et al. [19881). Rea and Blakely [1975] identified two tiny wiggles between anomalies 2 and 2A: the younger feature correlates with the Reunion subchron(s) [Gromme and Hay, 1971] and the older correlates with the "X"-anomaly [Heirtzler et al., 1968], for which there is only weak magnetostratigraphic evidence [Mankinen and Dalrymple, 1979]. More tentatively, Rea and Blakely [1975] identified a tiny wiggle between the Jaramillo and anomaly 2, which correlates with the Cobb Mountain subchron [Mankinen et al., 1978; Mankinen and Gromme, 1982; Clement and Kent, 1987]. The composite reversal sequence including these four tiny wiggles is shown in Figure 7 (top).

Anomaly $3 A$ to anomaly $4 A$. The sequence between anomaly $3 \mathrm{~A}$ and $4 \mathrm{~A}$ is not well constrained from published studies. Talwani et al. [1971] calculated a set of relative anomaly widths based on data from the Reykjanes Ridge, but due to the slow spreading rate the details of the polarity sequence were not clearly resolved. To determine the relative spacings, we averaged the widths of anomalies on four aeromagnetic profiles from the Chile Ridge (Figure 8) [Tebbens et al., 1990]. We chose these profiles because the areal coverage is good and the spreading pattern is very uniform (Figure 9). The stacked profile (Figure 9, top) reveals several small scale anomalies between anomalies $3 \mathrm{~A}$ and $4 \mathrm{~A}$ that may be indicative of short polarity intervals, including one anomaly on the old side of anomaly 4 that has been previously recognized (4.3), but also small anomalies on the young shoulder of anomaly $4 \mathrm{~A}$, on the young shoulder of anomaly 4, and on the old shoulder of anomaly $3 \mathrm{~B}$.

We stacked two profiles from the east flank of the fast spreading East Pacific Rise (Figure 10) to further investigate the small-scale anomalies seen in the Chile Rise stack. These profiles and their stack (Figure 11) reveal that the shoulder anomalies are indeed field related tiny wiggles. More speculatively, we point out that there is a suggestion of an even smaller tiny wiggle on the young shoulder of anomaly $3 \mathrm{~B}$, although we have not included it in our final model.

We have modeled the four tiny wiggles seen in the Chile Rise stack and confirmed in the EPR stack as due to short polarity intervals. The spacings for the South Atlantic framework, the 


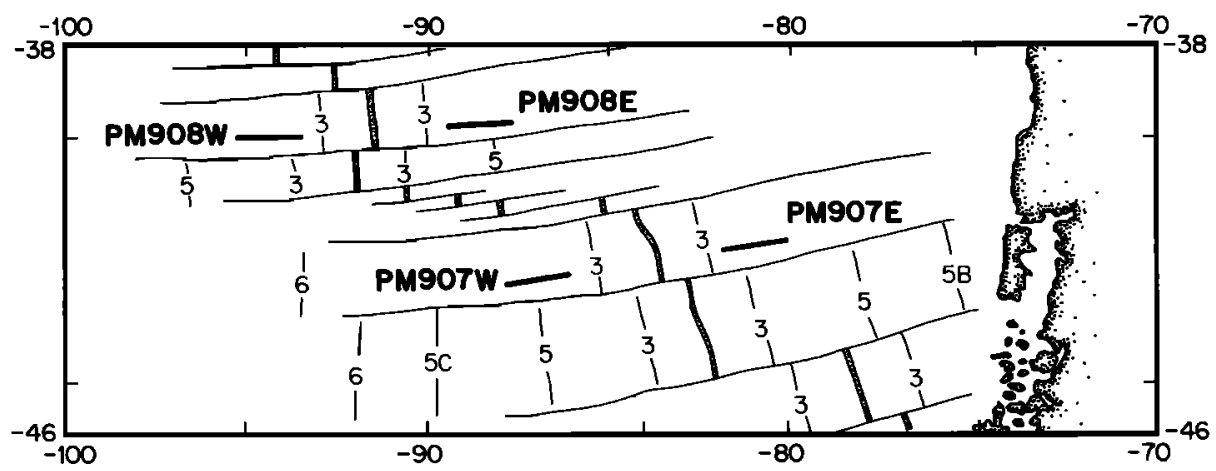

Fig. 8. Location of aeromagnetic profiles from the Chile Ridge used to constrain the relative widths of anomalies $3 \mathrm{~A}$ to $4 \mathrm{~A}$ in Figure 9.

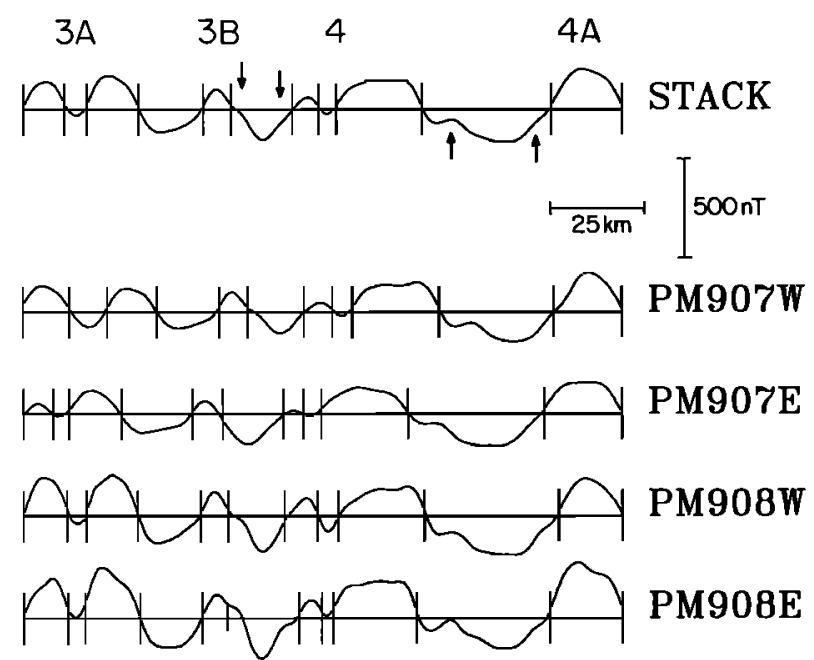

Fig. 9. Averaged widths of subintervals between anomalies $3 A$ and $4 A$, as indicated by vertical bars along top horizontal lines. Four profiles from the Chile Ridge, shown deskewed, were averaged to obtain the widths.

Chile Rise constraints, and the full reversal sequence including the tiny wiggles, are shown in Figure 12 (bottom, middle and top, respectively).

Anomaly $4 A$ to anomaly 6 . For this time interval, we have taken the spacings determined by Blakely [1974], who stacked 14 profiles from the North Pacific NOAA survey, and inserted them into our South Atlantic framework. In Figure 13 we show the South Atlantic spacings (bottom) and the composite reversal sequence based on the Blakely [1974] pattern (top).

Anomaly 6 to anomaly 8 . For this interval we stacked two profiles from the North Pacific NOAA survey located just to the west of the profiles analyzed by Blakely [1974]. The profiles were selected (see Figure 14 for location) to avoid the complex pattern of propagating rifts apparent in this region [e.g. Atwater and Severinghaus, 1989]. The profiles and their stack are shown in Figure 15.

The stack delineates the relative width of the many short anomalies within this interval. These apparent reversals have been inserted in the South Atlantic framework (Figure 16, center and bottom). In addition, we note a small anomaly on the young shoulder of anomaly $6 \mathrm{~B}$, a tiny wiggle in the center of anomaly $6 \mathrm{~B}$, and a tiny wiggle between anomalies $6 \mathrm{C}$ and 7 . We have modeled these anomalies and included them in the reversal pattem (Figure 16, top).

Anomaly 8 to anomaly 12 . We have stacked 7 profiles from the NOAA survey between anomalies 8 and 12 (see Figure 14 for location). The stack of these profiles (Figure 17) provides the spacing for the intervals between the twin peaks of anomalies

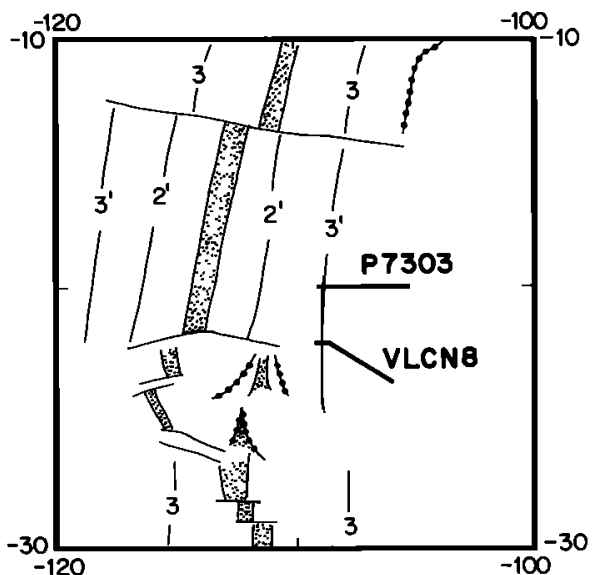

Fig. 10. Location of two profiles from the East Pacific Rise shown in Figure 11.

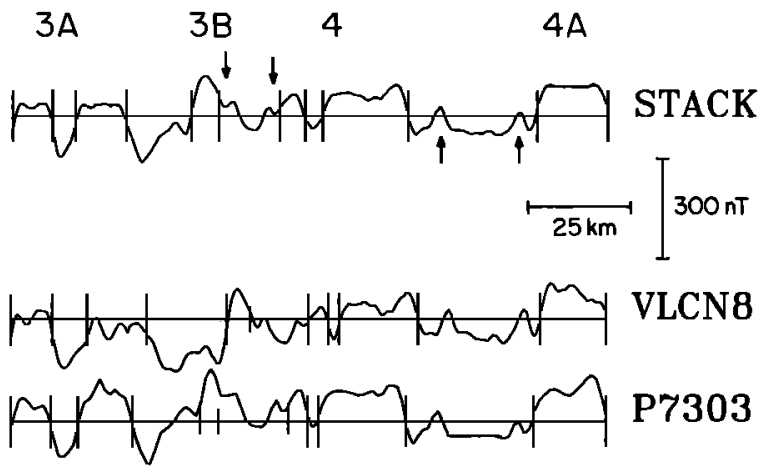

Fig. 11. Deskewed profiles from the East Pacific Rise showing correlatable tiny wiggles near anomalies 3B and 4.

10 and 11 . We have also identified eight tiny wiggles in the stack and have modeled them as discrete short polarity intervals. The South Atlantic framework, the detail from the stack, and the short polarity intervals as we have modeled them, are shown in Figure 18 (bottom, middle and top, respectively).

Anomaly 12 to anomaly 15 . From the same general area of the NOAA survey (Figure 14), we have selected and stacked five profiles crossing anomalies 12 to 15 (Figure 19). The stack reveals a pattern of tiny wiggles superimposed on both of the long negative anomalies. The eight tiny wiggles between anomalies 12 and 13 were described and modeled by Cande and LaBrecque [1974]; we recognize the same tiny wiggles in our model presented here. Between anomalies 13 and 15 we have identified and modeled four tiny wiggles, and we also identify a tiny wiggle within anomaly 13. (It is interesting to note that Heirtzler et al. [1968] included four short polarity intervals 


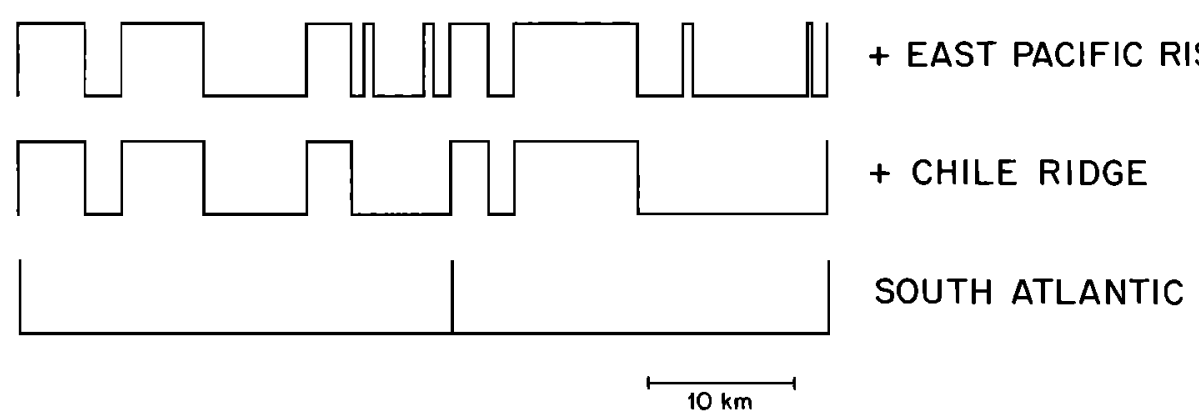

Fig. 12. Distances between anomalies $3 \mathrm{~A}$ and $4 \mathrm{~A}$ based on a combination of the category II South Atlantic distances (bottom), the averaged Chile Ridge profiles (middle), and models of the tiny wiggles observed in the East Pacific Rise profiles (top).

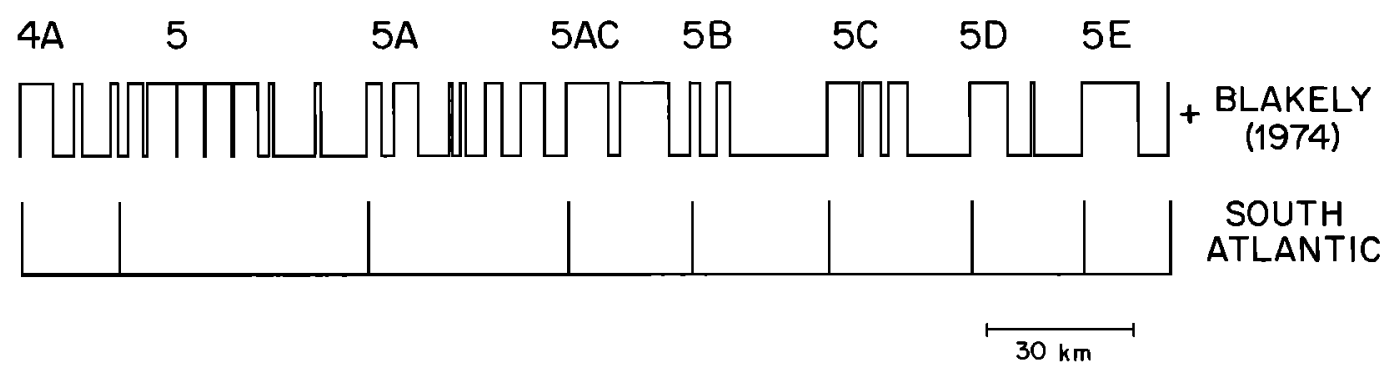

Fig. 13. Detailed spacings between anomalies $4 \mathrm{~A}$ and 6 based on the South Atlantic category I intervals (bottom), and the detailed study of the Northeast Pacific NOAA lines by Blakely [1974] (top).

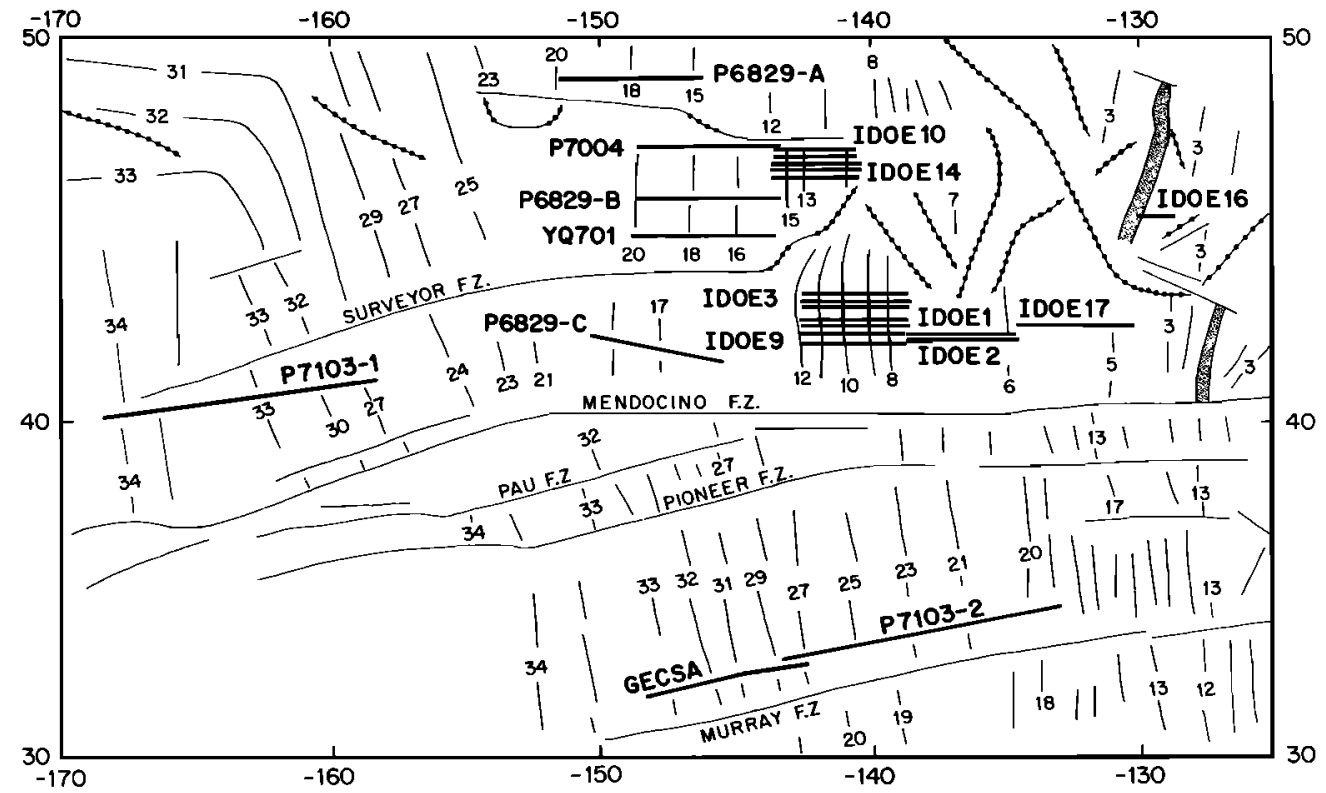

Fig. 14. Location of profiles in the Northeast Pacific used to constrain the fine details of anomalies 6 through 20 and anomalies 28 to 32 .

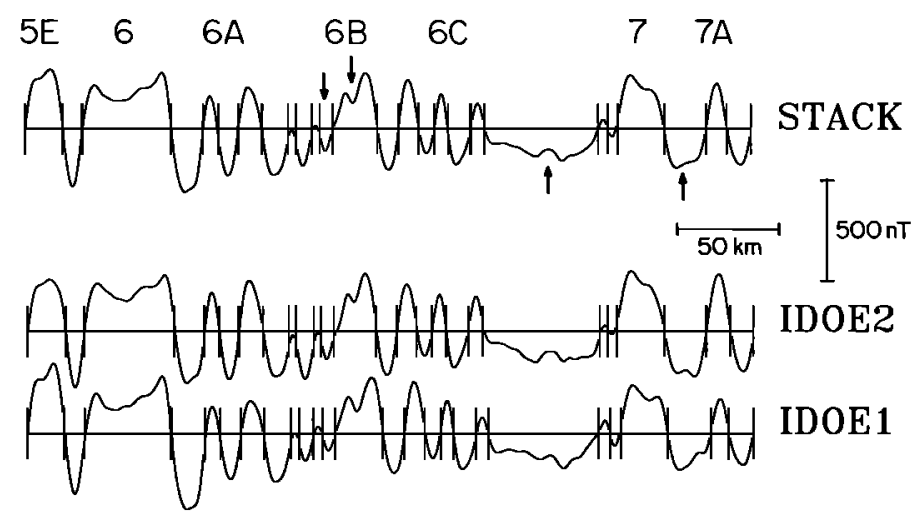

Fig. 15. Two NOAA lines from the Northeast Pacific that were averaged to constrain the widths of subintervals between anomalies $5 \mathrm{E}$ and 8. 


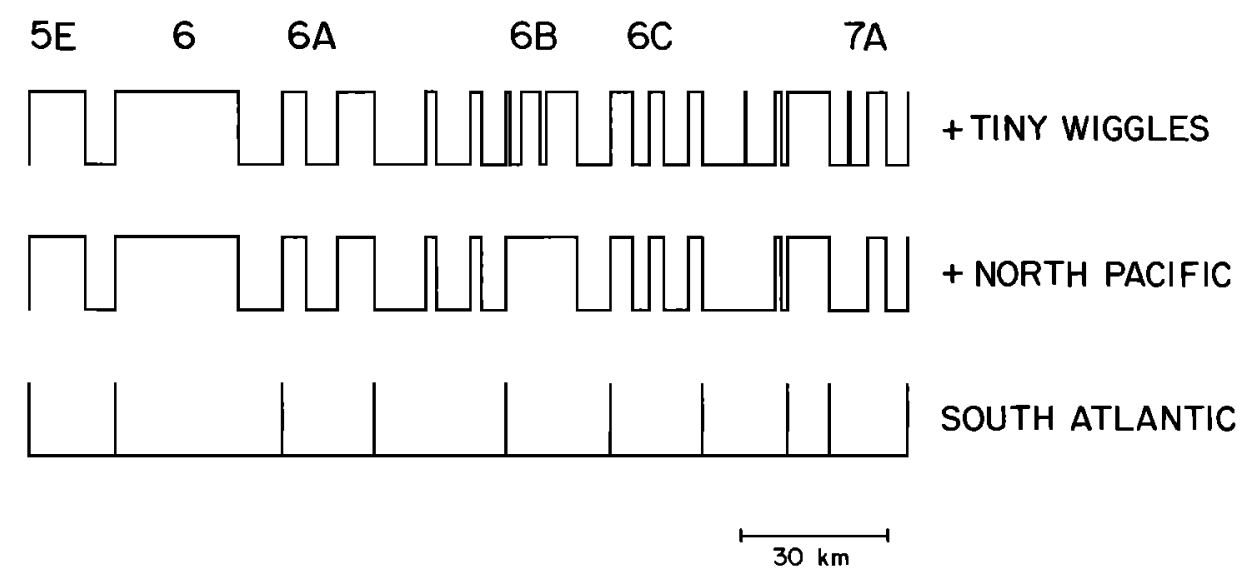

Fig. 16. Distances between anomalies $5 E$ to 8 as constrained by a combination of category II distances from the South Atlantic (bottom), the average of the two lines shown in Figure 15 (middle), and detailed modeling of the tiny wiggles within anomaly $6 \mathrm{~B}$, between anomalies $6 \mathrm{C}$ and 7 , and between anomalies 7 and $7 \mathrm{~A}$ (top).
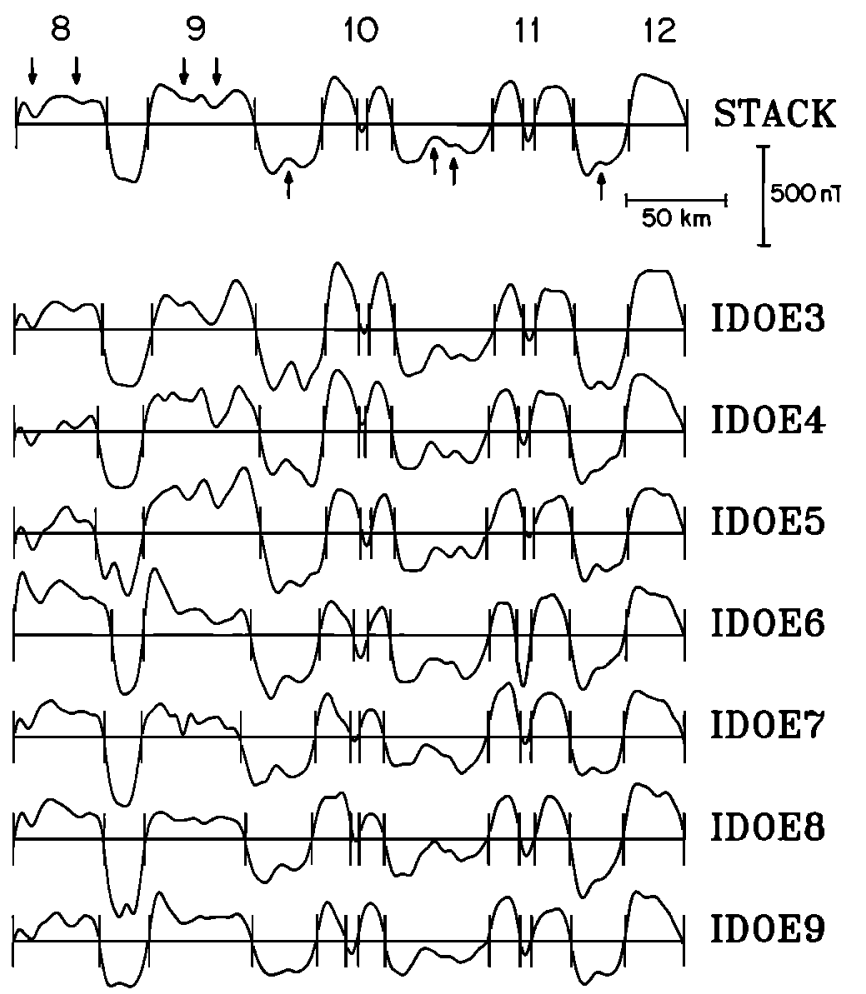

Fig. 17. Seven NOAA lines from the Northeast Pacific that were averaged to constrain the widths of subintervals between anomalies 8 and 12. between anomalies 13 and 15 in their time scale and the youngest of them was called anomaly 14.) We show the South Atlantic framework and the reversal sequence based on it in Figure 18 (bottom and middle) and the short polarity intervals based on the North Pacific data in Figure 18 (top).

Anomaly 15 to anomaly 20. The fine detail within anomalies 15 to 20 was constrained from five profiles from the North Pacific located to the west of the NOAA survey area (Figure 14). We show the profiles and their stack in Figure 20. The stack was used to constrain the relative widths of the anomalies (Figure 21, middle) and as a guide to model the fine detail within anomaly 17 (Figure 21, top). There are almost certainly additional correlatable tiny wiggles within this sequence. For example, within the young part of anomaly 18 there is a tiny wiggle observed on the two lowermost profiles in the stack. However, we have not modeled the tiny wiggles in this sequence as we have for anomalies 8 through 15 because the profiles are more widely separated than in the NOAA survey area and the stack is not as definitive a record of the reversal history. For example, the tiny wiggles within the negative intervals on either side of anomaly 19 are almost as distinct as the tiny wiggle within anomaly 18, yet we would feel uncomfortable in modeling it as a true field related event based only on these profiles. We prefer to leave the tiny wiggle record blank and note that in any case the features in question would be too short to be included in the final time scale.

Anomaly 20 to anomaly 23 . The reversal sequence in this time interval consists of several long reversed and normal polarity intervals. The South Atlantic spacings are adequate to

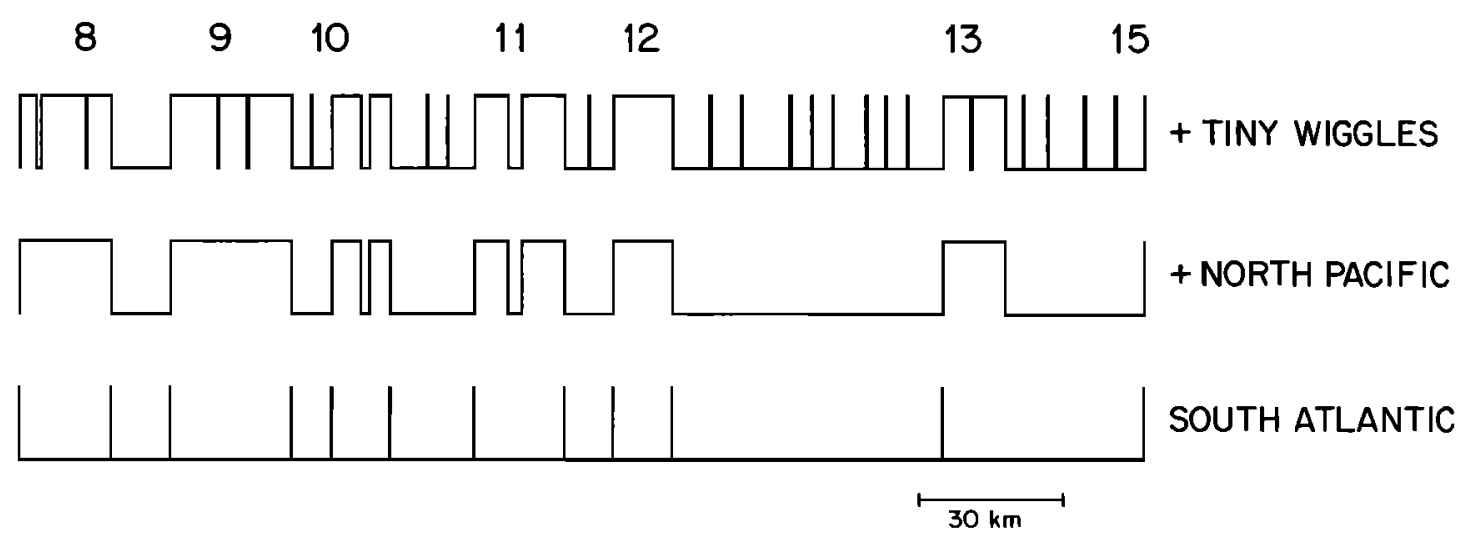

Fig. 18. Distances between anomalies 8 and 15 as constrained by a combination of the category II distances form the South Atlantic (bottom), the average of the NOAA lines shown in Figures 16 and 18 (center), and detailed modeling of the tiny wiggles observed in the stacks (top). 
model this interval and no exceptional surveys allow a systematic search for tiny wiggles on faster spreading ridges.

Anomaly 23 to anomaly 28 . We have stacked two profiles from the south flank of the Central Indian Ridge (Figure 23, see

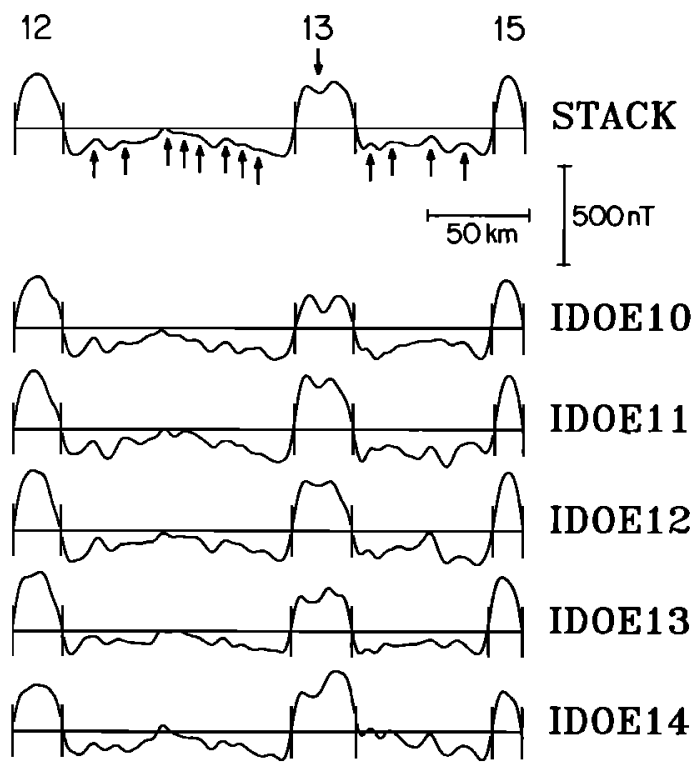

Fig. 19. Five NOAA lines from the Northeast Pacific that were averaged to constrain the width of anomaly 13 and to determine the location of the correlatable tiny wiggles between anomalies 13 and 15 .
Figure 22 for location) that record the reversal sequence in this time interval at the fast spreading rate of roughly $60 \mathrm{~mm} / \mathrm{yr}$ (half rate). We have used the stack to constrain the relative widths of the polarity intervals (Figure 24, middle).

There are numerous tiny wiggles in this time interval; a relatively long one ( -50 k.y.) has been previously modeled within anomaly 24 [Schlich, 1975]. In addition, from a detailed study of a large number of profiles from the Indian Ocean [Cande and Kent, 1992], we recognize an essentially continuous pattern of tiny wiggles between anomalies 24 and 27 . We find that almost all of the small scale features observed in the two profiles in Figure 23 are observed on other profiles in the Indian Ocean and are recognized in a stack of the profiles. In Cande and Kent [1992] we modeled the pattern of very short polarity intervals that simulates the small scale anomalies; this pattern is shown in Figure 24 (top).

The recognition of the continous pattern of tiny wiggles between anomalies 24 and 27 has led us [Cande and Kent, 1992] to develop an alternative model for their interpretation. Neither of the existing models for tiny wiggles is particularly appealing. If all tiny wiggles are due to short polarity events [e.g., Blakely, 1974], then it would require a sixfold increase in reversal frequency to account for the large number of tiny wiggles between anomalies 24 and 27 . Alternatively, the Cande and Labrecque [1974] model of long period intensity variations requires fluctuations of the dipole field at periods (50 to 200 kyr) substantially longer than generally attributed to core processes ( 10 kyr). In Cande and Kent [1992], we show that tiny wiggles can be attributed to random, short period (2 to 20 kyr) intensity variations of the dipole field which appear as 15

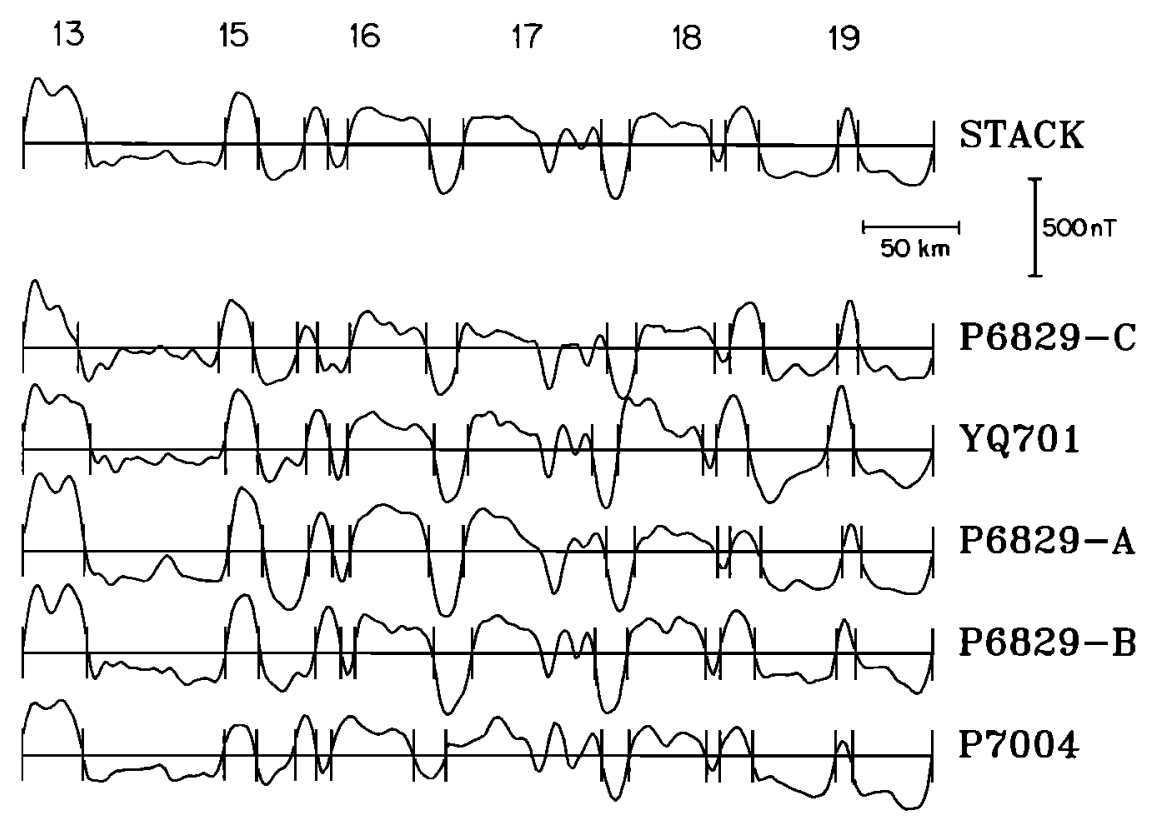

Fig. 20. Five profiles from the North Pacific that were averaged to constrain the widths of subintervals between anomalies 15 and 20 , as shown by the vertical bars on the top horizontal line.

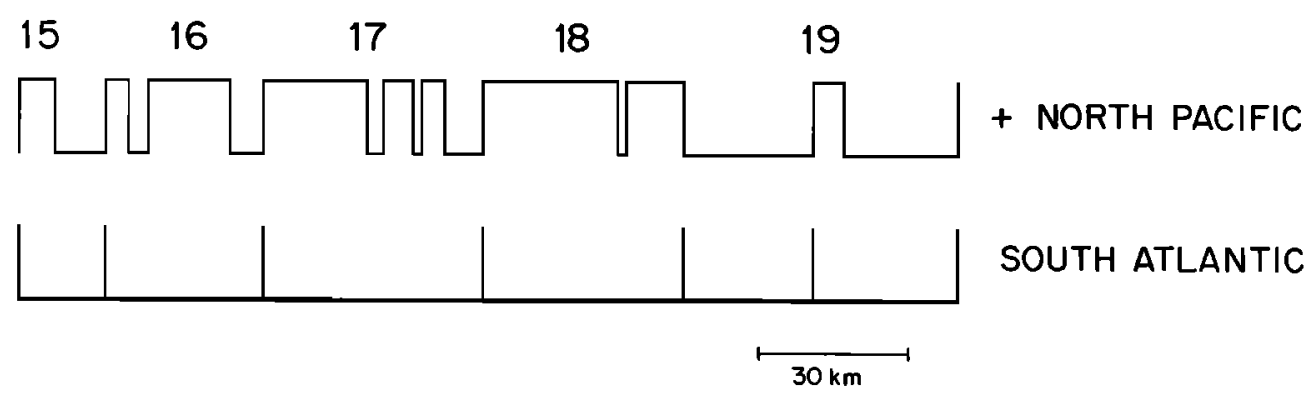

Fig. 21. Distances between anomalies 15 and 20 as constrained by a combination of the category II distances from the South Atlantic (bottom), and the detail from the averaged widths of the subintervals on the North Pacific profiles (top). 
to $25 \mathrm{~km}$ wavelength anomalies at the sea surface due to the bandpassing effect of the "Earth filter" [Schouten and McCamy, 1972]. This suggests that tiny wiggles do not require an unusal type of field behavior and, therefore, that they are not unexpected as a background signal in fast spreading rate, high resolution, marine magnetic anomaly records.

Anomaly 28 to anomaly 33 . We have constrained the relative widths of the polarity intervals in this time period using profiles from the North Pacific. The relative widths of anomalies in the North Pacific varies considerably between spreading corridors. Consequently, instead of taking the average of a stack we selected short sections of individual profiles: Geosecs-A (GECSA) from North of the Murray Fracture Zone for the relative widths of anomalies 28 and 29, and Pioneer 7103 (P7103-1) from just south of the Surveyor Fracture Zone for anomalies 30 to 32 . These profiles are shown in Figure 25; see Figure 14 for location. Except for a widely recognized short normal polarity interval between anomalies 32 and 33 and a tiny wiggle identified by Schlich [1975] between anomalies 28 and 29, we have not modeled any tiny wiggles in

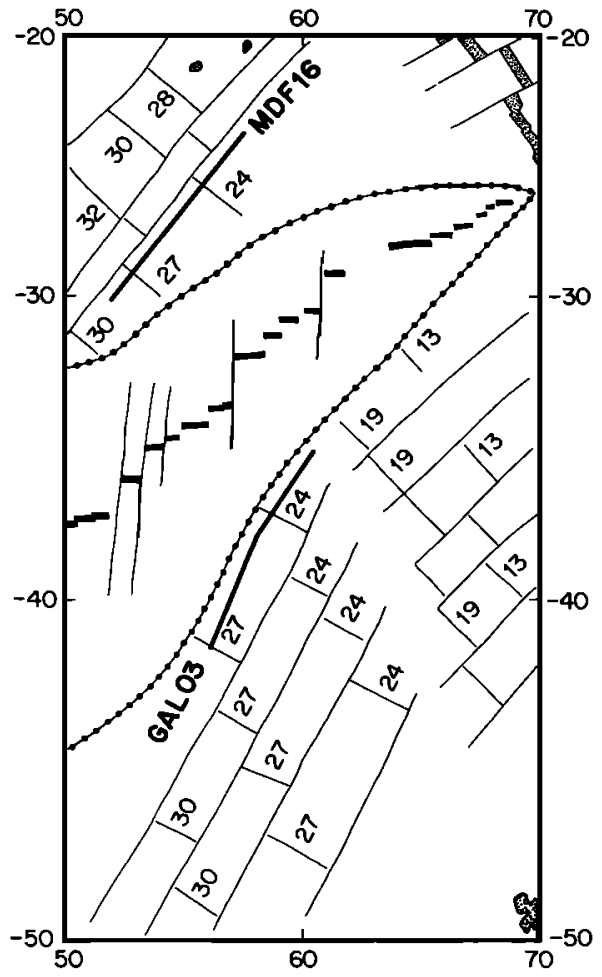

Fig. 22. Location of profiles in the Indian Ocean that were used to constrain the widths of anomalies 22 to 28 . this time interval. The resulting reversal pattern is shown in Figure 26.

Anomaly 33 to anomaly 34 . We have not modeled any fine detail in this time interval, as these distinctive, long wavelength anomalies are well constrained from the South Atlantic alone.

\section{Error Analysis}

Errors in the widths of the category I and category II intervals can be estimated in a straightforward fashion. We estimate that the confidence ovals and the errors in the rotation angles (estimated by Cande et al. [1988] to be roughly $0.05^{\circ}$ to $0.1^{\circ}$ ) for the finite rotation poles used to constrain the category $I$ intervals translate into an error of roughly $10 \mathrm{~km}$ in the distance along the flowline, or an accuracy of 1 to $3 \%$ depending on the width of the interval.

Errors in the widths of the category II intervals are calculated from the statistics of the individual estimates that were used to determine the average widths. By assuming that the individual estimates are normally distributed with a standard deviation $\sigma$, about the mean width, $\bar{x}$, of $N$ observations, the true mean, $\mu_{\text {is }}$ expected to lie with $95 \%$ confidence within the limits

$$
\bar{x}-\frac{1.96 \sigma}{\sqrt{N}}<\mu<\bar{x}+\frac{1.96 \sigma}{\sqrt{N}}
$$

In Table 4 we give the mean width, the number of observations, the $95 \%$ confidence interval and the percent error that the $95 \%$ confidence interval represents, for all of the category II intervals. The percent error ranges from $1.1 \%$ for the interval between anomalies 13 and 15 , to $17 \%$ for the interval between anomalies 23 and 24 . The average error is roughly $7 \%$.

Because the category III intervals are based on either one or two carefully selected profiles or else stacks of profiles from a small area, it is not possible to make a significant estimate of the error in these intervals.

\section{Adjustment to the Central Anomaly and the Composite Sequence}

To account for the finite width of the emplacement zone of magnetized oceanic crust, a small but systematic adjustment of the anomaly distances is required before the composite reversal sequence is calibrated to generate a time scale. The width of the transition zone over the Brunhes/Matuyama boundary in the South Atlantic as inferred from the shapes of magnetic anomalies is estimated at about $3 \mathrm{~km}$ [Carbotte et al., 1991]. Since the outward displacement of polarity boundaries due to this effect is expected to be about half the transition zone width [Atwater and Mudie, 1973], it is necessary to subtract roughly $1.5 \mathrm{~km}$ from all the anomaly distances in the composite

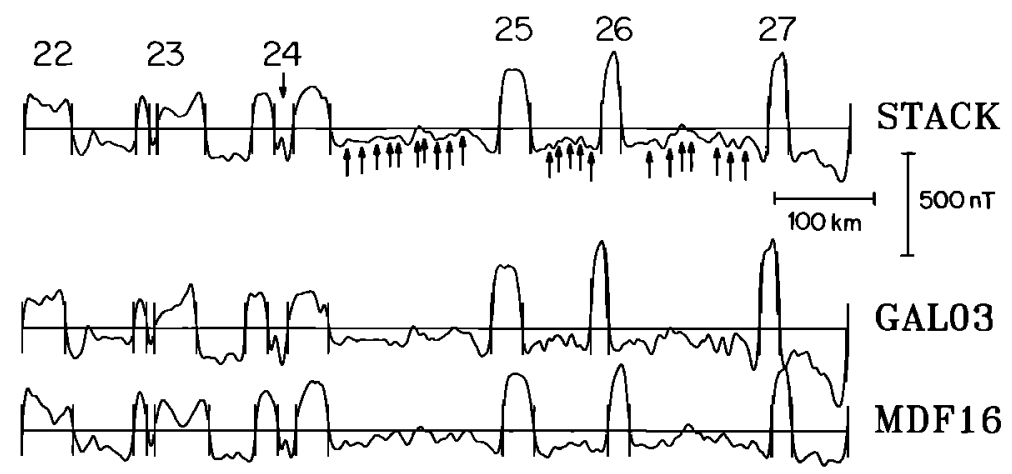

Fig. 23. Two deskewed profiles from the Indian Ocean that have been averaged to obtain the widths of the sub-intervals between anomalies 22 and 28 . The tiny wiggles between anomalies 24 and 27 are remarkably correlatable. 


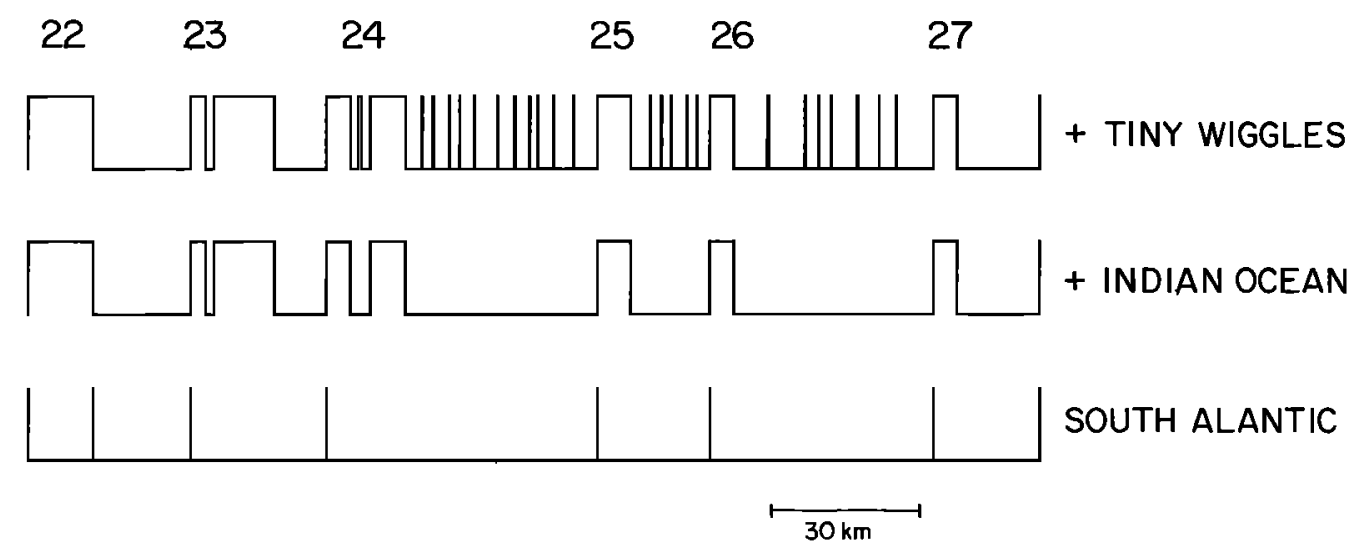

Fig. 24. The distances between anomalies 22 and 28 as constrained by a combination of the category II distances in the South Atlantic (bottom), the averaged widths of the subintervals on the Indian Ocean profiles (middle), and detailed modeling of the tiny wiggles between anomalies 24 and 27 (top).

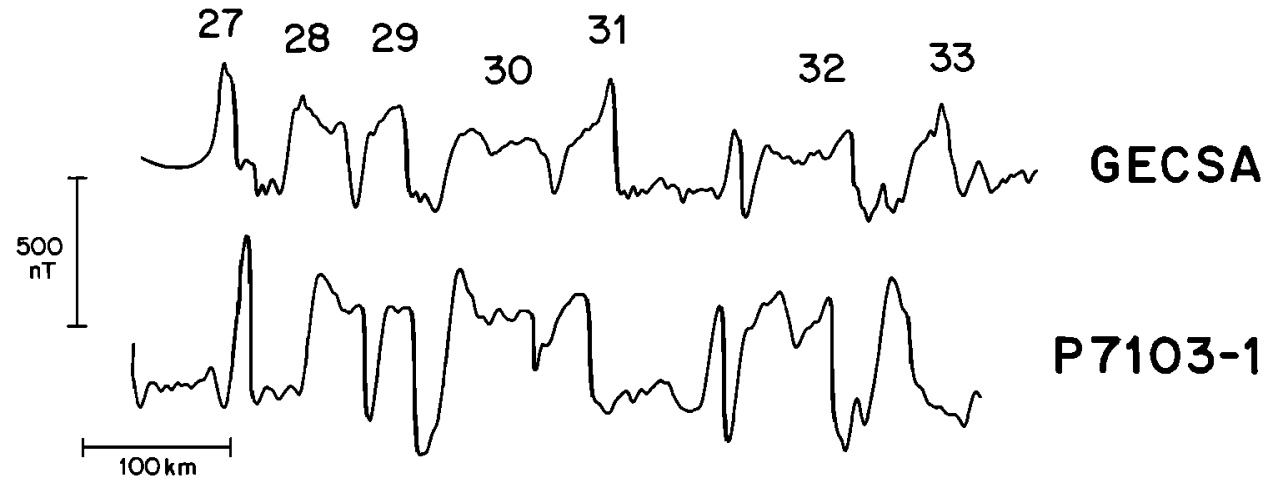

Fig. 25. Two profiles from the North Pacific used to constrain the widths of the subintervals between anomalies 28 and 33 .

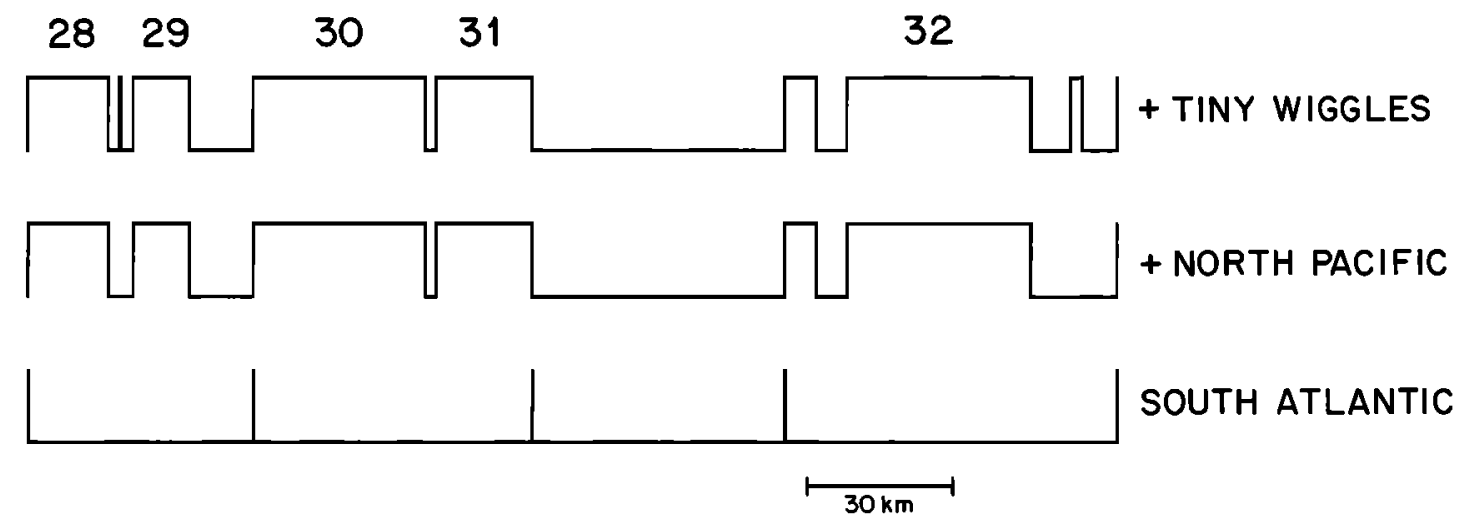

Fig. 26. Distances between anomalies 28 and 33 as constrained by a combination of the South Allantic category II distances (bottom), the North Pacific profile (center), and modeling of the short event between anomalies 32 and 33 and Schlich's [1975] tiny wiggle between anomalies 28 and 29 (top).

sequence. Failure to do so leads to an unreasonably old age of the Brunhes/Matuyama boundary of well over $0.8 \mathrm{Ma}$. The actual amount of the correction that we used, $1.29 \mathrm{~km}$, was determined by forcing the age of the Brunhes/Matuyama boundary to equal a predetermined value as discussed later. The consequence of this correction for Central Anomaly offset is that the half-width of the Central Anomaly is reduced from about $13.4 \mathrm{~km}$ to $12.2 \mathrm{~km}$ in the South Atlantic reference flow line.

\section{age Calibration of Composite Sequence}

We have derived a composite geomagnetic polarity sequence along a synthetic flow line for the South Atlantic ridge system (right-hand column of Figure 5; Tables 2 and 3). Age calibration of the geomagnetic polarity intervals to make a time scale is thus reduced to the determination of the seafloor spreading history of the South Atlantic.

Previous geomagnetic reversal time scale calibration methods assumed one or more extended intervals of constant spreading rate in the South Atlantic, ranging from over practically the entire ridge crest anomaly sequence (HDHPL68; LKC77) to the nominal duration ( 6 m.y.) of geologic stages [Lowrie and Alvarez, 1981] (LA81). The assumption of constant spreading rate over extended time intervals is clearly an oversimplification and is no longer necessary with the availability of more numerous age calibration data. On the other hand, strict linear interpolation can result in frequent and abrupt changes in apparent spreading rate that are simply artifacts of inaccuracies 
in closely spaced calibration tie points, as was pointed out for example, by Harland et al. [1982].

In our initial efforts to identify long profiles from different ridge systems that could be used as reference sequences, ridgeridge comparisons involving the South Atlantic showed the fewest kinks or sudden shifts in relative spreading. This suggested that South Atlantic spreading was relatively uniform and continuous. Accordingly, we assume for the purposes of temporal calibration a smoothly varying (but not necessarily constant) rate of spreading from anomaly 34 to the ridge axis for the South Atlantic ridge system. In practice, we chose nine more or less evenly distributed age calibration points, and fit them with a cubic spline approximation to interpolate the age of polarity intervals.

TABLE 4. Category II Statistics

\begin{tabular}{|c|c|c|c|c|}
\hline Anomaly & $\begin{array}{c}\text { Mean } \\
\text { Width,km }\end{array}$ & $\boldsymbol{N}$ & $\begin{array}{l}\text { 95\% Confidence } \\
\text { Interval, } \mathrm{km}\end{array}$ & \% Error \\
\hline $\ln$ & $13.425^{*}$ & 6 & 0.784 & 6.3 \\
\hline $\mathbf{1 r}$ & 15.662 & 6 & 1.782 & 11.3 \\
\hline 2 & 13.953 & 6 & 0.576 & 4.1 \\
\hline 2A-3n.1 & 28.809 & 6 & 2.118 & 7.3 \\
\hline $3 n .2-3 r$ & 26.314 & 6 & 3.524 & 13.3 \\
\hline 3A-3B & 29.605 & 6 & 1.789 & 6.0 \\
\hline 4 & 25.838 & 6 & 3.226 & 12.4 \\
\hline $4 A$ & 20.020 & 8 & 2.142 & 10.7 \\
\hline 5 & 51.186 & 8 & 2.355 & 4.6 \\
\hline 5A-5AB & 41.008 & 8 & 2.419 & 5.9 \\
\hline 5AC-5AD & 25.639 & 8 & 2.282 & 8.9 \\
\hline $5 \mathrm{~B}$ & 28.217 & 8 & 1.298 & 4.6 \\
\hline $5 C$ & $\mathbf{2 9 . 2 5 5}$ & 8 & 4.154 & 14.2 \\
\hline $5 D$ & 29.224 & 8 & 2.392 & 10.3 \\
\hline $5 \mathrm{E}$ & 17.775 & 8 & 1.653 & 9.3 \\
\hline 6 & 34.292 & 8 & 3.223 & 9.4 \\
\hline $6 A$ & 18.909 & 8 & 1.456 & 7.7 \\
\hline 6AA & 27.126 & 8 & 2.740 & 10.1 \\
\hline $6 B$ & 21.643 & 8 & 2.749 & 12.7 \\
\hline $6 \mathrm{Cn}$ & 18.794 & 8 & 1.428 & 7.6 \\
\hline 6Cr & 17.881 & 8 & 1.502 & 8.4 \\
\hline $7 n$ & 8.732 & 9 & 1.057 & 12.1 \\
\hline $7 r-7 A$ & 16.297 & 9 & 0.652 & 4.0 \\
\hline $8 n$ & 18.714 & 9 & 1.273 & 6.8 \\
\hline $8 r$ & 12.194 & 9 & 0.988 & 8.1 \\
\hline $9 n$ & 24.739 & 9 & 3.018 & 12.2 \\
\hline $9 r$ & 8.176 & 9 & 0.589 & 7.2 \\
\hline $10 \mathrm{n}$ & 12.146 & 9 & 1.494 & 12.3 \\
\hline $10 \mathrm{r}$ & 17.268 & 9 & 2.279 & 13.2 \\
\hline $11 n$ & 18.588 & 9 & 1.747 & 9.4 \\
\hline $11 r$ & 10.023 & 9 & 1.383 & 13.8 \\
\hline $12 n$ & 12.261 & 9 & 1.238 & 10.1 \\
\hline $12 \mathrm{r}$ & 56.206 & 9 & 3.091 & 5.5 \\
\hline 13 & 41.766 & 5 & 0.459 & 1.1 \\
\hline 15 & 17.754 & 5 & 0.728 & 4.1 \\
\hline 16 & 32.530 & 5 & 1.984 & 6.1 \\
\hline 17 & 45.142 & 5 & 2.754 & 6.1 \\
\hline $18 n$ & 41.386 & 5 & 2.856 & 6.9 \\
\hline $18 r$ & 26.744 & 5 & 0.749 & 2.8 \\
\hline 19 & 29.692 & 5 & 2.108 & 7.1 \\
\hline $20 n$ & 28.413 & 5 & 2.046 & 7.2 \\
\hline $20 r$ & 54.180 & 5 & 3.576 & 6.6 \\
\hline $21 n$ & 34.466 & 5 & 2.895 & 8.4 \\
\hline $21 r$ & 22.843 & 5 & 2.924 & 12.8 \\
\hline $22 n$ & 13.232 & 5 & 1.059 & 8.0 \\
\hline 22r & 20.046 & 5 & 2.385 & 11.9 \\
\hline 23 & 28.137 & 5 & 4.868 & 17.3 \\
\hline 24 & 55.547 & 5 & 5.221 & 9.4 \\
\hline 25 & 23.297 & 5 & 2.260 & 9.7 \\
\hline 26 & 46.001 & 5 & 2.806 & 6.1 \\
\hline 27 & 21.900 & 5 & 3.022 & 13.8 \\
\hline 28 & 46.136 & 5 & 4.475 & 9.7 \\
\hline $30-31 n$ & 57.297 & 8 & 5.730 & 10.0 \\
\hline 31r & 51.976 & 8 & 3.430 & 6.6 \\
\hline 32 & 68.291 & 8 & 5.736 & 8.4 \\
\hline $33 n$ & 174.348 & 6 & 5.753 & 3.3 \\
\hline 33r & 138.564 & 6 & 5.820 & 4.2 \\
\hline
\end{tabular}

*Not corrected for $1.29 \mathrm{~km}$ Central Anomaly offset. 
Harland et al. [1990] recently analyzed the available body of diagnostic radioisotopic age data in the form of chronograms for geologic stage boundaries. In essence, a chronogram portrays a measure of the overall inconsistency in a set of constraining radioisotopic age data as a function of trial ages for a particular boundary; the best chronogram estimate of the boundary age is that which minimizes the measure of inconsistency among the dates weighted according to their individual analytical errors. In principle, chronogram estimates thus embody the influence of all the available radioisotopic data and consequently should be robust. In practice, the chronograms often do not provide acceptable age control due mostly to the lack of an adequate number and distribution of reliable dates. Consequently, Harland et al. [1990] did not use chronogram estimates from virtually the Priabonian to Bartonian Stage boundary in the Eocene to the Campanian to Santonian Stage boundary in the Late Cretaceous for calibration of the GTS89 geomagnetic polarity time scale.

We selected magnetobiostratigraphically well-correlated calibration points spaced at approximately $10 \mathrm{~m} . \mathrm{y}$. intervals, comparable in temporal separation to the category I intervals used to construct the overall framework for South Atlantic seafloor spreading. The selected tiepoints in the Neogene largely conform to the chronogram estimates from Harland et al. [1990], whereas for the tiepoints in the Paleogene, we were guided by a recent assessment of correlations and age estimates by Berggren et al. [1992]; Late Cretaceous age assignments are similar to those in Berggren et al. [1985b] and Harland et al. [1990].

The nine selected calibration points (Table 5) are a distillation of a much larger number of individual radioisotopic dates as described below. The tiepoints reflect a preference for those data which can be tied to the magnetic anomaly sequence via marine magnetobiostratigraphic correlations and constraints from biostratigraphic correlation of sediments overlying oceanic basement [Cande et al., 1989]. An exception is the tiepoint at the Cretaceous/Paleogene boundary for which the iridium anomaly provides a means of precise correlation between the marine record and the nonmarine sediments from which the radioisotopic dates have been obtained. In general, though, data from terrestrial (i.e., nonmarine) sections are generally not sufficiently independent for time scale calibration because the radioisotopic age information itself tends to be used as a basis for detailed correlation to the marine magnetic anomaly sequence. A case in point are the two Oligocene ash layers in terrestrial deposits in western North America that provided important age calibration constraints for the Paleogene part of BKFV85, but whose correlation to the polarity sequence has been successively reinterpreted on the

TABLE 5. Age Calibrations for Geomagnetic Polarity Time Scale

$\begin{array}{lll}\text { Chron } & \begin{array}{l}\text { South Atlantic } \\ \text { distance, }\end{array} \text { km } & \text { Age, Ma }\end{array}$

$\begin{array}{lrr}\text { C2An(0.0) } & 41.75 & 2.6 \\ \text { C5Bn(0.0) } & 290.17 & 14.8 \\ \text { C6Cn.2r(0.0) } & 501.55 & 23.8 \\ \text { C13r(.14) } & 759.49 & 33.7 \\ \text { C21n(.33) } & 1071.62 & 46.8 \\ \text { C24r(.66) } & 1221.20 & 55.0 \\ \text { C29r..3) } & 1364.37 & 66.0 \\ \text { C33n(.15) } & 1575.56 & 74.5 \\ \text { C34n(0.0) } & 1862.32 & 83.0\end{array}$

* $1.29 \mathrm{~km}$ subtracted to account for Central Anomaly offset. basis of new, high-precision radioisotopic dating [Swisher and Prothero, 1990; Prothero and Swisher, 1992]. In the following section, we describe details of the calibration points using a chron nomenclature as defined in the appendix.

\section{Description of Calibration Points}

1. After the zero-age ridge axis, the youngest calibration point in virtually every geomagnetic polarity time scale since and including HDHPL68 has been for the old end of anomaly $2 \mathrm{~A}$ (= 2 Ar $(0.0)$ ), correlative to the Gauss/Gilbert boundary. Mankinen and Dalrymple [1979] give a chronogram estimate of 3.40 Ma for the Gauss/Gilbert boundary. Recently, however, it has been possible to date high resolution climate records for the Plio-Pleistocene by assuming that their variability was forced by the well-known variations in the Earth's orbital parameters. Astronomical time scales developed from climatic records from the equatorial Pacific [Shackleton et al., 1990] and the Mediterranean region [Hilgen, 1991a,b] reveal that the conventional radiosotopic age estimates for geomagnetic reversal boundaries in the Plio-Pleistocene are consistently too young by about 5 to 7\%. For example, Hilgen [1991b] derives an astrochronologic age of $3.58 \mathrm{Ma}$ for the Gauss/Gilbert boundary. Similarly, the astrochronologic age for the Brunhes/Matuyama boundary derived by Shackleton et al. [1990] is $0.78 \mathrm{Ma}$ as compared to the chronogram estimate of $0.73 \mathrm{Ma}$ given by Mankinen and Dalrymple [1979]. In a remarkable confirmation of this astrochronologic determination well-defined ${ }^{40} \mathrm{Ar} /{ }^{39} \mathrm{Ar}$ dates from lavas from Maui which lie within the Brunhes/Matuyama transition give an age of $0.783 \mathrm{Ma}$ [Baksi et al., 1992]. The precise agreement now emerging between the astrochronologic ages and new high precision radiometric ages for the last $5 \mathrm{~m} . \mathrm{y}$. [see also Baksi et al., 1991a,b; Walker et al., 1991; Tauxe et al, 1991] also suggests that the earlier conventional K/Ar dates that have been generally used to estimate the ages of the most recent geomagnetic reversal boundaries are the main cause of the discrepancies, rather than inaccuracies in the fundamental radiometric decay constants.

Acknowledging the break with tradition in attempting to take into account the new information, we use a calibration tiepoint at the Matuyama/Gauss boundary $(=\mathrm{C} 2 \mathrm{An}(0.0)$ ) set to $2.60 \mathrm{Ma}$, as determined from astronomical calibration of two independent sets of data by Shackleton et al. [1990] and Hilgen [1991b]. This compares with a chronogram estimate of $2.48 \mathrm{Ma}$ for the Matuyama/Gauss boundary determined by Mankinen and Dalrymple [1979]. We also used the astrochronologic estimate of $0.78 \mathrm{Ma}$ for the Brunhes/Matuyama boundary to determine the amount of correction for the outward displacement of the Central Anomaly $(1.29 \mathrm{~km})$ as discussed earlier.

2. Most recent time scales (e.g., BKFV85, GTS89) have a calibration point at anomaly 5 (= chron $C 5 n$ ). However, in view of the continued uncertainty (discussed below) regarding what is the best age estimate for chron C5n, we prefer to use instead a calibration point lower in the Miocene. Accordingly, we assign an age of $14.8 \mathrm{Ma}$ to the younger end of chron C5Bn (= C5Bn(0.0)). This is based on radioisotopic age constraints on the correlative N9/N10 foraminifera zone boundary of Miller et al. [1985] and Berggren et al. [1985b], as estimated in Japan (14.6 \pm 0.4 Ma [Tsuchi et al., 1981]) and in Martinique (15.0 \pm $0.3 \mathrm{Ma}$ [Andreieff et al., 1976]). This calibration agrees well with derived ages for chron C5Bn(0.0) of 14.87 Ma in BKFV85 and $14.98 \mathrm{Ma}$ in GTS89, as well as a chronogram estimate of $14.6 \mathrm{Ma}$ [Harland et al., 1990] for the approximately correlative Serravallian/Langhian boundary.

3. The Miocene/Oligocene (Aquitanian to Chattian) boundary can be correlated to the middle part of chron $\mathrm{C} 6 \mathrm{Cn}$ (= C6Cn.2r(0.0)) [Berggren et al., 1985b], and has a chronogram estimate of $23.8 \mathrm{Ma}$ (five dates listed for the Aquitanian, 20 
dates for the Chattian) according to Harland et al. [1990]. This is virtually identical to the age (23.7 Ma) estimated in BKFV85.

4. The Oligocene/Eocene (Rupelian to Priabonian) boundary has been correlated to a level within the upper part of chronozone $\mathrm{C} 13 \mathrm{r}(=\mathrm{C} 13 \mathrm{r}(0.14))$ in the proposed stratotype Massignano section in the Apennines [Nocchi et al., 1986]. Harland et al. [1990] give a chronogram estimate of $36.4 \mathrm{Ma}$ for this boundary. More recent assessments of radioisotopic age data [e.g., Berggren et al., 1992], however, suggest an age for the boundary that is at least 2 m.y. younger as constrained, for example, by dates of $33.9 \mathrm{Ma}$ to $34.6 \mathrm{Ma}$ on volcanic ashes from the lower part of chronozone $\mathrm{C13r}$ at Massignano [Montanari et al., 1988] and a date of $33.4 \mathrm{Ma}$ on oceanic basement associated with anomaly 13 (= chron C13n) at Ocean Drilling Project Site 706 [Duncan and Hargraves, 1990]. Odin et al. [1991] have critically evaluated the bio- and magnetostratigraphically well-controlled radioisotopic dates from the Paleogene sequence in the Apennines and based on additional analyses, obtain an estimate for the Eocene/ Oligocene boundary of $33.7 \pm 0.4 \mathrm{Ma}$ which we use for calibration.

5. Subdivisions of the Eocene do not provide chronogram estimates suitable for time scale calibration according to Harland et al. [1990], whereas recent work by Prothero and Swisher [1992] indicates that the radioisotopic dates from terrestrial deposits in Wyoming [Flynn, 1986] that were the basis for a calibration point of $49.5 \mathrm{Ma}$ for the younger end of chron C21n in BKFV85 are likely to be anomalously old. Bryan and Duncan [1983] obtained a K-Ar date of $46.8 \pm 0.5 \mathrm{Ma}$ on biotites from sediments in DSDP Hole 516F which are magnetobiostratigraphically constrained to the upper part of chron C21n (= C21n(0.33)) [Berggren et al., 1983,1992]. This calibration is supported by dates of $46.2 \mathrm{Ma}(\mathrm{K}-\mathrm{Ar})$ and $45.7 \mathrm{Ma}$ (Rb-Sr) reported by Harris and Fullager [1989] on bentonite from the lower Castle Hayne Formation of the Atlantic Coastal Plain which is biostratigraphically constrained to the older part of chron C20r [Berggren et al., 1992].

6. For the Paleocene/Eocene (Ypresian to Thanetian) boundary, Harland et al. [1990] rejected their chronogram estimate of $53.4 \mathrm{Ma}$ as too young because it is controlled entirely by glauconites; instead they used an interpolated age of
56.5 Ma. On the basis of new ${ }^{40} \mathrm{Ar} /{ }^{39} \mathrm{Ar}$ dates on volcanic ash from earliest Eocene marine deposits in Denmark and the North Sea Basin, Swisher and Knox [1991] estimate an age of $55 \mathrm{Ma}$ for the nannofossil NP9/NP10 boundary [see also Berggren et al., 1992]. This level, which approximates the position of the Paleocene/Eocene boundary occurs about 2/3 down in chron C24r (= C24r(0.66)) according to Berggren et al. [1985a, b].

7. The Cretaceous/Paleogene (Maastrichtian to Danian) boundary lies $3 / 10$ down in chron $\mathrm{C} 29 \mathrm{r}$ (= $229 \mathrm{r}(0.3)$ ) according to an average of 5 magnetostratigraphic sections [Preisinger et al., 1986]. Harland et al. [1990] obtained a chronogram estimate of $66 \mathrm{Ma}$ for the Cretaceous/Paleogene boundary (based on 20 dates listed for the Maastrichtian and 15 dates for the Danian), essentially the same value suggested by Obradovich $e t$ al. [1986] based on work on a magnetostratigraphic section in Red Desert Valley, Alberta. The $66 \mathrm{Ma}$ age estimate which we adopt is also supported by laser fusion ${ }^{40} \mathrm{Ar} /{ }^{39} \mathrm{Ar}$ dates on single crystals of sanidine extracted from the iridium-bearing lower Z Coal in Montana (C. Swisher and L. Dingus, written communication, 1990; see Berggren et al. [1992] for discussion of apparently conflicting data reported by lzett et al. [1991]).

8. In Umbria, the Maastrichtian/Campanian boundary is placed in the late part of Chronozone C33n (=C33n(0.15)) [Alvarez et al., 1977; Harland et al., 1990]. For a biostratigraphically correlative level in the Western Interior of North America, Obradovich and Cobban [1975] obtained constraining K-Ar dates on bentonites of 74 to $75 \mathrm{Ma}$ (corrected to new decay constants), which suggest an age of about $74.5 \mathrm{Ma}$ for the boundary (see Berggren et al. [1985a, pp. 194-195] for discussion of correlations). Information that supports this age estimate has been provided by Obradovich et al. [1986] who report an ${ }^{40} \mathrm{Ar} /{ }^{39} \mathrm{Ar}$ date of $73.4 \mathrm{Ma}$ for a bentonite near the top of a normal polarity magnetozone identified as Chron C33n in the San Juan Basin, New Mexico, and by J.D. Obradovich (written communication, 1990) who obtained a date of $75.2 \pm$ $0.5 \mathrm{Ma}$ on a bentonite in southwestern Arkansas from the lower part of the Globotruncana calcarata zone (the base of this biozone occurs about $1 / 3$ down in Chron $\mathrm{C} 33 \mathrm{n}$ in Umbria and is hence approximately $0.5-1$ m.y. older than the Maastrichtian/Campanian boundary which is placed at the $G$.

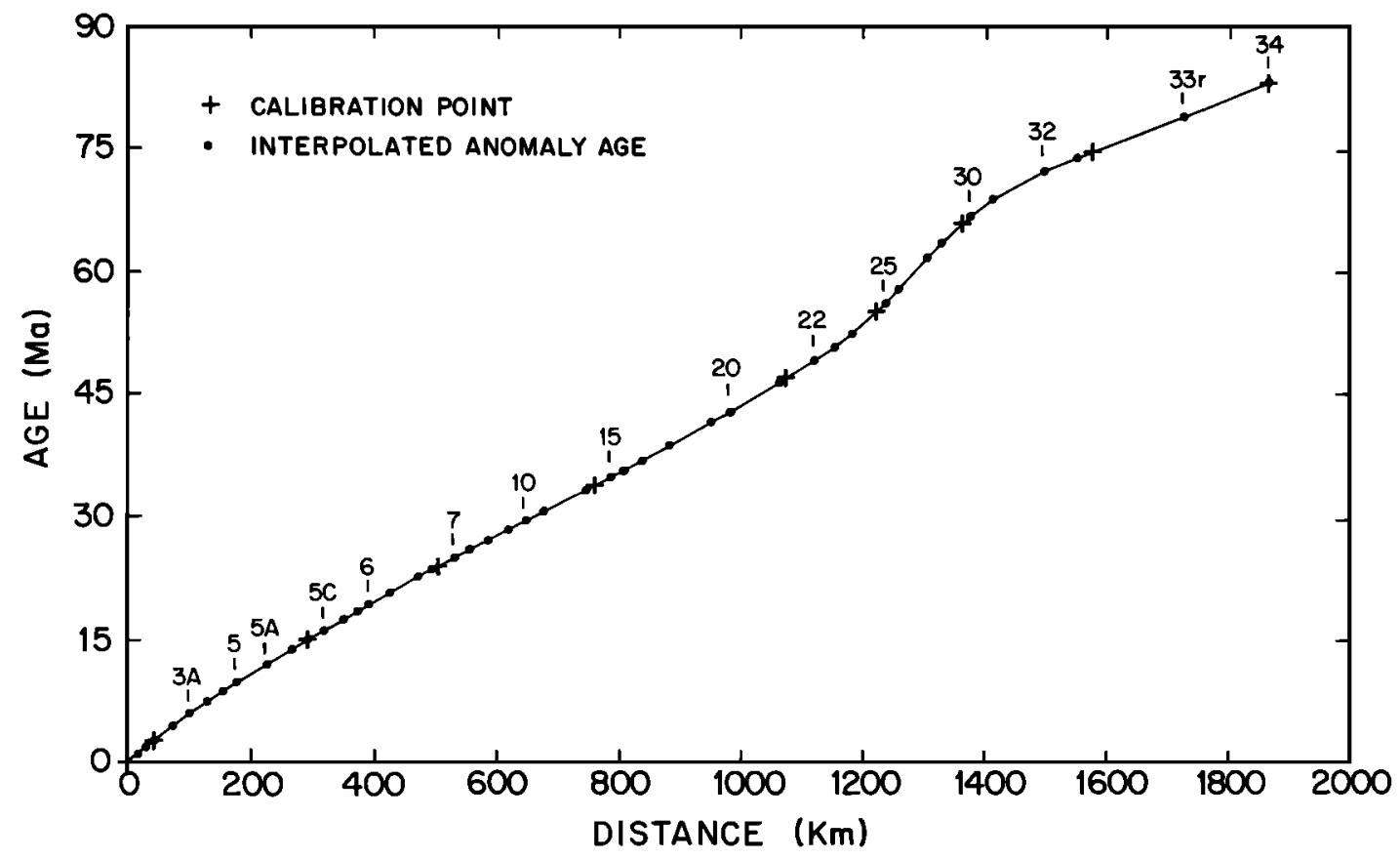

Fig. 27. Ages of magnetic anomalies (crosses) as determined by fitting a cubic spline approximation function to the calibration points (inverted triangles). 
calcarata/G. tricarinata zonal boundary [Alvarez et al., 1977]).

9. Arthur and Fischer [1977] show the Campanian/Santonian boundary at a level several meters below the top of the Gubbio Long Normal Zone, the young end of chron C34n (= C34n(0.0)). On the basis of biostratigraphically controlled ${ }^{40} \mathrm{Ar} /{ }^{39} \mathrm{Ar}$ dates on a bentonite from the Westem Interior of North America, Obradovich et al. [1986] confirm an age of about $84 \mathrm{Ma}$ for the Campanian/Santonian boundary that had been suggested by Obradovich and Cobban [1975] (corrected for new decay constants). We estimate an age of $83 \mathrm{Ma}$ for the stratigraphically younger $\mathrm{C} 34 \mathrm{n}(0.0)$ level.

\section{Determination of a New Time Scale}

A natural cubic spline function was fit to the nine calibration age-distance data plus the origin to interpolate the ages of anomalies. The calibration points and the anomaly ages are shown in a distance versus age plot in Figure 27. The new time scale (CK92; Table 6) is presented in Figure 28, u th geological correlations to anomalies at the stage level, adjusted to the new derived ages, based on BKFV85.

In Figure 29 we show an expanded version of the time scale, with names for all of the polarity chrons and subchrons. The occurrences as presently known of cryptochrons (those tiny wiggles modeled as events less than 30 ky duration, Table 7) are indicated by short horizontal lines to the right of the reversal pattern, reflecting the uncertainty in their interpretation and the nonuniformity of coverage.

In Tables 6 and 7 we give the ages of the normal polarity intervals to a resolution of $1 \mathrm{kyr}$. This is necessary because several of the tiny wiggles convert to cryptochrons that are less than $10 \mathrm{kyr}$ in duration and consequently might be lost if the ages of the bounding polarity reversals were rounded off to the nearest $10 \mathrm{ky}$. Between Tables 6 and 7, we recognize a total of 92 normal polarity chrons and subchrons (and of course a like number of reversed polarity intervals) and 54 cryptochrons over the past $83 \mathrm{~m} . \mathrm{y}$.

\section{Comparison to Previous Time Scales}

A comparison of our new time scale to some previous geomagnetic polarity time scales is shown in Figure 30. Differences can be expected as a result of the variety of calibration data and methodologies that have been used to construct the time scales, as well as changes made to the relative spacing of the polarity intervals.

Within the Neogene (to chron $\mathrm{C} 6 \mathrm{Cn}$ ), there are two key differences between our time scale and previous versions. First, since we used the astrochronologic calibration of $2.60 \mathrm{Ma}$ for the Matuyama/Gauss boundary that is about $5 \%$ older than the chronogram estimate of $2.48 \mathrm{Ma}$ based on conventional $\mathrm{K} / \mathrm{Ar}$ radiometric dates [Mankinen and Dalrymple, 1979], our time scale gives proportionately older ages for other geomagnetic reversal boundaries in the younger part of the time scale. There is already excellent agreement in the few available direct comparisons between astrochronologic and high precision radioisotopic age determinations, as outlined above in the description of calibration points, and we expect that further refinements in the chronology of Plio-Pleistocene and older reversals will be soon emerge with the increasing application of these high resolution dating methods.

The second key difference in the Neogene is the age of anomaly 5 (= chron $\mathrm{C} 5 \mathrm{n}$ ): our time scale gives predicted age limits (9.592 to $10.834 \mathrm{Ma}$ ) that are about 0.5 to $1.0 \mathrm{~m} . \mathrm{y}$. older than in virtually all previous time scales (e.g., 8.92 to 10.42 $\mathrm{Ma}$ in BKFV85, GTS89; 8.35 to $9.90 \mathrm{Ma}$ in LKC77). We did not use chron C5n as a calibration point. Moreover, more widely bracketing age constraints are not that different, for example, our calibration of $\operatorname{C5Bn}(0.0)$ at $14.80 \mathrm{Ma}$ is very
GEOMAGNETIC POLARITY TIME SCALE LATE CRETACEOUS TO RECENT

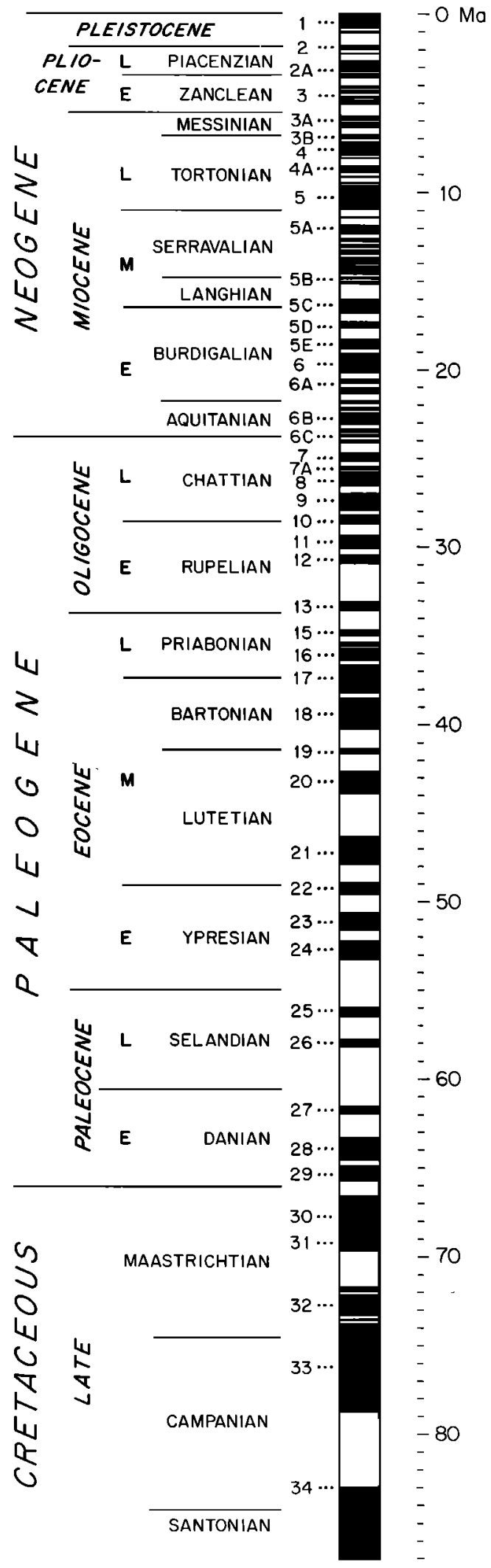

Fig. 28. New geomagnetic polarity time scale for the Late Cretaceous and Cenozoic. Correlation of geologic stages with polarity reversal pattem is taken from BKFV85. Polarity events shorter than $30 \mathrm{kyr}$ duration have been omitted from the reversal pattern. 
similar to the interpolated age of $14.87 \mathrm{Ma}$ in BKFV85 whereas the revised age we use for the Gauss/Matuyama calibration point accounts for a only a small part of the shift of chron C5n to an older age in our time scale (i.e., C5n would be $0.14 \mathrm{~m} . y$. younger if $2.48 \mathrm{Ma}$ was used instead of $2.60 \mathrm{Ma}$ for C2An (0.0)). Therefore, the different age we derive for C5n primarily results from changes in the relative spacing of the anomalies, a stretching between anomalies $4 \mathrm{~A}$ and 5 and $a$ relative contraction between anomalies 5 and $5 \mathrm{~A}$. Our predicted age range for chron $\mathrm{C} 5 \mathrm{n}$ agrees well with the most recent estimates based on radioisotopic dating of Icelandic lavas by $M c D o u g a l l$ et al. [1984], who give ages of $9.64 \mathrm{Ma}$ and $11.07 \mathrm{Ma}$ for the boundaries of a normal polarity magnetozone they correlate with chron C5n. Age estimates for the base of chron C5n obtained previously from the Icelandic sections (10.30 Ma by McDougall et al. [1984] and 10.47 Ma by Saemundsson et al. [1980]), as well as estimates from East African magnetostratigraphic sections (10.0 Ma by Tauxe et al. [1985] and 10.3 Ma by Deino et al. [1990]), are less compatible with our interpolated age for chron C5n.

In the Paleogene (nominally chron C6C to chron C29), where we have completely revised the relative spacings of polarity intervals, there are many detailed differences between CK92 and previous time scales. For example, even though the age for $\mathrm{C} 6 \mathrm{Cr}(0.0)$ is very similar (within -0.3 m.y.) in CK92 compared to GTS89, BKFV85, LA81 and LKC77, the duration of chron $\mathrm{C} 6 \mathrm{Cr}$ is about a factor of two shorter in CK92 compared to these other time scales derived from HDHPL68 $(\sim 0.7$ m.y. versus $\sim 1.4$ m.y.). A major cause of variation in the Paleogene, however, stems from the differences in the ages used for the calibration of the various time scales. Age estimates of the limits of the Paleogene (the Oligocene/Miocene at $23.8 \mathrm{Ma}$ and Cretaceous/Paleogene at $66 \mathrm{Ma}$ in this paper) may not have changed by more than $\sim 1 \mathrm{~m}$.y. in the decade since LA81, but the ages estimated for subdivisions of the Paleogene have evolved considerably (e.g., the Eocene/Oligocene boundary: $38 \mathrm{Ma}$ in

TABLE 6. Normal Polarity Intervals

TABLE 6. (continued)

\begin{tabular}{|c|c|c|c|c|c|c|c|}
\hline \multicolumn{3}{|c|}{$\begin{array}{l}\text { Normal Polarity } \\
\text { Interval, Ma }\end{array}$} & \multirow{2}{*}{$\begin{array}{r}\begin{array}{r}\text { Polarity } \\
\text { Chron }\end{array} \\
\text { C1n }\end{array}$} & \multicolumn{3}{|c|}{$\begin{array}{l}\text { Normal Polarity } \\
\text { Interval, } \mathrm{Ma}\end{array}$} & \multirow{2}{*}{$\begin{array}{r}\begin{array}{r}\text { Polarity } \\
\text { Chron }\end{array} \\
\text { C6Bn.1n }\end{array}$} \\
\hline 0.000 & - & 0.780 & & 22.599 & - & 22.760 & \\
\hline 0.984 & - & 1.049 & C1r.1n & 22.814 & - & 23.076 & C6Bn.2n \\
\hline 1.757 & - & 1.983 & C2n & 23.357 & - & 23.537 & C6Cn.1n \\
\hline 2.197 & - & 2.229 & C2r.In & 23.678 & - & 23.800 & C6Cn.2n \\
\hline 2.600 & - & 3.054 & C2An.1n & 23.997 & - & 24.115 & C6Cn.3n \\
\hline 3.127 & - & 3.221 & C2An.2n & 24.722 & - & 24.772 & C7n.1n \\
\hline 3.325 & - & 3.553 & C2An.3n & 24.826 & - & 25.171 & C7n.2n \\
\hline 4.033 & - & 4.134 & C3n.1n & 25.482 & - & 25.633 & C7An \\
\hline 4.265 & - & $\begin{array}{l}4.104 \\
4.432\end{array}$ & C3n.2n & 25.807 & - & 25.934 & C8n.1n \\
\hline 4.611 & - & 4.694 & C3n.3n & 25.974 & - & 26.533 & C8n.2n \\
\hline 4.812 & - & 5.046 & C3n.4n & 27.004 & - & 27.946 & C9n \\
\hline 5.705 & - & 5.946 & C3An.1n & 28.255 & - & 28.484 & C10n.1n \\
\hline 6.078 & - & 6.376 & C3An.2n & 28.550 & - & 28.716 & C10n.2n \\
\hline 6.744 & - & 6.901 & C3Bn & 29.373 & - & 29.633 & C11n.1n \\
\hline 6.946 & - & 6.981 & C3Br.1n & 29.737 & - & 30.071 & C11n.2n \\
\hline $\begin{array}{l}0.840 \\
7.153\end{array}$ & - & 7.187 & C3Br.2n & 30.452 & - & 30.915 & $\mathrm{C12n}$ \\
\hline 7.245 & - & 7.376 & C4n.1n & 33.050 & - & 33.543 & C13n \\
\hline 7.464 & - & 7.892 & C4n.2n & 34.669 & - & 34.959 & C15n \\
\hline 8.047 & - & 8.079 & C4r.1n & 35.368 & - & 35.554 & C16n.1n \\
\hline 8.529 & - & 8.861 & C4An & 35.716 & - & 36.383 & C16n.2n \\
\hline 9.069 & - & 9.149 & C4Ar.1n & 36.665 & - & 37.534 & C17n.1n \\
\hline $\mathbf{9 . 4 2 8}$ & - & 9.491 & C4Ar.2n & 37.667 & - & 37.915 & C17n.2n \\
\hline 9.592 & - & 9.735 & C5n.1n & 37.988 & - & 38.183 & C17n.3n \\
\hline 9.777 & - & 10.834 & C5n.2n & 38.500 & - & 39.639 & C18n.1n \\
\hline 10.940 & - & 10.989 & C5r.1n & 39.718 & - & 40.221 & C18n.2n \\
\hline 11.378 & - & 11.434 & C5r.2n & 41.353 & - & 41.617 & C19n \\
\hline 11.852 & - & 12.000 & C5An.1n & 42.629 & - & 43.868 & C20n \\
\hline 12.108 & - & 12.333 & C5An.2n & 46.284 & - & $\mathbf{4 7 . 8 6 1}$ & C21n \\
\hline 12.618 & - & 12.649 & C5Ar.1n & 48.947 & - & 49.603 & C22n \\
\hline 12.718 & - & 12.764 & C5Ar.2n & 50.646 & - & 50.812 & C23n.1n \\
\hline 12.941 & - & 13.094 & C5AAn & 50.913 & - & 51.609 & C23n.2n \\
\hline 13.263 & - & 13.476 & C5ABn & 52.238 & - & 52.544 & C24n.1n \\
\hline 13.674 & - & 14.059 & C5ACn & 52.641 & - & 52.685 & C24n.2n \\
\hline 14.164 & - & 14.608 & C5ADn & $\mathbf{5 2 . 7 9 1}$ & - & 53.250 & C24n.3n \\
\hline 14.800 & - & 14.890 & C5Bn.1n & 55.981 & - & 56.515 & C25n \\
\hline 15.038 & - & 15.162 & C5Bn.2n & 57.800 & - & 58.197 & C26n \\
\hline $\begin{array}{l}10.000 \\
16.035\end{array}$ & - & $\begin{array}{l}10.102 \\
16.318\end{array}$ & C5Cn.1n & 61.555 & - & 61.951 & C27n \\
\hline $\begin{array}{l}10.055 \\
16.352\end{array}$ & - & $\begin{array}{l}10.510 \\
16.515\end{array}$ & C5Cn.2n & 63.303 & . & 64.542 & C28n \\
\hline 16.583 & 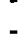 & 16.755 & C5Cn.3n & 64.911 & - & 65.732 & $\mathrm{C} 29 \mathrm{n}$ \\
\hline 17.310 & - & 17.650 & C5Dn & 66.601 & - & 68.625 & C30n \\
\hline $\begin{array}{l}1.010 \\
18.317\end{array}$ & 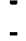 & 18.817 & C5En & 68.745 & - & 69.683 & C31n \\
\hline $\begin{array}{l}10.018 \\
19.083\end{array}$ & 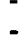 & 20.162 & C6n & 71.722 & - & 71.943 & C32n.1n \\
\hline 20.546 & - & 20.752 & C6An.1n & 72.147 & - & 73.288 & C32n.2n \\
\hline 21.021 & - & 21.343 & C6An.2n & 73.517 & - & $\mathbf{7 3 . 5 8 4}$ & C32r.1n \\
\hline 21.787 & 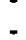 & 21.877 & C6AAn & 73.781 & - & $\mathbf{7 8 . 7 8 1}$ & C33n \\
\hline 22.166 & . & 22.263 & C6AAr.1n & $\mathbf{8 3 . 0 0 0}$ & - & (118.0) & C34n \\
\hline 22.471 & - & 22.505 & C6AAr.2n & & & & \\
\hline
\end{tabular}


LA81, 36.6 $\mathrm{Ma}$ in BKFV85, 35.4 $\mathrm{Ma}$ in GTS89, and 33.7 $\mathrm{Ma}$ in this paper; the Paleocene/Eocene boundary: $54.9 \mathrm{Ma}$ in LA81, $57.8 \mathrm{Ma}$ in BKFV85, 56.5 Ma in GTS89, and $55 \mathrm{Ma}$ in this paper).

For the broadly spaced polarity intervals in the Late Cretaceous (chrons C30n to C34n), differences are typically within -1 m.y. among the most recent time scales (BKFV85, GTS89, and CK92), but this apparent stability may be more a reflection of the sparsity of new data than of well determined age calibration levels.

TABLE 7. Cryptochrons From C1 to C13 and From C24 to C28

Interval, $\mathbf{M a}$

Cryprochron

\begin{tabular}{|c|c|c|c|}
\hline 0.493 & - & 0.504 & C1n-1 \\
\hline 1.201 & - & 1.212 & C1r.2r-1n \\
\hline 2.420 & . & 2.441 & C2r.2r-1 \\
\hline 8.463 & - & 8.479 & C4r.2r-1 \\
\hline 10.060 & - & 10.069 & C5n.2n-1 \\
\hline 10.317 & - & 10.342 & C5n.2n-2 \\
\hline 10.589 & . & 10.605 & C5n.2n-3 \\
\hline 17.860 & - & 17.888 & C5Dr-1 \\
\hline 24.469 & - & 24.480 & C6r-1 \\
\hline 25.325 & - & 25.341 & C7r-1 \\
\hline 26.328 & - & 26.339 & C8n.2n-1 \\
\hline 27.364 & - & 27.382 & $C 9 n-1$ \\
\hline 27.591 & - & 27.609 & C9n-2 \\
\hline 28.091 & - & 28.103 & C9r-1 \\
\hline 28.995 & - & 29.008 & C10r-1 \\
\hline 29.167 & - & 29.164 & C10r-2 \\
\hline 30.251 & - & 30.265 & C11r-1 \\
\hline 31.201 & - & 31.219 & $\mathrm{C} 12 \mathrm{r}-1$ \\
\hline 31.451 & - & 31.460 & C12T-2 \\
\hline 31.825 & - & 31.844 & C12r-3 \\
\hline 32.000 & - & 32.009 & $\mathrm{C} 12 \mathrm{r}-4$ \\
\hline 32.171 & - & 32.180 & $\mathrm{C} 12 \pi-5$ \\
\hline 32.432 & - & 32.451 & $C 12 \times-6$ \\
\hline 32.589 & . & 32.599 & C12r-7 \\
\hline 32.761 & - & 32.771 & C12r-8 \\
\hline 33.261 & . & 33.277 & C13n-1 \\
\hline 33.677 & - & 33.694 & C13r-1 \\
\hline 33.880 & . & 33.888 & C13r-2 \\
\hline 34.174 & - & 34.191 & C13r-3 \\
\hline 34.424 & . & 34.441 & $\mathrm{C} 13 \mathrm{r}-4$ \\
\hline 63.462 & - & 53.471 & C24r-1 \\
\hline 53.604 & - & 53.613 & C24r-2 \\
\hline 53.821 & - & 53.830 & $\mathrm{C} 24 \mathrm{r}-3$ \\
\hline 53.967 & - & 53.976 & $C 24 r-4$ \\
\hline 54.170 & - & 54.180 & C2Ar-5 \\
\hline 54.490 & . & 54.500 & $\mathrm{C} 24 \mathrm{r}-6$ \\
\hline 54.739 & - & 54.749 & C24r-7 \\
\hline 54.953 & - & 54.963 & $\mathrm{C} 24 \mathrm{r}-8$ \\
\hline 55.071 & - & $\mathbf{5 5 . 0 8 1}$ & C24r-9 \\
\hline 55.309 & - & 55.319 & C24r-10 \\
\hline 55.611 & - & 55.622 & C24r-11 \\
\hline 56.827 & - & 56.845 & C25r-1 \\
\hline 57.002 & - & $\mathbf{5 7 . 0 2 0}$ & C25r-2 \\
\hline 67.160 & - & 57.169 & $\mathrm{C} 25 \mathrm{r}-3$ \\
\hline 57.426 & - & 57.435 & $\mathrm{C} 25 \mathrm{r}-4$ \\
\hline 57.586 & . & $\mathbf{5 7 . 6 0 4}$ & C25r-5 \\
\hline 58.756 & - & 58.777 & $\mathrm{C} 26 \mathrm{r}-1$ \\
\hline 59.382 & - & 59.403 & $\mathrm{C} 26 \mathrm{r}-2$ \\
\hline 59.612 & - & 59.622 & $\mathrm{C} 26 \mathrm{r}-3$ \\
\hline 59.821 & - & 59.832 & $\mathrm{C} 26 \mathrm{r}-4$ \\
\hline 60.261 & & 60.282 & $\mathrm{C} 26 \mathrm{r}-5$ \\
\hline 60.638 & - & 60.648 & C26r-6 \\
\hline 60.931 & - & 60.941 & $\mathrm{C} 26 \mathrm{r}-7$ \\
\hline 64.704 & - & 64.732 & $\mathrm{C} 2 \mathrm{Br}-1$ \\
\hline
\end{tabular}

\section{Evaluation: Seafloor SpREading Rates in OTHER OCEANS}

The new time scale indicates a broadly varying rate of seafloor spreading in the South Atlantic (Figure 31, top). The Late Cretaceous was characterized by a rather sharp decrease from the highest (full) rate of almost $70 \mathrm{~mm} / \mathrm{yr}$ at around anomalies 33 and 34 time (Campanian) to the lowest rate of less than 30 $\mathrm{mm} / \mathrm{yr}$ by around anomaly 27 time (early Paleocene). Over the Paleogene, spreading rates first increased to reach a high of about $55 \mathrm{~mm} / \mathrm{yr}$ at anomaly 15 (latest Eocene), then gradually decreased over the Oligocene and early Miocene. Spreading rates decrease more rapidly starting in the middle Miocene to the recent value of $32 \mathrm{~mm} / \mathrm{yr}$. This systematic pattern of spreading inferred for the South Atlantic, especially over the Cenozoic (anomaly 29 to ridge axis), is new and unique to the time scale derived here, all previous time scales showing a much less regular variation in spreading rate over the Cenozoic (Figure 31).

The assumption of a smooth spreading history for the South Atlantic in our method of construction, in conjunction with the calibration tiepoints chosen to convert distance into time, obviously contribute strongly to the regular character of spreading rate variations with our timescale. While this seafloor spreading history for the South Atlantic seems reasonable, less circular assessments of the geomagnetic polarity time scale derived from the South Atlantic can be made by determining the implications of the new time scale to the spreading histories of other ridge systems. In particular, the assumption of smooth South Atlantic spreading can be tested by calculating spreading rates on various other ridges using the new time scale. We expect to find fewer fluctuations in spreading rate on the other ridges with the new time scale than with previous time scales, i.e., accelerations should be minimized within the constraints of the calibration data. This first order test also gives us the opportunity to examine whether there were globally synchronous variations in spreading rate, which was one of the motivating reasons for re-examining the time scale.

In the section below, we compare spreading rate histories based on our new time scale to the recent time scales of BKFV85 and GTS89 for several different ridge systems, including the East Pacific Rise at $20^{\circ} \mathrm{S}$ back to anomaly 5A, the Chile Ridge back to anomaly $5 \mathrm{E}$, the Southeast Indian Ridge along $130^{\circ} \mathrm{E}$ back to anomaly 20, the Pacific-Antarctic Ridge south of the Menard Fracture Zone back to anomaly 15, the Central Atlantic north of the Kane Fracture Zone back to anomaly 34, and the North Pacific along $40^{\circ} \mathrm{N}$ back to anomaly 34 .

\section{Method}

As in the South Atlantic, the key to examining spreading rates on other ridges is in the determination of an accurate synopsis of the magnetic anomaly pattern that takes into account localized occurrences of ridge jumps, propagating rifts and varying amounts of asymmetrical spreading. Therefore, whenever possible, we have developed spreading histories based on (1) an averaging of conjugate profiles or (2) the calculation of closely spaced finite rotation poles. In the two cases where we calculate finite rotation poles (the Southeast Indian Ridge and the East Pacific Rise), we have used published rotation poles at intervals of 5 to $10 \mathrm{~m}$.y. and simply calculated finite rotation angles that best fit the anomalies in a narrow corridor. With this method we can account for spreading asymmetries without having to analyze an entire ridge system, which is beyond the scope of this project.

\section{Errors}

Errors in spreading rate are a function of both errors in the time scale and errors in the estimates of the widths of the anomalies. We assume that the errors in the time scale (i.e., in 

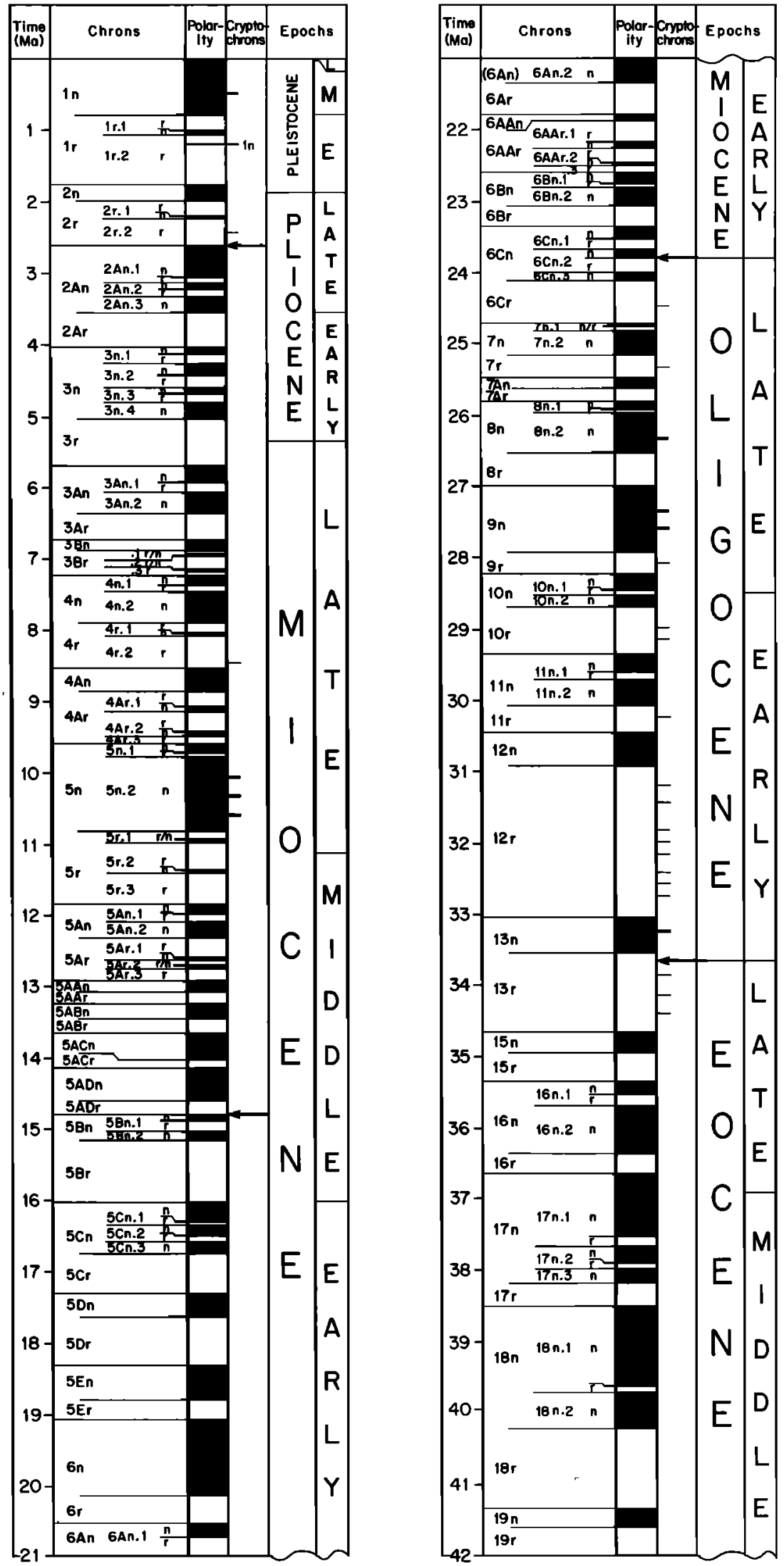

Fig. 29. Expanded version of new geomagnetic polarity timescale showing detailed nomenclature of chrons and polarity events. Naming convention is modified from Harland et al. [1990], as explained in text. Tiny wiggles correspond to polarity events of less than $30 \mathrm{kyr}$ duration and are shown by short horizontal lines to the right of the polarity column. 

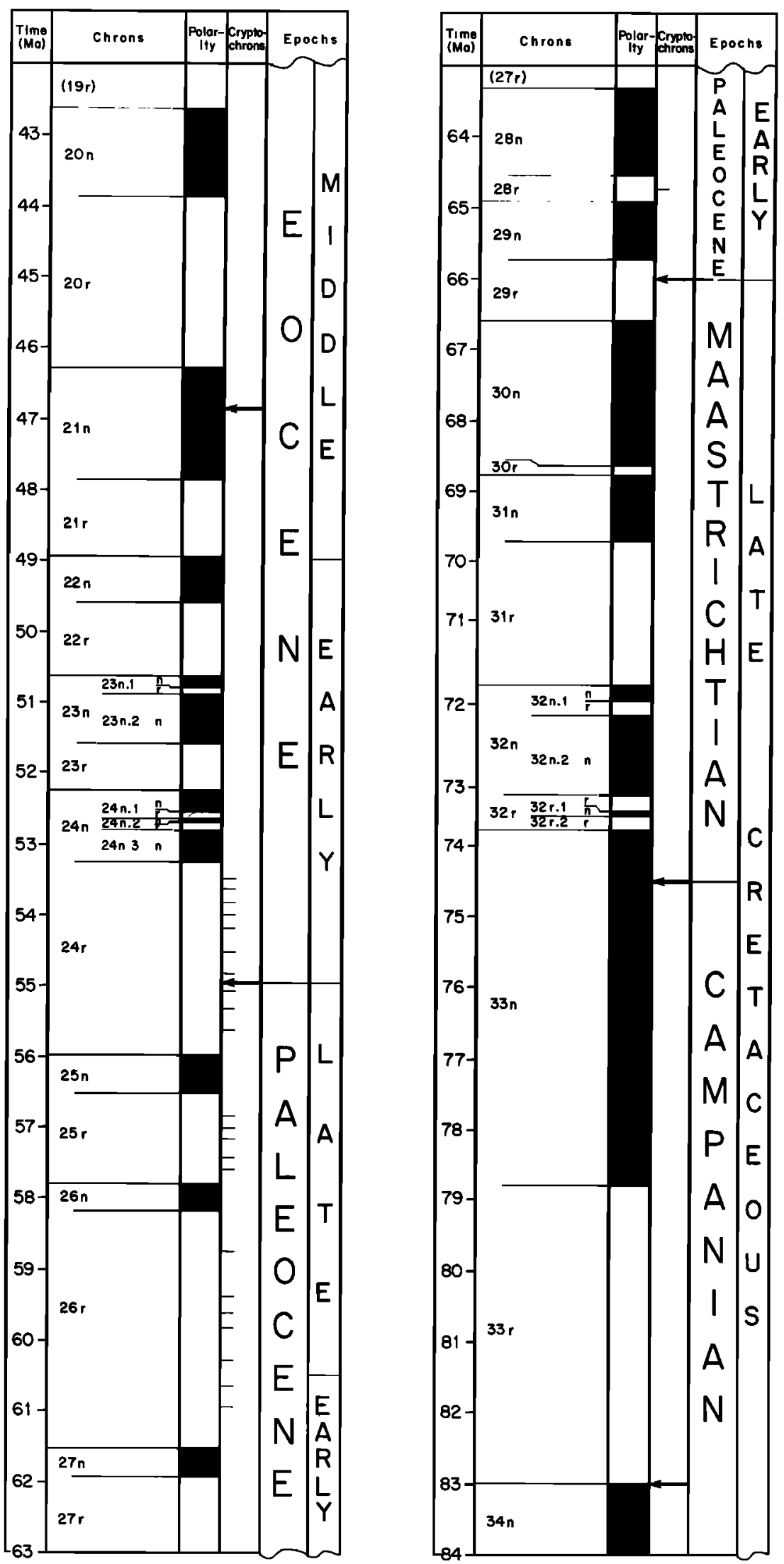

Fig. 29. (continued) 


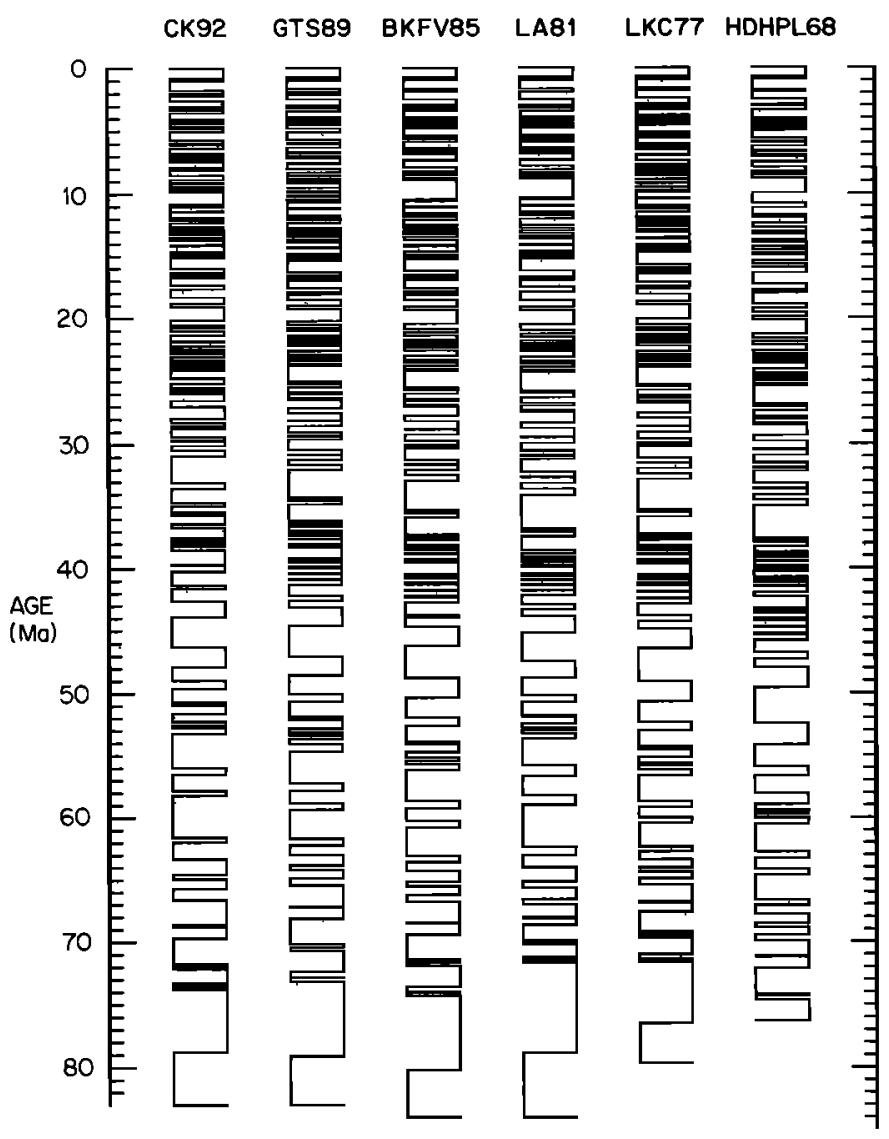

Fig. 30. Comparison of new time scale, left column (CK92), to several other time scales.

the width of the polarity intervals) are of the same magnitude as the errors in the widths of the anomalies in the South Atlantic (Table 4); these are typically about $7 \%$ but vary between $1 \%$ and $17 \%$ depending on the anomaly. In Figure 31 (top) we show the effect of these errors, at the $95 \%$ confidence level, on the anomaly-by-anomaly estimate of spreading rates in the South Atlantic. The fact that the shape of the South Atlantic spreading rate profile is smooth is largely a function of the spline, whereas the particular shape of the curve is dependent on the particular set of calibration points used.

The errors in spreading rate on other ridge systems can only be meaningfully estimated for those ridges where we have calculated finite rotation angles. In general, a finite rotation angle can be estimated with an accuracy of $0.05^{\circ}$ to $0.1^{\circ}$ depending on the quality of the reconstruction. This error translates into a wide range of absolute errors in spreading rates depending on the width of the anomaly interval and the spreading rate; for a fast spreading ridge the error is relatively small, for a slow spreading ridge the error can be quite large. For both the East Pacific Rise and the Southeast Indian Ridge we have calculated the error in spreading rate assuming an error of $0.05^{\circ}$ in the rotation angle. These error bars are displayed on Figures 33 and 36, respectively. For the East Pacific Rise the errors are roughly $4 \%$ for a $1 \mathrm{~m} . y$. interval and $2 \%$ for a $2 \mathrm{~m} . \mathrm{y}$. interval, while for the Southeast Indian Ridge the error is more typically $8 \%$ for a 1 m.y. interval and $4 \%$ for a 2 m.y. interval.

The total error in any given spreading rate is a combination of the error due to the estimate of the local anomaly widths and the error due to the global estimate of the polarity durations. If we assume the two errors are independent then we can estimate a total error by taking the square root of the sum of the squares. For the East Pacific Rise, the average error is roughly $8 \%$, while for the Southeast Indian Ridge it is closer to $9 \%$.

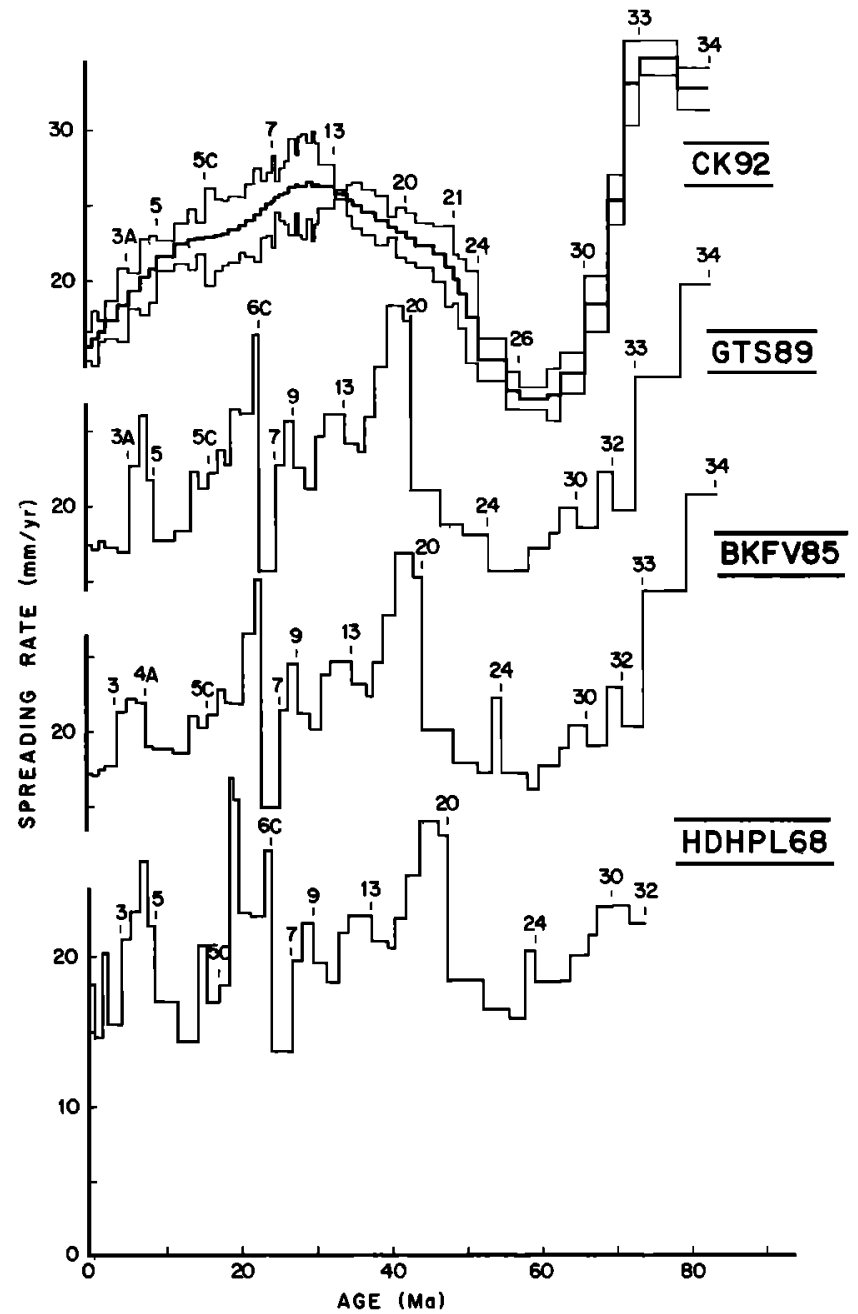

Fig. 31. Half spreading rates in the South Atlantic based on the new time scale (top), compared to three other time scales, including HDHPL68 (bottom), as evaluated over roughly $2 \mathrm{Ma}$ increments. The distances between anomalies are taken from the composite synthetic flow line data shown in Figure 5. The smooth, broad variations in spreading rate based on CK92 are a result of applying a spline function to the set of nine calibration points. The light lines drawn above and below the CK92 profile represent the $95 \%$ confidence limits as discussed in the text.

\section{East Pacific Rise at $20 \%$}

A synthetic spreading flow line was constructed for the East Pacific Rise back to anomaly 5A based on magnetic anomaly data between $15^{\circ} \mathrm{S}$ and $25^{\circ} \mathrm{S}$. The magnetic anomaly picks shown in Figure 32 were digitized and then finite rotation angles were calculated that would bring the conjugate picks back together. The finite rotation pole of Minster and Jordan [1978] for the Pacific-Nazca plate for anomaly 3 to present was assumed and only the angle of rotation was calculated. The resulting finite rotation parameters are given in Table 8.

Using the finite rotation parameters for anomalies $\mathrm{J}$ to $5 \mathrm{~A}$, spreading rates were calculated based on the CK92, GTS89 and BKFV85 time scales as shown in Figure 33. This figure shows that, using GTS89 and BKFV85, there was an interval of faster spreading rate in the late Neogene of a similar magnitude and timing as these time scales predicted for the South Atlantic (Figure 31). With CK92 this interval of faster spreading is removed, and, if anything, there has been a gradual decrease in spreading rate since anomaly $5 \mathrm{~A}$. 


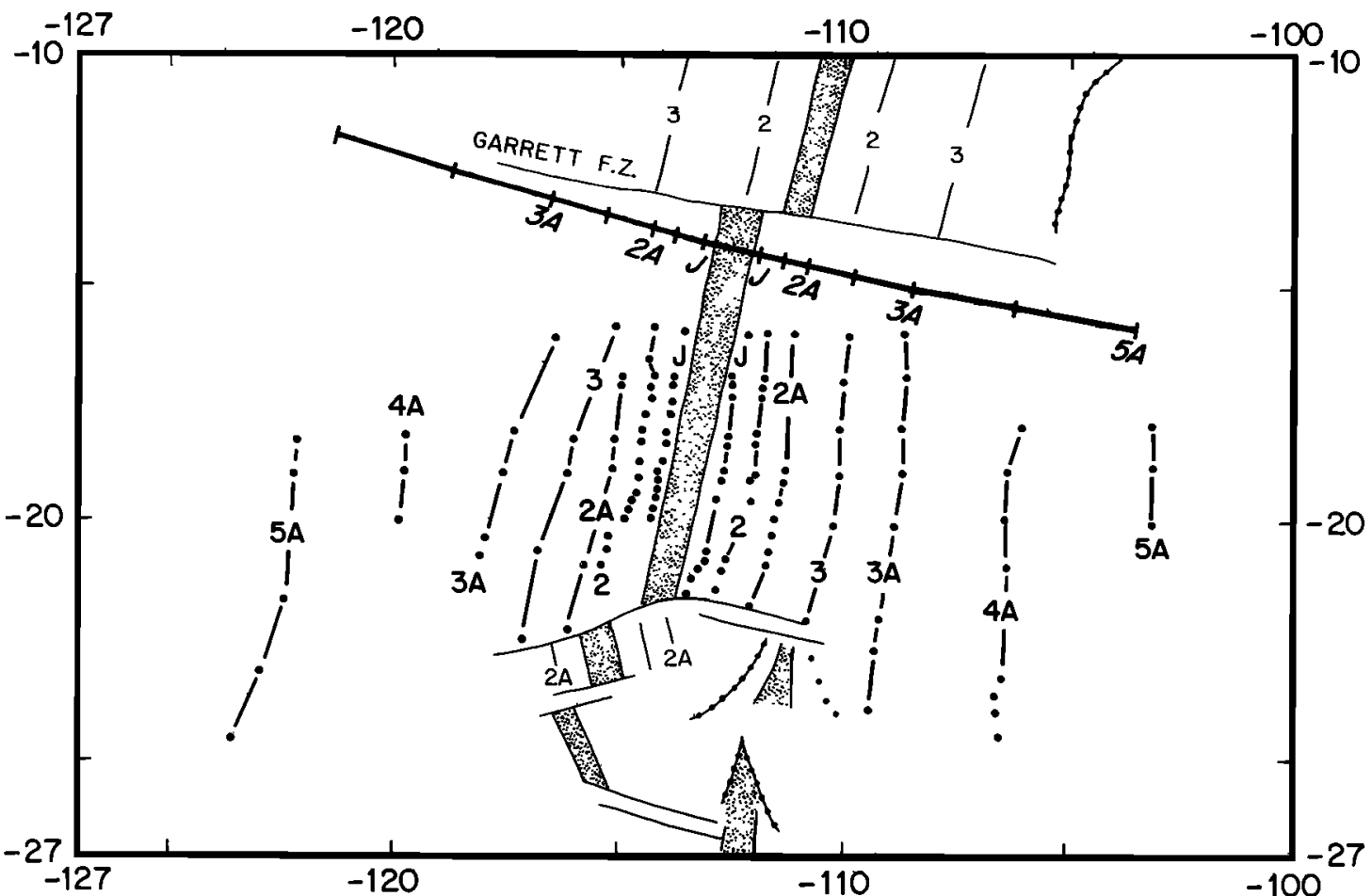

Fig. 32. Location of magnetic anomaly picks on the East Pacific Rise that were used to constrain a set of finite rotation poles for the last $12 \mathrm{Ma}$. The resulting synthetic flowline spreading history is shown by the heavy line south of the Garrett Fracture Zone.

TABLE 8. Finite Rotation Parameters: East Pacific Rise

\begin{tabular}{cccc}
\hline & & & \\
Latitude & Longitude & Angle & Anomaly \\
& & & \\
\hline 56.64 & -87.88 & 18.5 & 6A \\
56.64 & -87.88 & 13.0 & 4 A \\
56.64 & -87.88 & 8.40 & $\mathbf{3 A}$ \\
56.64 & -87.88 & 5.70 & 3 \\
56.64 & -87.88 & $\mathbf{3 . 6 0}$ & $\mathbf{2 A}$ \\
56.64 & -87.88 & 2.48 & 2 \\
56.64 & -87.88 & 1.32 & J \\
\hline
\end{tabular}

\section{Chile Ridge}

Magnetic anomaly spacings for the Chile Ridge were constructed based on a long aeromagnetic profile collected in 1990 that crossed both flanks of the ridge (see Figure 8 for location) [Tebbens et al., 1990]. The distances between anomalies on the two conjugate profiles were averaged to produce a composite profile of magnetic anomaly spacings from anomaly $5 \mathrm{E}$ to the ridge axis.

Spreading rates for the Chile Ridge from anomaly $5 \mathrm{E}$ to the ridge axis were calculated for CK92, GTS89 and BKFV85 (Figure 34). An interval of faster spreading between anomalies 5 and $3 \mathrm{~A}$ ( 3 in BKFV85) is observed based on all three time scales. However the magnitude of the increase is about one-half to onethird the amplitude using the CK92 time scale than using the other two time scales.

\section{Southeast Indian Ridge}

The Southeast Indian Ridge is characterized by large asymmetries in spreading rates. In order to calculate a representative magnetic anomaly pattern for this ridge we

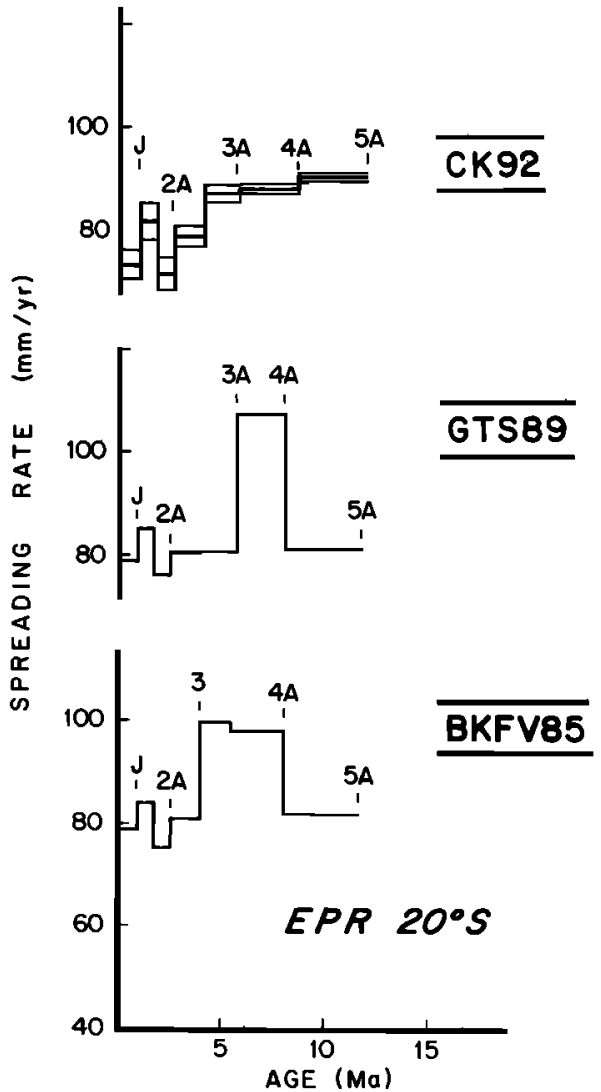

Fig. 33. Half spreading rates on the East Pacific Rise based on three different time scales. Distances between anomalies were constrained by the synthetic flow line spreading history shown in Figure 32 . Note that the interval of faster spreading between anomalies $4 \mathrm{~A}$ and 3 based on BKFV85 and GTS89 is not observed based on CK92 (top). The light lines drawn above and below the CK92 curve are an estimate of the error limits as discussed in the text. 


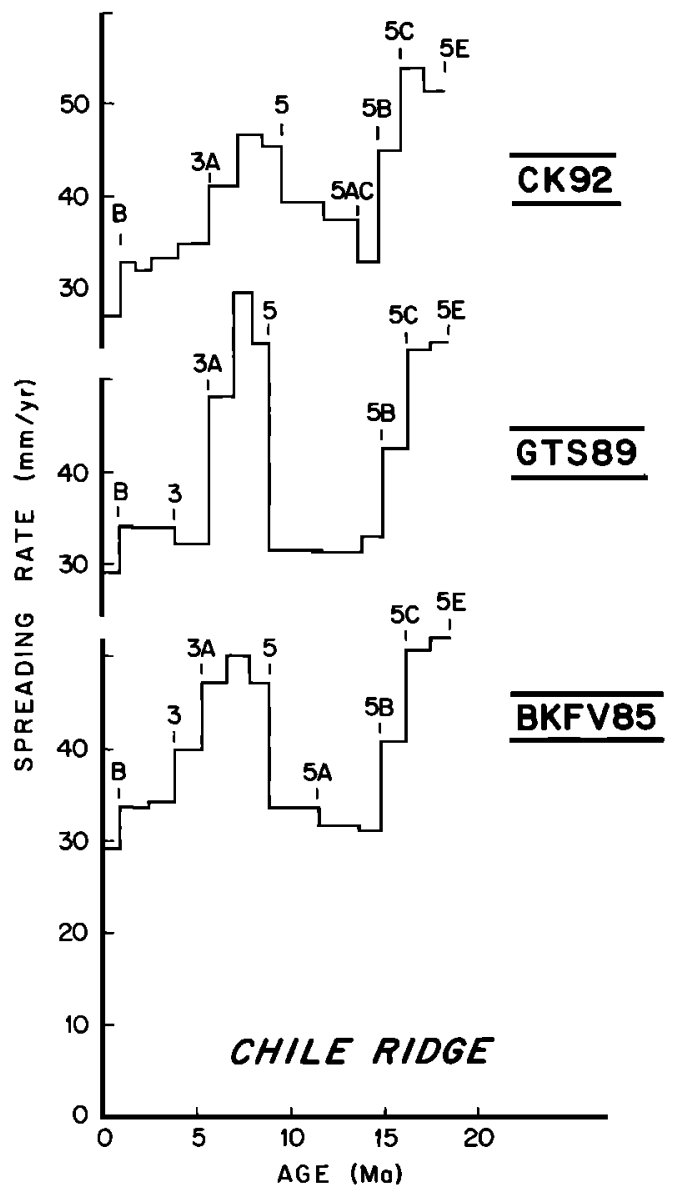

Fig. 34. Half spreading rates on the Chile Ridge based on three different time scales. The spacing between anomalies was constrained by the aeromagnetic profiles, and their extension, shown in Figure 9. Note that the amplitude of the pulse of faster spreading between anomalies 5 and 3 based on BKFV85 and GTS89 is greally reduced relative to CK92.

analyzed shipboard magnetics data from just east of the Discordant Zone between $125^{\circ} \mathrm{E}$ and $135^{\circ} \mathrm{E}$ (Figure 35). As on the East Pacific Rise, we digitized the location of anomaly picks in a narrow corridor and calculated finite rotation angles for closely spaced intervals. The rotation poles of Weissel et al. [1977] were used to provide the latitude and longitude of the rotation poles; we simply calculated new angles of rotation to bring the conjugate anomaly picks back together. Based on these finite rotation parameters (Table 9), we synthesized a magnetic anomaly pattern along a synthetic flowline at $139^{\circ} \mathrm{E}$.

Spreading rates along the synthesized flow line were calculated based on the CK92, GTS89 and BKFV85 time scales (Figure 36). The pattern of spreading rate variations derived with the CK92 time scale is considerably simpler than with the other two time scales. We note that a single step-wise increase in rate of roughly $25 \%$ occurred in the late Neogene at anomaly 3A time based on CK92. According to GTS89 there was a larger increase (roughly 35\%) at anomaly 5, while BKFV85 displays an increase at anomaly 5 and $3 \mathrm{~A}$ and an abrupt decrease at anomaly 3. Both GTS 89 and BKFV85 cause the large swings in apparent spreading rate between anomalies 7 and $6 \mathrm{~A}$ that were also seen in the South Atlantic. With the CK92 time scale these wide swings have been replaced by a much more gradual decrease in spreading rates between anomalies 7 and $6 \mathrm{C}$. Between anomalies 7 and 12 the CK92 based spreading rates are also smoother. Prior to anomaly 12 time there were wide swings based on all three time scales.

\section{Pacific-Antarctic Ridge}

It is difficult to derive a reliable set of anomaly spacings for the Pacific-Antarctic Ridge. The biggest problem is the sparsity of data on the east flank of the ridge and the lack of ship tracks that followed along flow lines of spreading. We have selected an individual track, the Southtow cruise of the $R V$ Washington, that followed a flowline on the west flank of the ridge south of the Menard Fracture Zone (Figure 37). This cruise crossed the ridge only out as far as anomaly 3 on the east flank. We calculated anomaly spacings based on an average of the two flanks out to anomaly 3 , and using just the west flank data between anomaly 3 and 15 .

Spreading rate variations based on the Southtow line were calculated for the three time scales and (Figure 38). The history of spreading in the late Neogene was similar to that on the Southeast Indian Ridge: based on CK92, the principal variation is an increase in spreading rate around anomaly $3 \mathrm{~A}$; based on GTS89, the principal change was around anomaly 5; based on BKFV85, the peak in spreading was between anomaly $3 \mathrm{~A}$ and 3. The wide swings in spreading rate which apparently occurred between anomalies $5 \mathrm{D}$ and 12 illustrate the problem of trying to interpret spreading rate variations on a single profile from one flank of a ridge where it is difficult to distinguish variations that are caused by minor discontinuities in spreading on this particular flowline from those that are characteristic of the entire ridge system.

\section{Central Atlantic}

A profile collected on leg 93 of the RV Atlantis II crossed the Central Atlantic between the Kane and Atlantis fracture zones from anomaly 34 on the east flank to anomaly 34 on the west flank (Figure 39) following a flow line. We averaged the spacings between anomalies on the two ridge flanks in order to derive a reliable representation of the magnetic anomaly spacings.

Spreading rates for the Central Atlantic (Figure 40) show large fluctuations between anomalies $4 A$ and $3 A$ with GTS89, between anomalies 6 and 8 and between anomalies 18 and 20 with both GTS89 and BKFV85. These large fluctuations are diminished using CK92 (Figure 40). The general pattern of a period of slow spreading in the latest Cretaceous followed by faster spreading in the Paleocene and into the early Eocene is observed based on all three time scales.

\section{North Pacific}

We represented the magnetic anomaly pattern in the North Pacific by constructing a composite profile near $40^{\circ} \mathrm{N}$. This composite profile consisted of (1) two Surveyor-Seamap profiles across the Juan de Fuca Ridge and out to anomaly 5E (profiles IDOE16 and IDOE17 in Figure 14), (2) the averaged sections we used for constructing the detailed time scale spacings between anomalies $5 E$ and 20, (3) a profile from Pioneer 7103 collected just north of the Murray Fracture Zone between anomalies 20 and 28 (profile P7103-2 in Figure 14), and 4) a profile from Pioneer 7103 from south of the Surveyor Fracture Zone between anomalies 28 and 34 (P7103-1 in Figure 14). For times younger than anomaly 20 , this composite line corresponds to spreading on the Pacific-Vancouver section of the ridge. We have to assume that spreading was symmetrical because only one half of the spreading system exists, except for the small conjugate part on the Juan de Fuca plate.

Spreading rate variations in the North Pacific for the last 80 Ma based on the CK92, as well as the BKFV85 and GTS89 time scales, are shown in Figure 41. It is apparent that with CK92 there are actually larger swings in spreading rate than with BKFV85 and GTS89, particularly between anomalies $6 C$ and 13 , near anomalies 17 and 20, and between anomalies 32 and 33 . 


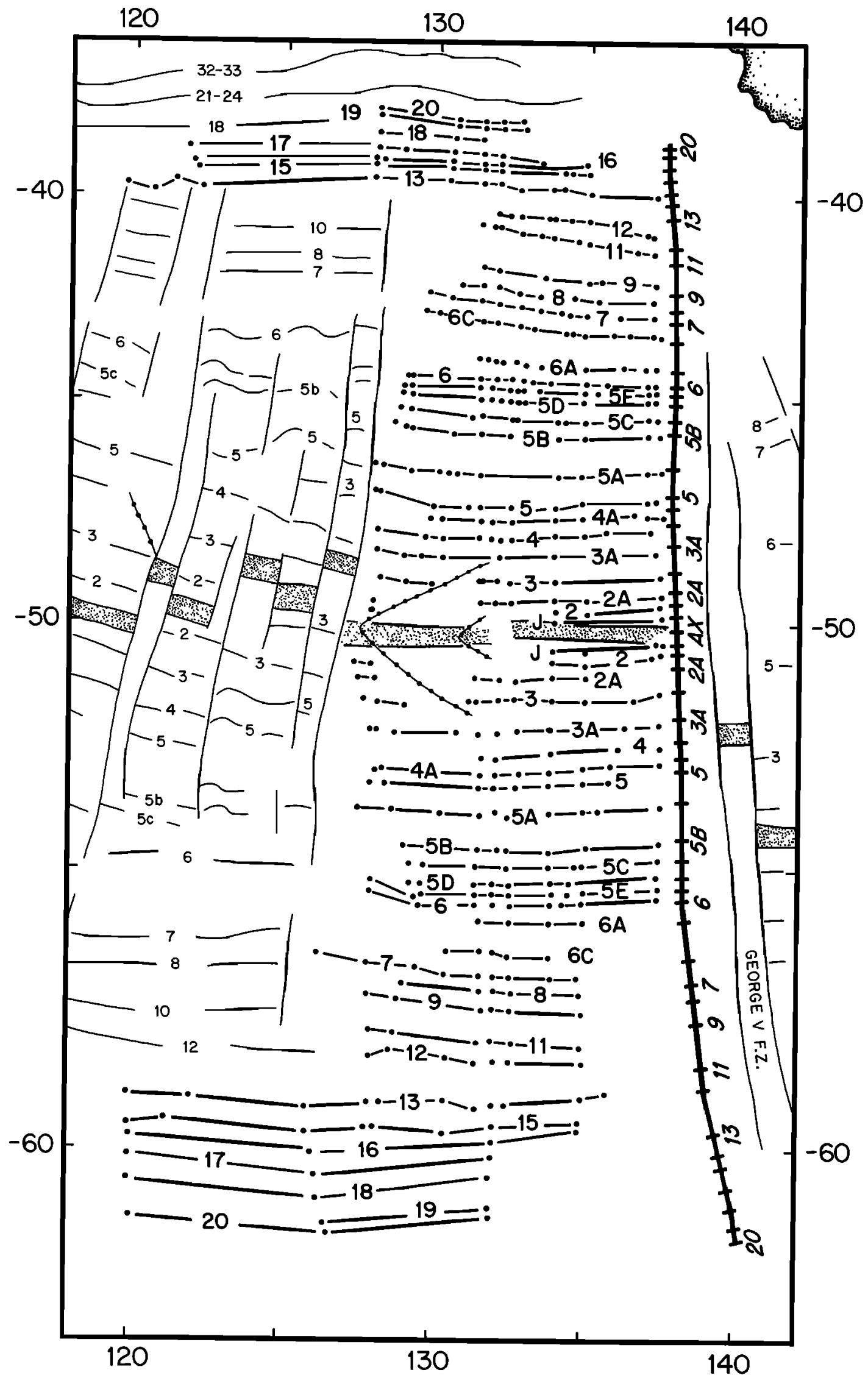

Fig. 35. Location of magnetic anomaly picks between Australia and Antarctica used to calculate a set of finite rotation poles for the last $45 \mathrm{Ma}$. The finite rotation poles were used to determine a synthetic flow line spreading history just west of the George V Fracture Zone (heavy line). 
TABLE 9. Finite Rotation Parameters: Southeast Indian Ridge

\begin{tabular}{|c|c|c|c|}
\hline Latitude & Longitude & Angle & Anomaly \\
\hline 10.3 & 34.75 & 23.7 & 20 \\
\hline 10.3 & 34.75 & 23.3 & 19 \\
\hline 10.3 & $\mathbf{3 4 . 7 5}$ & 22.6 & 18 \\
\hline 10.7 & 34.6 & 22.0 & 17 \\
\hline 11.1 & 34.6 & 21.3 & 16 \\
\hline 11.3 & 34.5 & 20.85 & 15 \\
\hline 11.9 & 34.4 & 20.1 & $\overline{\mathbf{1 3}}$ \\
\hline 12.5 & 34.4 & 18.6 & 12 \\
\hline 12.85 & 34.12 & 17.86 & $\overline{11}$ \\
\hline 13.83 & 33.52 & 16.3 & 9 \\
\hline 14.25 & 33.25 & 15.48 & 8 \\
\hline 14.167 & 33.501 & 14.80 & 7 \\
\hline 14.041 & 33.882 & $\mathbf{1 3 . 8 5}$ & $6 \mathrm{C}$ \\
\hline 13.878 & 34.369 & 12.27 & $6 A$ \\
\hline 13.8 & 34.6 & 11.50 & 6 \\
\hline 13.617 & 34.686 & 11.07 & $5 E$ \\
\hline 13.373 & 34.801 & 10.56 & 5D \\
\hline 13.005 & 34.973 & 9.81 & EC \\
\hline 12.580 & 35.172 & 9.06 & $\mathbf{B B}$ \\
\hline 11.241 & 35.793 & 7.37 & $5 \mathbf{A}$ \\
\hline 9.7 & 36.5 & 6.07 & 5 \\
\hline 9.7 & 36.5 & 5.47 & $4 \mathrm{~A}$ \\
\hline 9.7 & 36.5 & 4.74 & 4 \\
\hline 9.7 & 36.5 & 3.83 & $\mathbf{3 A}$ \\
\hline 9.7 & 36.5 & 2.63 & 3 \\
\hline 9.7 & 36.5 & 1.68 & $2 A$ \\
\hline 9.7 & 36.5 & 1.12 & 2 \\
\hline 9.7 & 36.5 & .62 & $\mathbf{J}$ \\
\hline
\end{tabular}

\section{Discussion}

We observe that for all of the ridge systems examined except the North Pacific (and perhaps the South Pacific for which the data base is poor), the spreading rate variations are considerably smoother using CK92 than using BKFV85 or GTS89. We see that the new time scale either eliminates or greatly reduces 1 ) the "pulse" of faster spreading observed between anomalies 5 and 3 (or $3 \mathrm{~A}$ depending on the time scale) in the South Atlantic, the EPR and on the Chile Ridge, (2) the sharp swings between anomalies 7 and 6 in the South Atlantic, the Southeast Indian Ridge and in the Central Atlantic, and (3) the large swings around anomaly 20 in the South Atlantic and in the Central Atlantic. We also note that between anomaly $6 \mathrm{C}$ and the ridge axis the Southeast Indian Ridge spreading rate was constant except for a step at anomaly $3 \mathrm{~A}$. These observations strongly support our initial assumption that seafloor spreading rates in the South Atlantic were smoothly varying without the sudden changes observed in the Pacific. This is a somewhat different picture of spreading in the South Atlantic than that presented by Aubry et al. [1988], who found distinct breaks in the South Atlantic pattern. We suggest that these breaks can be attributed to irregularities in the individual profiles used by Aubry et al. [1988].

It is clear that there were several large, rapid changes in apparent spreading rate in the North Pacific, in particular, the sharp drops at anomaly 20 time and at anomaly $6 \mathrm{C}$ time. We can thus identify the source of some of the "artifacts" that are present in the spacings in HDHPL68 and that have been handed down from time scale to time scale through to GTS89. Heirtzler et al. [1968] used the North Pacific to define the details of the reversal pattern and interpolated this pattern into the South Atlantic framework. In some parts of the time scale the interpolation points were quite far apart; e.g., between anomaly 5 and 7 there was only a single interpolation point at anomaly
6. Thus the sharp swings observed in all of the ridges except the North Pacific using HDHPL68 and derivative time scales like BKFV85 and GTS89 were the result of taking the North Pacific pattern and inserting the sharp drop at anomaly $6 \mathrm{C}$ into the South Atlantic pattern. The sharp swings around anomaly 20 may be due to a similar effect.

\section{TECTONIC IMPLICATTONS}

The new time scale provides an opportunity to investigate changes in plate motion on a finer scale than previously possible. We have re-examined earlier observations of global changes in spreading rate based on HDHPL68 and its derivatives with our independently derived time scale. As is apparent from the discussion in the previous section, the previous time scales gave the misleading impression that there was a globally synchronous "pulse" of faster spreading in the late Neogene, starting around anomaly 5 time and ending around anomaly $3 \mathrm{~A}$ or 3 time [e.g., Vogt, 1986]. With the new time scale we see a much simpler pattern of spreading rate changes. The Central and South Atlantic are generally seen to be slowly varying while, in contrast, more frequent abrupt changes occurred in the spreading rates of ridges in the Pacific and Indian Oceans. Although we do not see evidence for proposed global pulses in spreading rate, we can document major, regionally synchronous changes in plate motion.

A clear example of a regional plate reorganization that is better understood with the new time scale is the circum-Pacific event that occurred in the late Neogene. Cox and Engebretson [1985] and Pollitz [1986] proposed that there was a change in the absolute motion of the Pacific plate at about $5 \mathrm{Ma}$, whereas Harbert and Cox [1989] proposed that it occurred at a younger time, at about 3.5 Ma. With previous time scales it was difficult to relate the changes in spreading rate on the various ridge systems with this change in absolute plate motion. We now see that there was an increase in spreading rate on the PacificAntarctic Ridge at around anomaly $3 \mathrm{~A}$ time (Figure 42 ). The change in spreading rate on the Pacific-Antarctic Ridge corresponds to a dramatic change in the character of the geoid anomaly over the southernmost fracture zones on this ridge system as imaged in the Geosat altimeter data [Haxby et al., 1992]. Simultaneously, we see a sharp increase in spreading rate on the Southeast Indian Ridge at anomaly $3 \mathrm{~A}$ time (Figure 42) which also corresponds to a time of a $20^{\circ}$ clockwise rotation in spreading direction on the Southeast Indian Ridge [e.g., Munschy et al., 1992]. These spreading changes may correlate with the change in Pacific absolute plate motion, although, using the new time scale, we would suggest a slightly older age of $5.6 \mathrm{Ma}$.

Other circum-Pacific events that occurred at nearly the same time (anomaly 3A) include the initial rifting of the Lau Basin which was dated at $5.6 \mathrm{Ma}$ by drilling on ODP Leg 135 [ $\mathrm{Leg} 135$ Scientific Party, 1992], the rifting of Baja California [Larson, 1972], and a decrease in spreading rate on the Chile Ridge (Figure 34).

A second example of a significant plate motion reorganization that can be viewed in a different perspective with the new time scale are the circum-Pacific events around Anomaly 6C time, near the Oligocene/Miocene boundary. This time interval is associated with the breakup of the Farallon plate into the Nazca and Cocos plates [Hey, 1977; Lonsdale and Klitgord, 1978]. The old time scales predicted a slowdown in North Pacific spreading rates and erratic swings in spreading rates on virtually all of the other ridge systems. With the new time scale, we see a precipitous drop in Pacific-Vancouver (North Pacific) spreading rates (Figure 42) that correlates in time with a large change in the position of the rotation pole [Wilson, 1988] and a small, but distinct, drop in spreading rate on the Southeast Indian Ridge (Figure 42). This suggests that the 


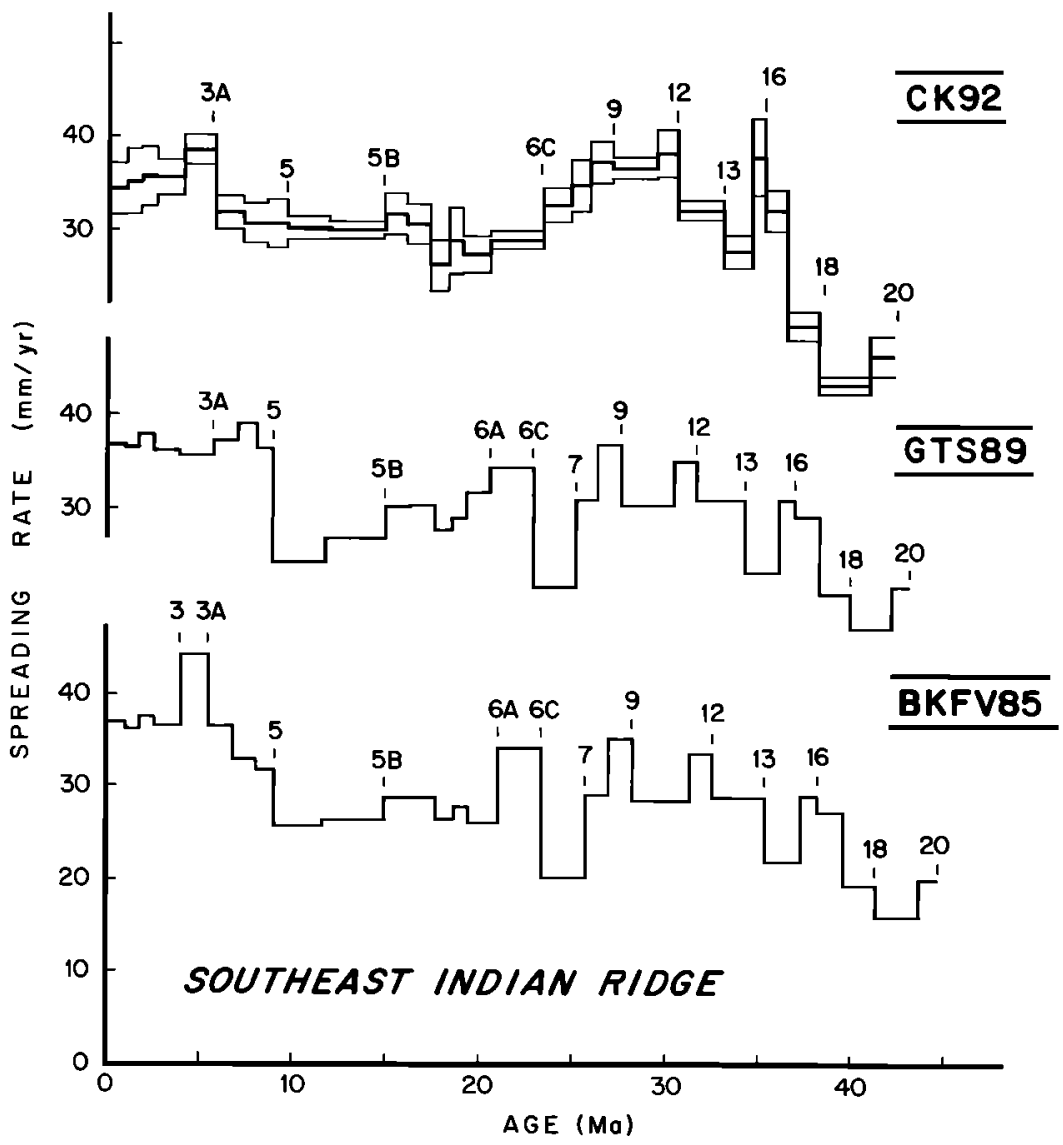

Fig. 36. Half spreading rates on the Southeast Indian Ridge for the last $45 \mathrm{Ma}$ based on three different time scales. The spacings between anomalies are taken from the synthetic flowline spreading history in Figure 35. Note that the fluctuations in spreading rate since anomaly 12 are greatly reduced relative to CK92. The light lines drawn above and below the CK92 curve are an estimate of the error limits as discussed in the text.

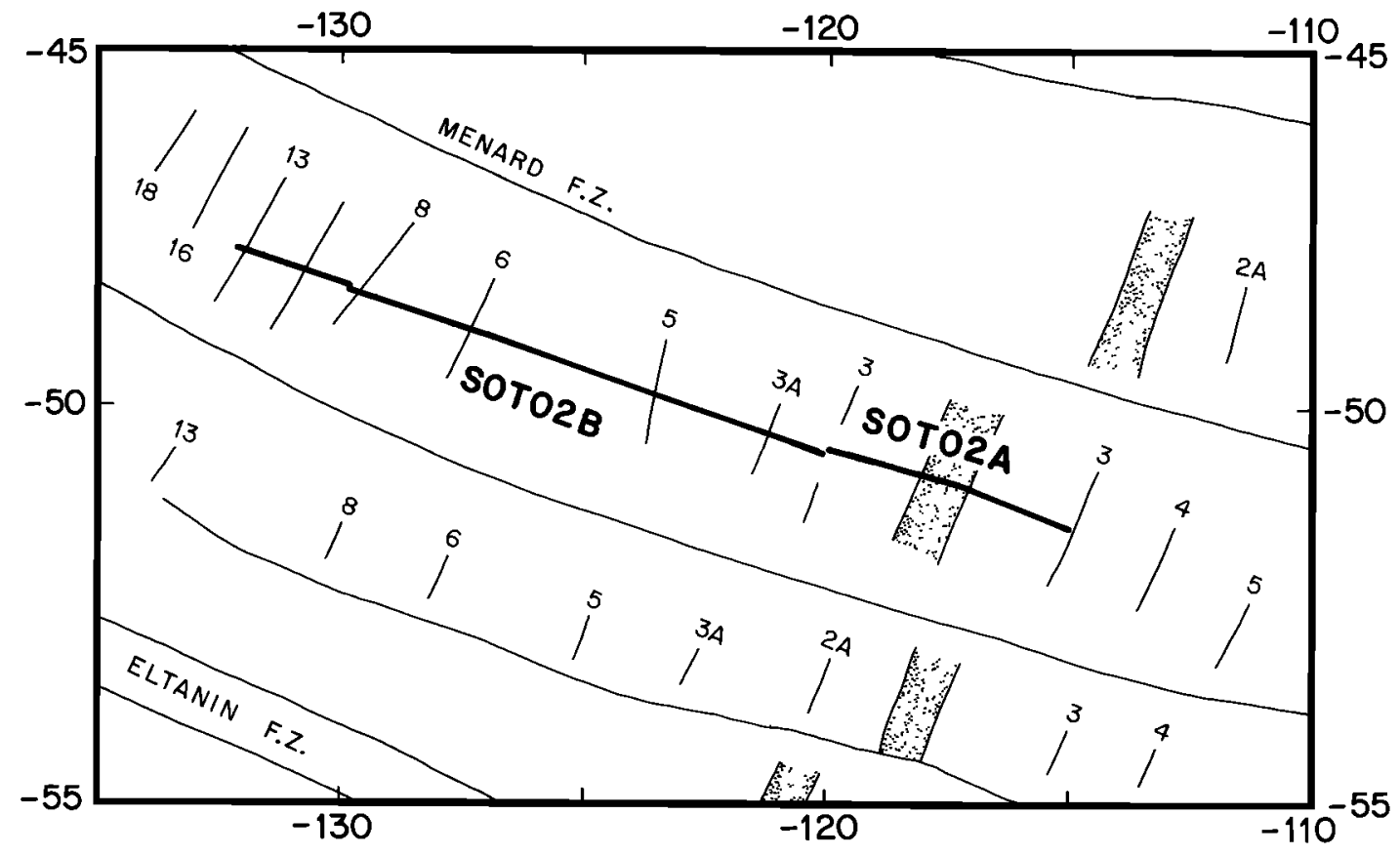

Fig. 37. Location of the Southtow profile in the South Pacific used to constrain the spreading rate history of the PacificAntarctic Ridge. 
Southeast Indian Ridge system is again responding to a major change in Pacific plate motion.

A major puzzle of Pacific tectonics is that while a large change in the absolute motion of the Pacific plate apparently occurred at $43 \mathrm{Ma}$ as inferred from the bend in the HawaiianEmperor chain, which in BKFV85 corresponded to anomaly 19, there was no apparent change at that time in the Pacific-Farallon (Vancouver) relative motion; the major change in the direction of Pacific-Farallon spreading occurred around anomaly 24 time, which was dated at $55 \mathrm{Ma}$ [e.g., Atwater, 1989]. With the new time scale, anomaly 24 has become about 2 m.y. younger, still

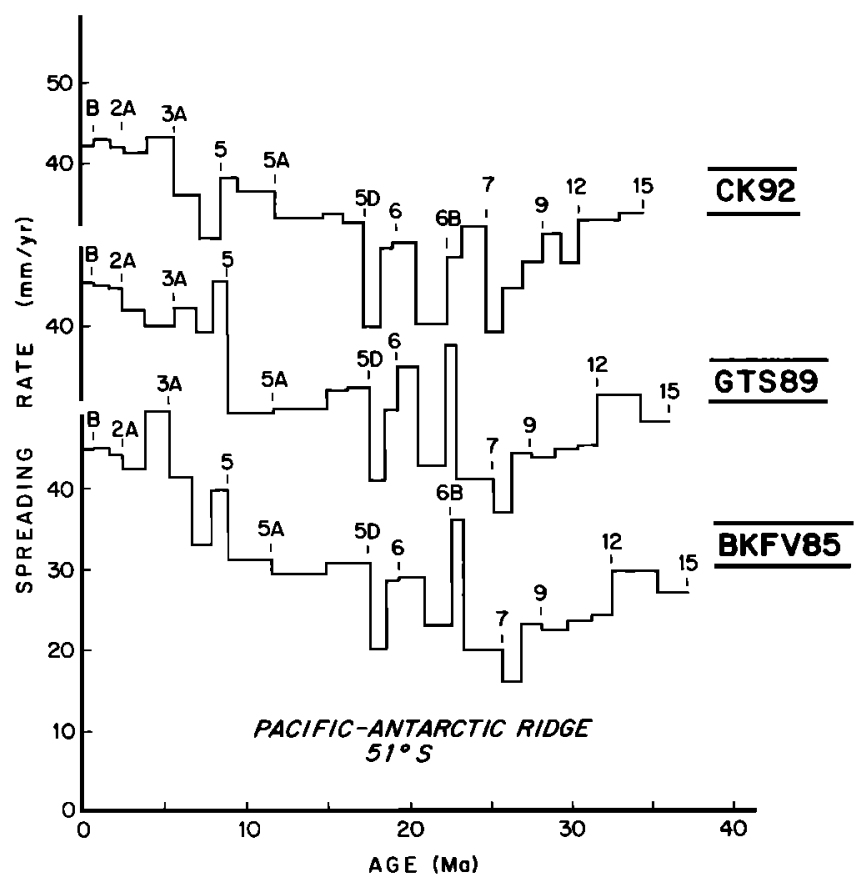

Fig. 38. Fluctuations in the half spreading rate on the Pacific-Antarctic ridge based on three different time scales. anomaly spacings are taken from the Southtow profile shown in Figure 37. Fluctuations in spreading rate relative to all three time scales shows difficulties of constraining spreading rate history based on a single profile. some 10 m.y. older than the bend. We do however see a large drop in Pacific-Vancouver spreading rate at $43 \mathrm{Ma}$ (Anomaly 20) which also correlates with the time of increased spreading rates on the Southeast Indian Ridge [Cande and Mutter, 1982]. Although it is tempting to correlate these changes in spreading rate to the bend in the Hawaiian-Emperor chain, it has to be emphasized that the spreading rate history of the North Pacific is based on a single composite profile, and that the conjugate, Farallon plate side of the spreading history is long gone.

The North Pacific can now be viewed as a system with large swings in spreading rate relative to the smooth spreading rate history of the South Atlantic. This irregular spreading rate history (at least as recorded on our single composite profile) may reflect the changing configuration of subducting slabs around much of the perimeter of the plate. The irregularities in Pacific-Vancouver spreading rates appear to increase as the Vancouver plate diminishes in size, again apparently reflecting the effect of the varying subducting slab. One unexplained aspect is that the Pacific-Vancouver spreading rate changed so drastically at anomaly 6C time, when the primary Pacific basin event is supposedly the breakup of the Farallon plate. It is surprising that there is so much linkage of events on the Farallon plate to events on the Pacific-Vancouver ridge system and even, apparently, on the Southeast Indian Ridge.

The Late Cretaceous remains a time of poorly constrained spreading rates. With our calibration points it is clear that there must be a sharp drop in spreading rates in the South Atlantic in the late Cretaceous. However, because of the sharpness of the drop, and the relative sparsity of calibration points, the actual timing of the drop is not well constrained. It may have occurred gradually between anomalies 33 and 30 , as we propose here, or it may have occurred more abruptly at around anomaly 29 , near the Cretaceous/Paleogene boundary. This is a critical time interval to resolve with more numerous and precise age calibration data because of the large changes in spreading rate that must have occurred in the Indian Ocean [e.g., Schlich, 1975; Patriat, 1983].

\section{SUMMaRY AND CONCLUSIONS}

We have constructed a new geomagnetic polarity time scale for the late Cretaceous and Cenozoic based on an analysis of magnetic profiles from the world's major oceanic ridge systems.

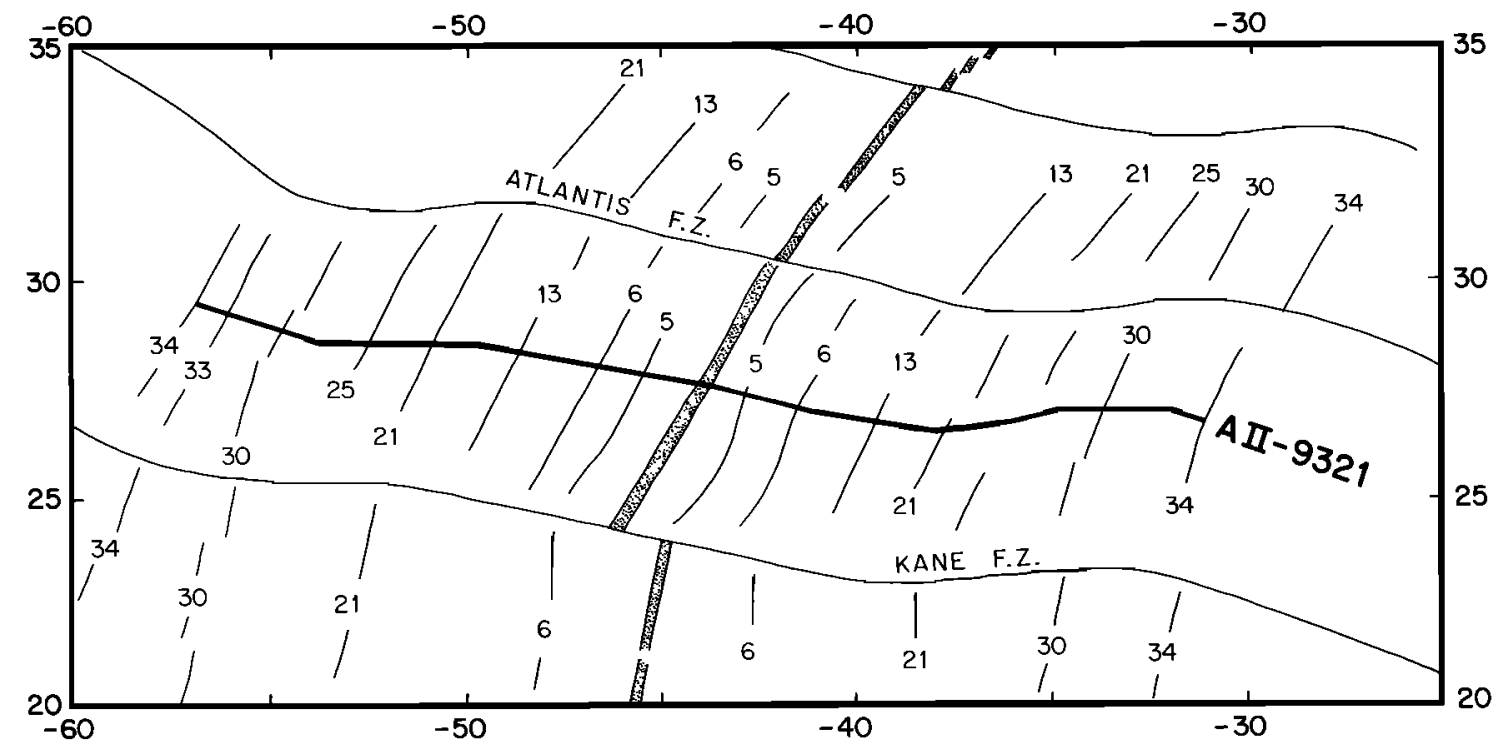

Fig. 39. Location of the All9321 profile from the Central Atlantic. 


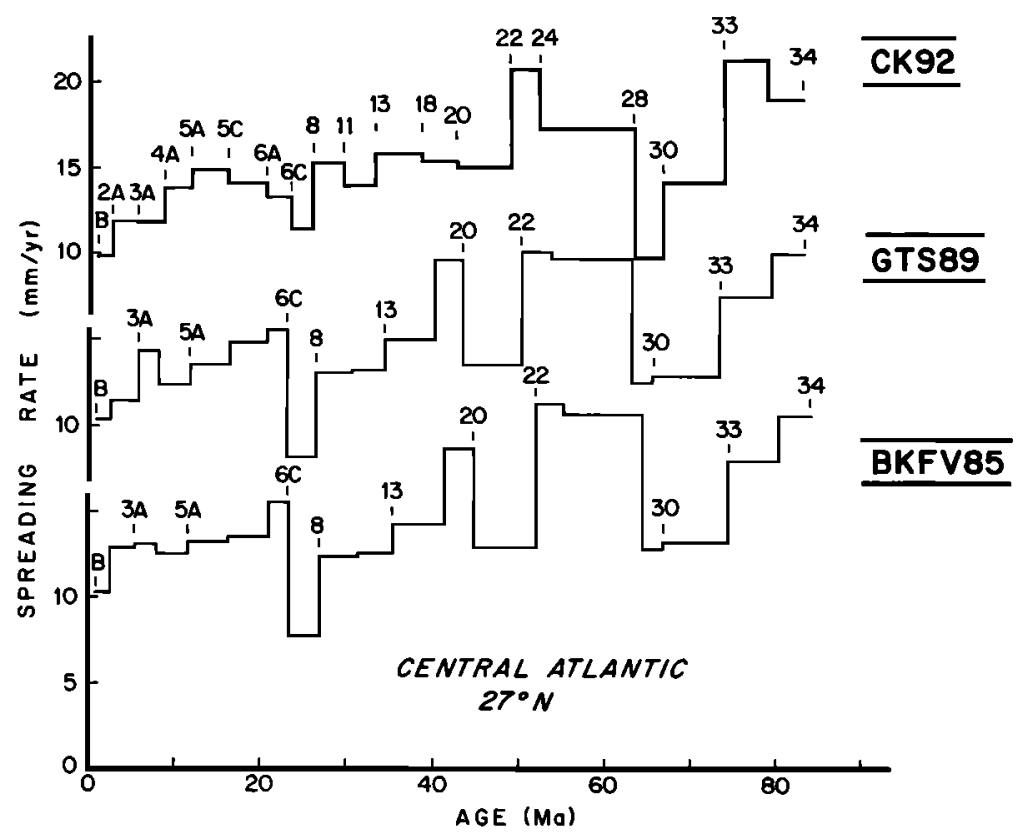

Fig. 40. Fluctuations in half spreading rate in the Central Atlantic relative to three different time scales. Anomaly spacings were determined by averaging the distances between anomalies on both flanks of the Mid-Atlantic ridge on the AII-93 profile. Note the smoother spreading rate history over the last $50 \mathrm{Ma}$ relative to CK92.

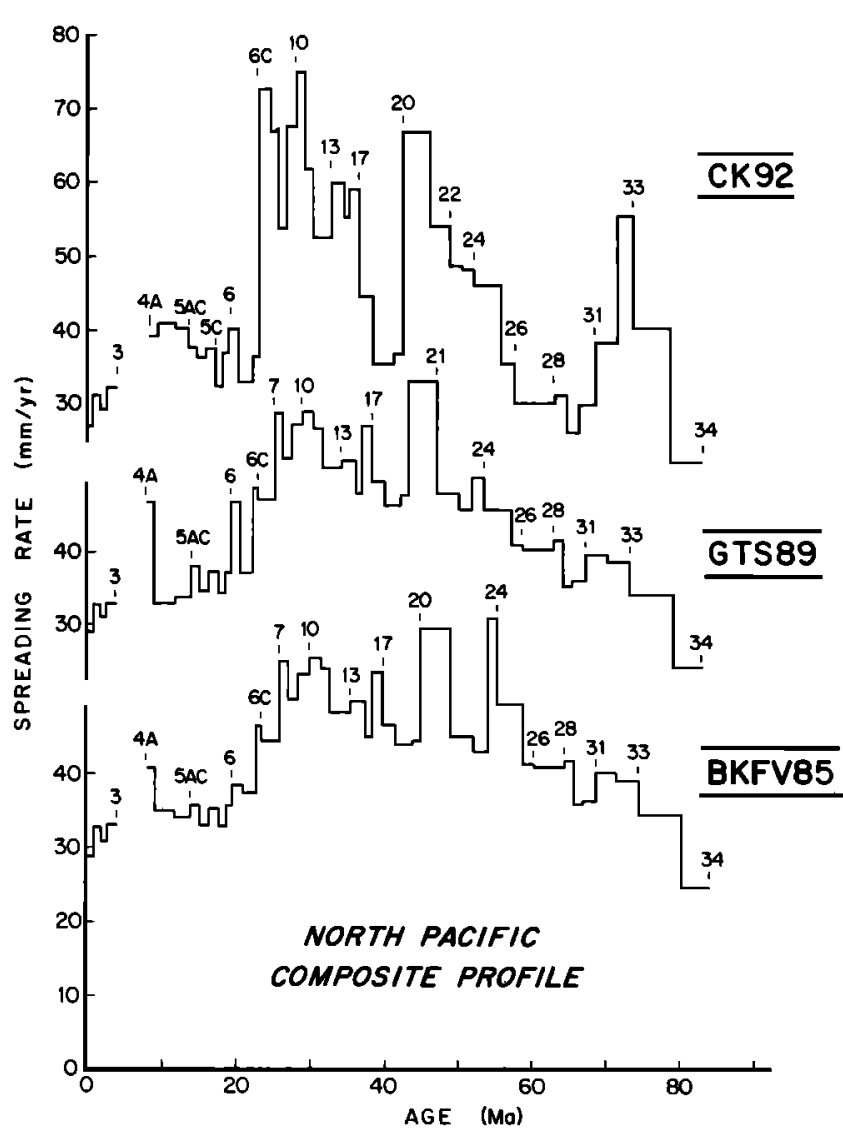

Fig. 41. Half spreading rates in the North Pacific relative to three time scales. Distances between anomalies were constrained from a composite profile. Note the larger fluctuations in spreading rate relative to CK92, particularly around anomaly $6 C$, between anomalies 10 and 7 , and between anomalies 20 and 17.
This project was initiated because of our suspicion that there were errors in the relative widths of the polarity intervals in HDHPL68 and that these errors resulted in misinterpretations of tectonic events. In addition, we felt that there was now a sufficient increase in the amount of magnetic profile data to justify a reappraisal of the complete magnetic anomaly sequence.

There are several significant changes in the spacings and ages of the polarity intervals. For example, the derived age of anomaly 5 is about $0.5 \mathrm{~m}$.y. older than in most other time scales but is now in agreement with the results of the most recent radioisotopic ages of basaltic flows on Iceland. The effect of this change is that the global "pulse" of faster spreading that appeared to have occurred between anomalies 5 and 3 has been eliminated. In addition, the relative spacings of reversals between anomalies 5 and 3 have been changed. As a result, a late Neogene plate motion change on the Southeast Indian Ridge is now seen to be temporally related to a spreading rate change on the Pacific-Antarctic Ridge and also with other tectonic events that occured around anomaly $3 \mathrm{~A}$ time throughout the Pacific.

Other significant changes to the reversal sequence were made between anomalies 7 and 6 . Erratic swings in spreading rate that had been previously interpreted in most oceans, except the North Pacific, have been replaced with much smoother changes, or no change, while the North Pacific now shows a precipitous drop in spreading rate at anomaly $6 \mathrm{C}$ time.

The age of reversals between anomalies 7 and 24 are 2-3 m.y. younger than in most previous time scales, reflecting the revised ages of calibration points in the Paleocene-Oligocene. The effect of these changes is that spreading rates in several oceans appear to have a large but gradual increase starting in the mid-Eocene and culminating in the early Oligocene.

The largest uncertainties in our new time scale are probably for the anomaly spacings in the Late Cretaceous and early Cenozoic. This corresponds to the time interval of the most rapid change in spreading rate (and rapid migration of the rotation poles) in the South Atlantic and, consequently, a time 


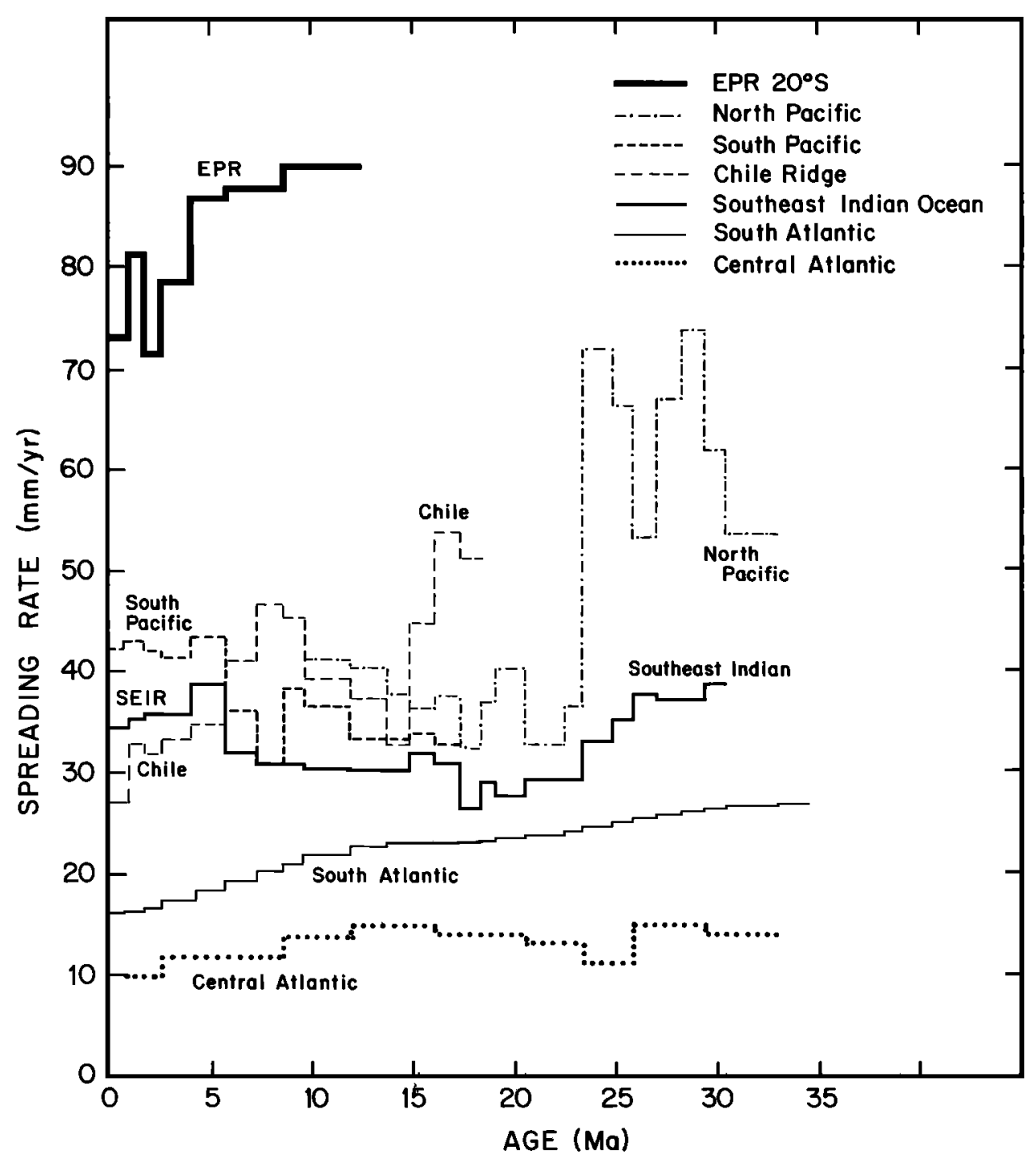

Fig. 42. Half spreading rates in the late Paleogene and Neogene on several different ridges. Note the synchronous fluctuations on the Southeast Indian, Pacific-Antarctic (South Pacific) and Chile ridges at $5.6 \mathrm{Ma}$.

when there is the most potential for enror in defining the South Atlantic spreading pattern and its age calibration.

One interesting implication of our study is that spreading rates in the North Pacific now appear to have been quite variable, starting in the mid-Eocene and continuing through the Oligocene. We speculate that as the Farallon and Vancouver plates became smaller, their motion was more and more effected by small variations in the configuration of the subducting slabs around their eastern perimeters. Spreading in the South Atlantic, where there is little interaction with subduction zones, is probably driven primarily by more gradually evolving ridge push. This interocean variation in driving mechanisms justifies our dependence on anomaly spacings in the South Atlantic, as opposed to plates in the Pacific, to construct the new time scale.

We have also identified the source of some of the errors that are apparent in HDHPL68 and its descendents. HDHPL68 was a blend of two profiles: the Vema 20 profile from the South Atlantic and a profile from the North Pacific. The data from the North Pacific were inserted into the South Atlantic spacings at variable and often quite large intervals. The erratic swings in spreading rate between anomalies 7 and 6, for example, can now be attributed to the use of the spacings exclusively from the North Pacific over this long time interval in earlier time scales.

Finally, we have identified many additional anomalies that may represent reversals of the global geomagnetic field, for example, between anomalies $3 \mathrm{~A}$ and $4 \mathrm{~A}$. Most importantly, we observe an essentially continuous pattern of small scale anomalies between anomalies 24 and 27 that appear to be an "Earth-filtered" record of short period ( 2 to $20 \mathrm{kyr}$ ) intensity variations of the dipole field. We believe that this type of dipole field behavior, previously recognized within anomaly 5 and between anomalies 12 and 13, may have characterized the geomagnetic dynamo throughout the Cenozoic. The present results provide motivation for a continued study of small scale anomalies on high-resolution marine magnetic profiles.

Further refinement of the geomagnetic time scale in general and its tectonic and geomagnetic consequences await more detailed analyses of magnetic anomaly patterns along flow lines on the ocean ridges, and more precise and closely spaced age calibration points.

\section{APPENDIX: NOMENCLATURE}

The polarity chron nomenclature we use is similar to that of Tauxe et al. [1983] and Harland et al. [1990], with some modifications. Like Harland et al. [1990], we refer to the longest intervals of predominantly one polarity by the corresponding anomaly number followed by the suffix $n$ for 
normal polarity, or $r$ for the preceding reversed polarity interval. When these chrons are subdivided into shorter polarity intervals, we refer to them as subchrons and identify them by appending, from youngest to oldest, a $0.1,0.2$, etc., to the primary chron name, and adding an $n$ for a normal polarity interval, or an $r$ for a reversed interval. For example, the three normal polarity intervals composing anomaly $6 \mathrm{C}$ (chron $\mathrm{C6Cn}$ ) are called subchrons $\mathrm{C6Cn.1n,} 66 \mathrm{Cn} .2 \mathrm{n}$, and $\mathrm{C6Cn.3n}$, whereas Harland et al. [1990] refer to them as chrons C6C.1n, C6C.2n, and $\mathrm{C6C.3n}$. Similarly we refer to the reversed interval preceding (older than) subchron $\mathrm{C} 6 \mathrm{Cn} .1 \mathrm{n}$ as subchron $\mathrm{C} 6 \mathrm{Cn} .1 \mathrm{r}$, whereas Harland et al. [1990] call this interval chron C6C.1r.

We use this form of nomenclature so that we can name every chron and subchron without resorting to odd constructions. For example, there are polarity subdivisions of both chrons $\mathrm{C} 4 \mathrm{n}$ and C4r, which we designate as Subchrons C4n.1n, C4n.2n, C4r.1r and C4r.2r (Figure 29), and which Harland et al. [1990] would designate $C 4.1 n, C 4.2 n, C 4.1 r$, and $C 4.2 r$, respectively. With the Harland et al. [1990] nomenclature, the reversed intervals preceding $\mathrm{C} 4.1 \mathrm{n}$ and $\mathrm{C4.2n}$ cannot be named $\mathrm{C4} .1 \mathrm{r}$ and $C 4.2 r$ without confusing them with the subchrons within chron C4.1r, thus forcing the use of the awkward designation C4.1nr and C4.2nr; with our nomenclature, we refer to these intervals as C4n.1r and C4n.2r.

For more precise correlation, the fractional position within a chron or subchron is referred to by the equivalent decimal number appended, within parentheses, to the chron or subchron name, following the approach of LaBrecque et al. [1983]. As examples, the younger end of chron C29n is $\mathrm{C} 29 \mathrm{n}(0.0)$ or $C 29(0.0)(=C 29 n(y)$ in Harland et al. [1990]), the older end of chron C29n (= C29n(o) in Harland et al. [1990]) is conveniently designated as $\mathrm{C} 29 \mathrm{r}(0.0)$ since it is equivalent to the younger end of Chron C29r, whereas a level within chron $\mathrm{C} 29 \mathrm{r}$ and 3/10 from its younger end is referred to as $\mathrm{C29} \mathrm{r}(0.3)$.

We use the designation $-1,-2$, etc., following the primary chron or the subchron designation to denote apparently very short polarity intervals corresponding to the tiny wiggles which, upon calibration, convert to durations of less than 30 kyr. In view of their uncertain origin, we refer to these globally mapped geomagnetic features as cryptochrons. Thus the tiny wiggles between anomalies 12 and 13 (within chron $\mathrm{C} 12 \mathrm{r}$ ) are called from youngest to oldest cryptochrons C12r-1, C12 $\mathrm{r}-2$, etc. This differs from Harland et al. [1990] who used a duration of $100 \mathrm{kyr}$ or less to distinguish the class of shortest polarity intervals, a cut-off value which often fragments the chron heirarchy in a manner inconsistent with the magnetic anomaly identifications. For example, the four positive anomalies composing anomaly 3 (which correspond to the Cochiti, Nunivak, Sidufjall, and Thvera subchrons of the Late Cenozoic $\mathrm{K}-\mathrm{Ar}$ geomagnetic reversal time scale [Mankinen and Dalrymple, 1979]), are designated by Harland et al. [1990], from youngest to oldest, as C3.1n, C3.2n, C3.2r-1n and C3.3n, while we refer to them as $C 3 n .1 n, C 3 n .2 n, C 3 n .3 n$ and $C 3 n .4 n$, respectively.

We believe that the $30 \mathrm{kyr}$ cut-off is more realistic in separating the anomalies that are well characterized and most probably reflect true geomagnetic polarity reversals from the smaller scale anomalies (i.e., tiny wiggles) that are generally less uniformly well documented and whose origin may be due to paleointensity variations or incomplete reversals of the geomagnetic field. A cryptochron can be elevated to the status of a subchron if it is demonstrated that the tiny wiggle corresponds to a pair of geomagnetic polarity reversals, as appears to be the case for the Cobb Mountain subchron at about 1.1 Ma [Mankinen et al., 1978; Mankinen and Gromme, 1982; Clement and Kent, 1987]. In such cases we also add a polarity suffix to the name, hence the Cobb Mountain subchron is designated C1r.2r-1n.
Acknowledgments. This project benefited from discussions with many of our colleagues, including Tanya Atwater, William Berggren, William Lowrie, Peter Molnar, John Obradovich, Philippe Patriat, Walter Pitman, Hans Schouten, and Carl Swisher. We especially thank Bill Ryan and Ken Miller, who reviewed the manuscript, Bill Haxby, who provided valuable assistance in calculating cubic splines, and the JGR reviewers, who provided constructive criticisms. The aeromag-netics data from the Chile Ridge were collected during a joint Naval Research Lab-LDGO-Chile project with Skip Kovacs, Juan Carlos Parra, John LaBrecque, and SCC as coinvestigators. Data from the Indian Ocean, used to define the fine details of the reversal pattem between anomalies 24 and 27 , were obtained from Roland Schlich at EOPG Strasbourg as part of a joint US-French Indian Ocean data compilation project. SCC's participation in both the Chile Ridge and Indian Ocean projects was funded by the National Science Foundation. Betty Batchelder assisted with the drafting, and Bel Hautau and Diana Saaby contributed to the preparation of the manuscript. This work was supported by grants OCE88-11339 and OCE91-04447 of the National Science Foundation. LDGO contribution 4951.

\section{REFERENCES}

Alvarez, W., M.A. Arthur, A.G. Fischer, W. Lowrie, G. Napoleone, and I. Premoli-Silva, Upper Cretaceous-Paleocene magnetic stratigraphy at Gubbio, Italy, V, Type section for the late Cretaceous-Paleocene geomagnetic reversal time scale, Geol. Soc. Am. Bull., 88, 383-389, 1977.

Andreieff, P., H. Bellon, and D. Westercamp, Chronometrie et stratigraphie comparee des edifices volcaniques et formations sedimentaires de la Marinique (Antilles francaises), Bull. Bur. Rech. Geol. Min., 4, 335-346, 1976.

Arthur, M.A., and A.G. Fischer, Upper Cretaceous-Paleocene magnetic stratigraphy at Gubbio, Italy, I, Lithostratigraphy and sedimentology, Geol. Soc. Am. Bull., 88, 367-371, 1977.

Atwater, T., Plate tectonic history of the Northeast Pacific and Westem North America, in The Geology of North America, vol. N, The Eastern Pacific Ocean and Hawaii, edited by E.L. Winterer, D.M. Hussong and R.W. Decker, Geological Society of America, Boulder, Colo., 1989.

Atwater, T., and J. D. Mudie, Detailed near-bottom geophysical study of the Gorda Rise, J. Geophys. Res., 78, 8665-8686, 1973.

Atwater, T., and J. Severinghaus, Tectonic maps of the Northeast Pacific, in The Geology of North America, vol. N, The Eastern Pacific Ocean and Hawaii, edited by E.L. Winterer, D.M. Hussong and R.W. Decker, Geological Society of America, Boulder, Colo., 1989.

Aubry, M-P., W.A. Berggren, D.V. Kent, J.J. Flynn, K.D. Klitgord, J.D. Obradovich, and D.R. Prothero, Paleogene geochronology: an integrated approach, Paleoceanography, 3, 707-742, 1988.

Baksi, A., B. Houghton, M. McWilliams, H. Tanaka, and G. Tumer, What is the age of the Brunhes-Matuyama Polarity Transition?, Eos, Trans. AGU, 72, 135, 1991a.

Baksi, A., K.A. Hoffman, and M. McWilliams, Preliminary results of ${ }^{40} \mathrm{Ar} /{ }^{39} / \mathrm{Ar}$ dating studies directed to testing the accuracy of the geomagnetic polarity time scale (GPTS) at 2-5 Ma, Eos, Trans. AGU, 72, 135, $1991 b$.

Baksi, A.K., V. Hsu, M.O. McWilliams, and E. Farrar, ${ }^{40} \mathrm{Ar} /{ }^{39} \mathrm{Ar}$ dating of the Brunhes-Matuyama geomagnetic field reversal, Science, 256,

Barker, P.F., The history of ridge-crest offset at the Falkland-Agulhas Fracture Zone from a small-circle geophysical profile, Geophys J. R. Astron. Soc., 59, 131-145, 1979.

Berggren, W.A., N. Hamilton, D.A. Johnson, C. Pujol, W. Weiss, P. Cepek, and A.M. Gombos, Jr., Magneto-biostratigraphy of Deep Sea Drilling Project Leg 172, Sites 515-518, Rio Grande Rise (South Atlantic), Init. Rep. Deep Sea Drill. Proj., 72, 939-948, 1983.

Berggren, W.A., D. V. Kent, and J. J. Flynn, Paleogene geochronology and chronostratigraphy, The chronology of the geological record, Mem. Geol. Soc. Am., 10, 141-195, 1985a.

Berggren, W.A., D. V. Kent, J. J. Flynn, and J.A. Van Couvering, Cenozoic geochronology, Geol. Soc. Am. Bull., 96, 1407-1418, $1985 b$.

Berggren, W.A., D.V. Kent, J.D. Obradovich, and C.C. Swisher III, Toward a revised Paleogene geochronology, in Eocene-Oligocene Climatic and Biotic Evolution, edited by D.R. Prothero and W.A. Berggren, 29-45, Princeton Univ. Press, Princeton, NJ., 1992. 
Blakely, R.J., Geomagnetic reversals and crustal spreading rates during the Miocene, J. Geophys. Res., 79, 2979-2985, 1974.

Bryan, N.B., and R. A. Duncan, Age and provenance of clastic horizons from Hole 516F, Init. Rep. Deep Sea Drill. Proj., 72, 475-477, 1983.

Cande, S.C., and D.V. Kent, Ultra-high resolution marine magnetic anomaly profiles: a record of continuous paleo-intensity variations?, J. Geophys. Res., in press, 1992.

Cande, S.C., and Y. Kristoffersen, Late Cretaceous magnetic anomalies in the North Atlantic, Earth Planet. Sci. Lett., 35, 215-224, 1977.

Cande, S.C., and J. L. LaBrecque, Behaviour of the Earth's paleomagnetic field from small scale marine magnetic anomalies, Nature, 247, 26-28, 1974.

Cande, S.C., and J.C. Mutter, A revised identification of the oldest seafloor spreading anomalies between Australia and Antarctica, Earth Planet. Sci. Lett., 58, 151-160, 1982.

Cande, S., J.L. LaBrecque, and W.F. Haxby, Plate kinematics of the South Atlantic: Chron C34 to present, J. Geophys. Res., 93, 13,479$13,492,1988$.

Cande, S.C., J.L. LaBrecque, R.L. Larson, W.C. Pitman III, X Golovchenko, and W.F. Haxby, Magnetic lineations of the world's ocean basins, map with text, Am. Assoc. Petrol. Geol., Tulsa, Okla., 1989.

Carbotte, S., S.M. Welch, and K.C. Macdonald, Spreading rates, rif propagation, and fracture zone offset histories during the past $5 \mathrm{~m} . \mathrm{y}$. on the Mid-Atlantic Ridge, $25^{\circ}-27^{\circ} 30^{\prime} S$ and $31^{\circ}-34^{\circ} 30^{\prime} \mathrm{S}$, Mar. Geophys. Res., 13, 51-80, 1991.

Champion, D.E., G.B. Dalrymple, and M.A. Kuntz, Radiometric and paleomagnetic evidence for the Emperor reversed polarity event at $0.46 \pm 0.05 \mathrm{~m} . y$. in basalt lava flows from the eastem Snake River Plain, Idaho, Geophys. Res. Lett., 8, 1055-1058, 1981.

Champion, D.E., M.A. Lanphere, and M.E. Kuntz, Evidence for a new geomagnetic reversal from lava flows in Idaho: discussion of short polarity reversals in the Brunhes and late Matuyama polarity chrons, J. Geophys. Res., 93, 11,667-11,680, 1988.

Clement, B.M., and D.V. Kent, Short polarity intervals within the Matuyama: Transitional field records from hydraulic piston core sites in the Nonth Atlantic, Earth Planet. Sci. Letl., 81, 253-264, 1987.

Cox, A., and D. Engebretson, Change in motion of the Pacific plate at 5 Ma, Nature, 313, 472-474, 1985.

Deino, A., L. Tauxe, M. Monaghan, and R. Drake, ${ }^{40} \mathrm{Ar} /{ }^{39} \mathrm{Ar}$ age calibration of the litho- and paleomagnetic stratigra-phies of the Ngorora Formation, Kenya, J. Geol., 98, 567-587, 1990.

Duncan, R.A., and R.B. Hargraves, ${ }^{40} \mathrm{Ar} /{ }^{39} \mathrm{Ar}$ geochronology of basement rocks from the Mascarene Plateau, the Chagos Bank, and the Maldives Ridge, Proc. Ocean Drill. Program, Sci. Results, 115, $43-51,1990$.

Flynn, J.J., Correlation and geochronology of Middle Eocene strata from the westem United States, Palaeogeogr. Palaeoclimatol. Palaeoecol., 55, 335-406, 1986.

Gromme, C.S., and R.L. Hay, Geomagnetic polarity epochs: Age and duration of the Olduvai normal polarity event, Earth Planel. Sci. Lett., 10, 179-185, 1971.

Haq, B.U., J. Hardenbol, and P.R. Vail, Mesozoic and Cenozoic chronostratigaphy and cycles of sea-level change, Spec. Publ., Soc. Econ. Paleontol. Mineral., 42, 71-108, 1988.

Harbert, W., and A. Cox, Late Neogene motion of the Pacific plate, $J$. Geophys. Res., 94, 3052-3064, 1989.

Harland, W. B., A.V. Cox, P.G. Llewellyn, C.A.G. Pickton, A.G. Smith, and R. Walters, A Geologic Time Scale, 131 pp., Cambridge University Press, Cambridge, New York, 1982.

Harland, W.B., R. Amstrong, A.Cox, L. Craig, A. Smith, and D. Smith A Geologic Time Scale 1989, 263 pp., Cambridge University Press, New York, 1990.

Harris, N.B., and P.D. Fullagar, Comparison of Rb-Sr and K-Ar dates of middle Eocene bentonite and glauconite, southeastem Atlantic Coastal Plain, Geol. Soc. Am. Bull., 101, 573-577, 1989.

Haxby, W.F., C.A. Raymond, S.C. Cande, W.B.F. Ryan, S. Tebbens, S. O'Hara, D. Mueller, B. O'Brien, and M. Wilkinson, Preliminary results of a Hydrosweep, gravity and magnetics survey of a PacificAntarctic Ridge fracture zone: Part 2, Crustal Structure, Eos Trans. $A G U, 73,278,1992$

Heirtzler, J.R., G.O. Dickson, E.M. Herron, W.C. Pitman III, and X. LePichon, Marine magnetic anomalies, geomag-netic field reversals, and motions of the ocean floor and continents, J. Geophys. Res., 73, 2119-2136, 1968.
Hey, R. N., Tectonic evolution of the Cocos-Nazca spreading center, Geol, Soc. Am. Bull., 88, 1414-1420, 1977.

Hilgen, F.J., Astronomical calibration of Gauss to Matuyama sapropels in the Mediterranean and implication for the geomagnetic polarity time scale, Earth Planet. Sci. Lett., 104, 226-244, 1991 a.

Hilgen, F.J., Extension of the astronomically calibrated (polarity) time scale to the Miocene/ Pliocene boundary, Earth Planet. Sci. Lett., 107, 349-368, $1991 b$.

Izett, G.A., G.B. Dalrymple, and G.B. Snee, ${ }^{40} \mathrm{Ar} /{ }^{39}$ Ar age of the Cretaceous-Tertiary boundary tektites from Haiti, Science, 252, 1539-1542, 1991

Kent, D.V., and F. M. Gradstein, A Jurassic to recent chronology, in The Geology of North America, vol. M, The Western North Atlantic Region, edited by P.R. Vogt and B.E. Tucholke, pp. 45-50, Geological Society of America, Boulder, Colo., 1986.

Klitgord, K.D. and H. Schouten, Plate kinematics of the central Atlantic, in The Geology of North America, vol. M, The Western North Atlantic Region, edited by P.R. Vogt and B.E. Tucholke, 351377, Geological Society of America, Boulder, Colo., 1986.

Klitgord, K.D., S. P. Heustis, J.D. Mudie, and R. L. Parker, An analysis of near-bottom magnetic anomalies: Sea floor spreading and the magnetized layer, Geophys. J. R. Astron. Soc., 43, 387-424, 1975.

LaBrecque, J.L., K.J. Hsu, M.F. Carman, Jr., A-M. Karpoff, J.A. McKenzie, S.F. Percival, Jr., N.P. Petersen, K.A. Pisciotto, E. Schreiber, L. Tauxe, P. Tucker, H.J. Weissert, and R. Wright, DSDP Leg 73: Contributions to Paleogene stratigraphy in nomenclature, chronology and sedimentation rates, Palaeogeogr., Palaeoclimatol., Palaeoecol., 42, 91-125, 1983.

LaBrecque, J.L., D.V. Kent, and S.C. Cande, Revised magnetic polarity time scale for the Late Cretaceous and Cenozoic time, Geology, 5 , 330-335, 1977.

Larson, R.L., Bathymetry, magnetic anomalies, and plate tectonic history of the mouth of the Gulf of California, Geol. Soc. Amer. Bull., 83, 3345-3360, 1972.

Larson, R.L., and W.C. Pitman III, Worddwide correlation of Mesozoic magnetic anomalies, and its implications, Bull. Geol. Soc. Am., 83, 3645-3662, 1972.

Leg 135 Scientific Party, Evolution of back arc basins: ODP Leg 135, Lau Basin, Eos, Trans. AGU, 73, 241, 1992.

Lonsdale, P., and K.D. Klitgord, Structure and tectonic history of the eastern Panama basin, Geol. Soc. Am. Bull., 89, 981-999, 1978.

Lowrie, W., and W. Alvarez, Upper Cretaceous-Paleocene stratigraphy at Gubbio, Italy, III, Upper Cretaceous magnetic stratigraphy, Geol. Soc. Am. Bull., 88, 374-377, 1977.

Lowrie, W., and W. Alvarez, One hundred million years of geomagnetic polarity history, Geology, 9. 392-397, 1981.

Mankinen, E.A., and G. B. Dalrymple, Revised geomagnetic polarity time scale for the interval 0-5 m.y.B.P., J. Geophys. Res., 84, 615626, 1979.

Mankinen, E.A., and C.S. Gromme, Paleomagnetic data from the Coso Range, California, and the current status of the Cobb Mountain normal geomagnetic event, Geophys. Res. Lett., 9, 1279-1282, 1982.

Mankinen, E.A., J.M. Donnelly, and C.S. Gromme, Geomagnetic polarity event recorded at 1.1 m.y.B.P. on Cobb Mountain, Clear Lake volcanic field, Califomia, Geology, 6, 653-656, 1978.

McDougall, I., L. Kristjansson, and K. Saemundsson, Magnetostratigraphy and geochronology of northwest Iceland, $J$. Geophys. Res., 89, 7029-7060, 1984.

Miller, K.G., M.J. Kahn, M-P. Aubry, W.A. Berggren, D.V. Kent, and A. Melillo, Oligocene to Miocene bio-, magneto-, and isotope stratigraphy of the westem North Aulantic, Geology, 13, 257-261, 1985.

Minster, J.B., and T.H. Jordan, Present-day plate motions, J. Geophys. Res., 83, 5331-5334, 1978.

Montanari, A., A.L. Deino, R.E. Drake, B.D. Turrin, D.J. DePaola, G.S. Odin, G.H. Curtis, W. Alvarez, and D. Bice, Radioisotopic dating of the Eocene-Oligocene boundary in the pelagic sequences of the northeastem Apennines, in The Eocene-Oligocene Boundary in the Marche-Umbria Basin (Italy), edited by I. Premoli-Silva, R. Cocioni, and A. Montanari, pp. 195-208, Intemational Subcommission Paleogene Stratigraphy, Eocene/Oligocene Boundary Meeting, Ancona, Oct. 1987, Special Publication, 1988.

Munschy, M., J. Dyment, M.O. Boulanger, D. Boulanger, J.D. Tissot, R. Schlich, and M.F. Coffin, Breakup and seafloor spreading between 
the Kerguelen Plateau-Labuan Basin and the Broken RidgeDiamantina Zone, Proc Ocean Drill. Program, Sci. Results, 120, 931-944, 1992.

Ness, G., S. Levi, and R. Couch, Marine magnetic anomaly timescales for the Cenozoic and Late Cretaceous: $A$ precis, critique, and synthesis, Rev. Geophys., 18, 735-770, 1980.

Nocchi, M., G. Parisi, P. Monaco, S. Monechi, M. Mandile, G. Napoleone, M. Ripepe, M. Orlando, I. Premoli-Silva, and D.M. Brice, The Eocene-Oligocene boundary in the Umbrian pelagic regression, in Terminal Eocene Events, Dev. in Palaeontol. and Stratigr., vol. 9, edited by C. Pomerol, and I. Premoli-Silva, 25-40, Elsevier, New York, 1986.

Obradovich, J.D., and W.A. Cobban, A time scale for the Late Cretaceous of the westem interior of North America, Geol. Assoc. Can. Spec. Pap. 13, 31-54, 1975.

Obradovich, J.D., J.F. Sutter, and M.J. Kunk, Magnetic polarity chron tie points for the Cretaceous and early Tertiary, Terra Cognita, 6, $140,1986$.

Odin, G.S., A. Montanari, A. Deino, R. Drake, P.G. Guise, H. Kreuzer, and D.C. Rex, Reliability of volcano-sedimentary biotite ages across the Eocene-Oligocene boundary (Apennines, Italy), Chem. Geol., Isolope Geosci. Secl., 86, 203-224, 1991.

Patriat, P., Reconstitution de l'evolution du systeme de dorsales de l'ocean Indien par les methodes de la Cinematique des Plaques, Doctoral d'Etat, Universite Paris 6, 1983.

Pitman, W.C., III, and J.R. Heirtzler, Magnetic anomalies over the Pacific-Antarctic Ridge, Science, 154, 1164-1171, 1966.

Pollitz, F., Pliocene change in Pacific plate motion, Nature, 320, 738$741,1986$.

Preisinger, A., E. Zobetz, A.J. Gratz, R. Lahodynsky, M. Becke, H.J. Mauritsch, G. Eder, F. Grass, F. Rogl, H. Stradner, and R. Surenian, The Cretaceous/Tertiary boundary in the Gosau Basin, Austria, Nature, 322, 794-799, 1986.

Prothero, D.R., and C.C. Swisher III, Magnetostratigraphy and geochronology of the terrestrial Eocene-Oligocene transition in North America, in Eocene-Oligocene Climatic and Biotic Evolution, edited by D.R. Prothero and W.A. Berggren, 46-73, Princeton Univ. Press, Princeton, N.J., 1992

Rea, D.K., and R.J. Blakely, Short-wavelength magnetic anomalies in a region of rapid seafloor spreading, Natwre, 255, 126-128, 1975.

Ryan, W.B.F., Stratigraphy of late Quatemary sediments in the eastem Mediterranean, in The Mediterranean Sea: A Natural Sedimentation Laboratory, edited by D.J. Stanley, Dowden, Hutchinson and Ross, Stroudsburg, Pa., 1972.

Saemundsson, K., L. Kristjansson, I. McDougall, and N.D. Walkins, KAr dating, geological and paleomagnetic study of a $5-\mathrm{km}$ lava succession in northern Iceland, $J$. Geophys. Res., 85, 3628-3646, 1980.

Schlich, R., Structure et age de l'ocean Indien occidental, Mem. Hors Ser. Soc. Geol. Fr., no. 6, 103 pp., 1975.

Schouten, $H$. , and $K$. McCamy, Filtering marine magnetic anomalies, $J$. Geophys. Res., 77, 7089-7099, 1972.

Shackleton, N.J., A. Berger, and W.R. Peltier, An altemative astronomical calibration of the lower Pleistocene timescale based on ODP Site 667, Trans. R. Soc. Edinburgh Earth Sci., 81, 251-261, 1990.
Swisher, C.C., and R.W.O'B. Knox, The age of the Paleocene/Eocene Boundary: ${ }^{40} \mathrm{Ar} /{ }^{39} \mathrm{Ar}$ dating of the lower part of NP10, North Sea Basin and Denmark, paper presented at the International Geological Correlation Project 308: Paleocene/Eocene Boundary, Brussels meeting, Dec. 2-6, 1991

Swisher, C.C., and D.R. Prothero, Single-crystal ${ }^{40} \mathrm{Ar} /{ }^{39} \mathrm{Ar}$ dating of the Eocene-Oligocene transition in North America, Science, 249. 760-762, 1990.

Talwani, M., C.C. Windisch and M.G. Langseth, Jr., 1971, Reykjanes Ridge crest: a detailed geophysical study, J. Geophys. Res., 76, 473517.

Tauxe, L., P. Tucker, N.P. Petersen and J.L. LaBrecque, The magnetostratigraphy of Leg 73 sediments, Palaeogeogr., Palaeoclimatol. Palaeoecol., 42, 65-90, 1983.

Tauxe, L., M. Monaghan, R. Drake, G. Curtis, and H. Staudigel, Paleomagnetism of Miocene East African Rift sediments and the calibration of the geomagnetic reversal time scale, J. Geophys. Res., 90, 4639-4646, 1985.

Tauxe, L., A.D. Deino, A.K. Behrensmeyer, and R. Potts, Pinning down the Brunhes/Matuyama and upper Jaramillo boundaries: A reconciliation of orbital and isotopic time scales, Earth Planet. Sci. Lett., 109, 561-572, 1991.

Tebbens, S.F., S.C. Cande, J. Kovacs, and J.L. Labrecque, Neogene Antarctic-Nazca plate motions, Eos Trans. AGU, 71, 1641, 1990.

Tsuchi, R., Y. Takayanagi and K. Shibata, Neogene bio-events in the Japanese Islands, in Neogene of Japan - Its Biostratigraphy and Chronology, edited by R. Tsuchi, pp. 15-32, Kurofune Printing Co., Shizuoka, 1981

Vine, F.J.,and D.H. Mauhews, Magnetic anomalies over oceanic ridges, Nature, 199, 947-949, 1963.

Vogt, P.R., Plate kinematics during the last 20 m.y. and the problem of "present" motions, in The Geology of North America, vol. M, The Western North Atlantic Region, edited by P.R. Vogt and B.E. Tucholke, pp. 405-425, Geological Society of America, Boulder, Colo., 1986.

Walker, R.C., P.C. Manega, R.L. Hay, R.E. Drake, and G.H. Curtis, Laser-fusion ${ }^{40} \mathrm{Ar} /{ }^{39} \mathrm{Ar}$ dating of Bed 1 , Olduvai Gorge, Tanzania, Nature, 354, 145-149, 1991.

Weissel, J. K., D.E. Hayes, and E.M. Herron, Plate tecionics synthesis: The displacements between Australia, New Zealand, and Antarctica since the Late Cretaceous, Mar. Geol., 25, 231-277, 1977.

Wilson, D.S., Tectonic history of the Juan de Fuca ridge over the last 40 million years, J. Geophys. Res., 33, 11863-11876, 1988.

Wilson, D.S. and R.N. Hey, The Galapagos axial magnetic anomaly: evidence for the emperor event within the Brunhes and for a two-layer magnetic source, Geophys. Res. Lett., 8, 1051-1054, 1981.

S. C. Cande, Scripps Institution of Oceanography, La Jolla, CA 92091.

D. V. Kent, Lamont-Doherty Geological Observatory of Columbia University, Palisades, NY 10964.

(Received October 3, 1991;

revised May 11, 1992;

accepted May 27, 1992.) 